\title{
ALEXANDRE SCHMAEDECKE
}

Avaliação biomecânica de diferentes bloqueios transcorticais de interlocking nail em relação às forças de torção, encurvamento e axiais atuantes em fraturas diafisárias de fêmur de cães - estudo in vitro

\author{
Tese apresentada ao Programa de Pós- \\ graduação em Clínica Cirúrgica \\ Veterinária da Faculdade de Medicina \\ Veterinária e Zootecnia da Universidade \\ de São Paulo para obtenção do título de \\ Doutor em Medicina Veterinária \\ Departamento: \\ Clínica Cirúrgica
}

Área de concentração:

Clínica Cirúrgica Veterinária

Orientador:

Prof. Dr. Cássio Ricardo Auada Ferrigno 
Autorizo a reprodução parcial ou total desta obra, para fins acadêmicos, desde que citada a fonte.

\section{DADOS INTERNACIONAIS DE CATALOGAÇÃO-NA-PUBLICAÇÃO}

(Biblioteca da Faculdade de Medicina Veterinária e Zootecnia da Universidade de São Paulo)

T.1381 Schmaedecke, Alexandre

FMVZ Estudo quantitativo das fibras nervosas do periósteo acetabular em cães / Alexandre Schmaedecke - São Paulo : A. Schmaedecke, 2004.

$101 \mathrm{f}$ : : il.

Dissertação (mestrado) - Universidade de São Paulo. Faculdade de Medicina Veterinária e Zootecnia. Departamento de Cirurgia, 2004.

Programa de Pós-graduação: Anatomia dos Animais Domésticos e Silvestres.

Área de concentração: Anatomia dos Animais Domésticos e Silvestres.

Orientador: Prof. Dr. Cássio Ricardo Auada Ferrigno.

1. Displasia coxo-femoral animal. 2. Periósteo. 3. Pelve. 4. Cães. I. Título. 


\section{UNIVERSIDADE DE SÃO PAULO \\ Faculdade de Medicina Veterinária e Zootecnia}

Cidade Universitária "Armando de Salles Oliveira"

Comissão de Bioética

\section{CERTIFICADO}

Certificamos que o Projeto intitulado "Avaliação biomecânica do bloqueio transcortical dos implantes de interlocking nail em relação às forças de torção e axiais atuantes em fraturas diafisárias de fêmur em cães - estudo in vitro", protocolo n'655/2005, utilizando 15 cadáveres de cães, sob a responsabilidade do Prof. Dr. Cássio Ricardo Auada Ferrigno, está de acordo com os princípios éticos de experimentação animal da Comissão de Bioética da Faculdade de Medicina Veterinária e Zootecnia da Universidade de São Paulo e foi aprovado "ad referendun".

(We certify that the Research "Biomechanical analysis of transcortical blocks of interlocking nail pins relative to torsion and axial forces that acts in diaphyseal femoral fractures in dogs - in vitro study", protocol number 655/2005, utilizing 15 corpses of dogs, under the responsibility of Prof. Dr. Cássio Ricardo Auada Ferrigno, agree with Ethical Principles in Animal Research adopted by Bioethic Commission of the Faculty of Veterinary Medicine and Zootechny of University of São Paulo and was approved "ad referendun", meeting).

São Paulo, 03 de maio de 2005

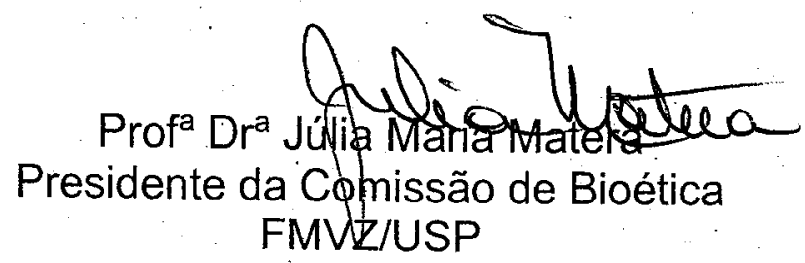

Av. Prof. Dr. Orlando Marques de Paiva, 87 - 05508-000 - Cid. Univ. "Armando de Salles Oliveira" Fones: (011) 3091-7671/3091 17676 Fax: (011) 3032-2224 


\section{FOLHA DE AVALIAÇÃO}

Nome do autor: SCHMAEDECKE, Alexandre

Título: Avaliação biomecânica de diferentes bloqueios transcorticais de interlocking nail em relação às forças de torção, encurvamento e axiais atuantes em fraturas diafisárias de fêmur de cães - estudo in vitro

Tese apresentada ao Programa de Pósgraduação em Clínica Cirúrgica Veterinária da Faculdade de Medicina Veterinária e Zootecnia da Universidade de São Paulo para obtenção do título de Doutor em Medicina Veterinária

Data:

1

\section{Banca Examinadora}

Prof. Dr. Instituição:

Julgamento: Assinatura:

Prof. Dr. Instituição:

Julgamento: Assinatura:

Prof. Dr. Instituição:

Julgamento: Assinatura:

Prof. Dr. Instituição:

Julgamento: Assinatura:

Prof. Dr. Instituição: 


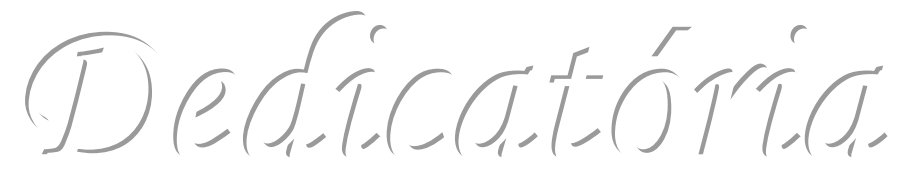


No caráter, na conduta, no estilo, em todas as coisas, a simplicidade é a suprema virtude.

Henry Wadsworth Longfellow

Aos meus pais, Luiz Renato e Neide

e meu irmão

André

pelos conselhos, ajuda e exemplos que construíram meu caráter e norteiam minha vida pessoal e profissional 
Os anjos se fazem notar apenas para aqueles que acreditam na sua existência, embora sempre estejam presentes.

Paulo coelho

Por estar comigo todo este tempo, compartilhar as alegrias, me acolher nas adversidades, entender minhas ausências: por fazer parte da minha vida

E seus pais Hélio e Selma

Pelo carinho e dedicação com que me acolheram como membro

desta família 
O degrau de uma escada não serve simplesmente para que alguém permaneça em cima dele, destina-se a sustentar o pé de um homem pelo tempo suficiente para que ele coloque o outro um pouco mais alto

Thomas Huxley

Aos meus amigos

João Paulo Elsen Saut

Que há doze anos segue comigo esta trilha

E Ewaldo de Mattos Júnior

Companheiros incansáveis nas alegrias e adversidades,

Obrigado por tudo 
Saber é ampliar os limites conscientes de sua própria ignorância

Confúcio

Primeiro aprenda a ser um artesão. Isso não impedirá você de ser um gênio.

Eugene Delacroix

Aos Professores

Antônio Felipe Paulino de Figueiredo Wouk

Cássio Ricardo Auada Ferrigno

Pelos exemplos de conduta profissional que me incentivaram a buscar a cirurgia e a ortopedia como

especialidade

A verdadeira medida de um homem não é como ele se comporta em momentos de conforto e conveniência, mas como ele se mantém em tempos de controvérsia e desafio

Martin Luther King

\section{À Professora \\ Sílvia Renata Gaido Cortopassi}

Por todos os momentos de dedicação

à minha formação;

momentos em que a psicóloga superou

a brilhante anestesista

Obrigado pelos conselhos,

exemplo,

atenção e carinho

a mim dispensados 
Fica estabelecida a possibilidade de sonhar coisas impossíveis e de caminhar livremente em direção aos sonhos.

Luciano Luppi

Ao tecnólogo

César Augusto Martins Pereira

Um gênio dedicado à pesquisa, sem o qual não seria possível a realização deste trabalho

Obrigado por sua dedicação 
Se você abre uma porta, você pode ou não entrar em uma nova sala. Você pode não entrar e ficar observando a vida. Mas se você vence a dúvida, o temor, e entra, dá um grande passo: nesta sala vive-se! Mas, também, tem um preço... São inúmeras outras portas que você descobre. Às vezes curte-se mil e uma.

O grande segredo é saber quando e qual porta deve ser aberta.

A vida não é rigorosa, ela propicia erros e acertos.

Os erros podem ser transformados em acertos quando com eles se aprende. Não existe a segurança do acerto eterno. A vida é generosa, a cada sala que se vive, descobre-se tantas outras portas. E a vida enriquece quem se arrisca a abrir novas portas.

Ela privilegia quem descobre seus segredos e generosamente oferece afortunadas portas. Mas a vida também pode ser dura e severa

Se você não ultrapassar a porta, terá sempre a mesma porta pela frente.

É a repetição perante a criação, é a monotonia monocromática perante a multiplicidade das cores, é a estagnação da vida... Para a vida, as portas não são obstáculos, mas diferentes passagens!

Içami Tiba

\section{Eveline Alessandra Rocha Alves José Geraldo Meirelles Palma Isola, Juliana de Araújo Caldeira, Lilian Mieko Saito, Lucas Bahdour Corsi, Márcio Hamamura, Raquel Niero Orsoli,}

E todos os residentes do Hospital Veterinário da Faculdade de Medicina Veterinária do Centro Universitário de Rio Preto

Pela incansável dedicação diária apresentada e pela boa relação de trabalho que desenvolvemos 


\section{Agradecimentos}

Ao Departamento de Cirurgia da Faculdade de Medicina Veterinária e Zootecnia da Universidade de São Paulo, pela oportunidade concedida.

Ao laboratório de análises mecânicas do Instituto de Ortopedia e Traumatologia da Faculdade de Medicina da Universidade de São Paulo, por permitir a realização deste trabalho

À Faculdade de Medicina Veterinária do Centro Universitário de Rio Preto, por entender que a valorização de seus profissionais é crescimento da própria instituição

Ao secretário Belarmino Ney Pereira, do departamento de Clínica Cirúrgica da Faculdade de Medicina Veterinária e Zootecnia da Universidade de São Paulo, pela ampla e irrestrita disponibilidade em todos os momentos que precisei.

Aos meus colegas, professores Alfredo Maia Filho e Everton Regonato, que por muitas vezes se desdobraram e me substituíram em momentos de ausência para realização deste trabalho

À Marina Corbucci Trefiglio, Filipe Matheus de Araújo, Juliana Gonçalves Ramos, Dênio Fachin, e todos os alunos da Faculdade de Medicina Veterinária do Centro Universitário de Rio Preto, motivos da minha eterna busca por aprimoramento

Aos funcionários Daniel, Cláudia, José Inácio, Tânea, Fabiana, Lindalva, Lígia e ao biólogo Fabiano, do Hospital Veterinário da Faculdade de Medicina Veterinária do Centro Universitário de Rio Preto, pelo auxílio indispensável na conclusão deste projeto.

A todos que, direta ou indiretamente fizeram parte desta conquista 


\section{RESUMO}

SCHMAEDECKE, A. Avaliação biomecânica de diferentes bloqueios transcorticais de interlocking nail em relação às forças de torção, encurvamento e axiais atuantes em fraturas diafisárias de fêmur de cães Estudo in vitro [Biomechanical evaluation of different transcortical blockades of Interlocking nail in relation to torsion, bending and axial forces, acting in diaphiseal femoral fractures in dogs - an in vitro study] 2007. $144 \mathrm{f}$. Tese (Doutorado em Medicina Veterinária) - Faculdade de Medicina Veterinária e Zootecnia, Universidade de São Paulo, São Paulo, 2007.

O advento da osteossíntese biológica é importante avanço no desenvolvimento da ortopedia. As vantagens que as hastes de Interlocking Nail têm demonstrado clinicamente, como método de fixação interna que promove formação de calo ósseo adequado, respeitando as premissas básicas da ortopedia moderna, com paciente retomando suas atividades de forma ativa, precoce e indolor, transportam esta técnica à condição de principal em termos de tratamento de fraturas cominutivas de fêmur em pacientes humanos e animais de companhia. No entanto, face a pouca disponibilidade de dados biomecânicos disposta em bibliografia, buscou-se, através deste estudo biomecânico não destrutivo, disponibilizar o padrão de movimentação interfragmentária do foco da fratura, mediante osteossíntese com hastes bloqueadas. Foi realizado estudo contemplando cinco grupos diferentes, com seis elementos cada, em análise in vitro, em relação a quatro diferentes possibilidades de bloqueio transcortical. Avaliou-se também comportamento do sistema quando utilizada haste de comprimento menor ao ideal, submetidos aos ensaios de compressão excêntrica, encurvamento crânio-caudal e rotação, através de análise fotogramétrica e confrontamento de dados aos obtidos pela análise de rigidez disponibilizada pela máquina universal de ensaios mecânicos Kratos ${ }^{\circledR}$ modelo 5002 dotada de célula de carga de 981 N (100 kgf). A análise 
dos resultados obtidos não apresentou diferença significativa entre os grupos nos ensaios propostos, tanto para análise fotogramétrica quanto análise de rigidez, sendo menor que 1,0 mm a média da movimentação interfragmentária de todos os grupos estudados. Estes dados demonstram biomecanicamente a aplicabilidade da técnica em fraturas cominutivas de terço médio de diáfise femoral em cães, possibilitando, frente à necessidade do cirurgia, optar por qualquer das técnicas de bloqueio aqui estudadas.

Palavras-chave: Biomecânica:Fraturas: Cirurgia: Cães. 


\begin{abstract}
SCHMAEDECKE, A. Biomechanical evaluation of different transcortical blockades of Interlocking nail in relation to torsion, bending and axial forces, acting in diaphiseal femoral fractures in dogs - an in vitro study. [Avaliação biomecânica de diferentes bloqueios transcorticais de interlocking nail em relação às forças de torção, encurvamento e axiais atuantes em fraturas diafisárias de fêmur de cães - Estudo in vitro] 2007. 144 f. Tese (Doutorado em Medicina Veterinária) - Faculdade de Medicina Veterinária e Zootecnia, Universidade de São Paulo, São Paulo, 2007.
\end{abstract}

The advent of biological osteosynthesis is an important advance in the orthopedics development. The advantages that the rods of Interlocking Nail have clinically demonstrated, as method of internal fixation that promotes adequate bone callous formation, respecting the basic premises of the modern orthopedics, with patient retaking its activities of active, precocious and painless form, carry this technique to the first choice in terms of treatment of femoral comminutive fractures in human and small animal patients. However, face to few availability of biomechanical data disposed in bibliography, this non destructive biomechanical study had the aim to demonstrate the standard of interfragmentary motion, in Interlocking nails osteosynthesis. This research was developed contemplating five different groups, with six elements each group, in an in vitro analysis, in relation to four different possibilities of transcortical blockade. The behavior of the system when the osteosynthesis was made through one lesser length to the ideal interlocking rod was also evaluated. All groups were submitted to the assays of eccentric compression, bending and torsion, through photogrammetric analysis and comparison to the analysis of rigidity data, disposed for the Kratos ${ }^{\circledR}$ universal machine of mechanical assays, model 5002 endowed with 981 N (100 kgf) load cell. The analysis of disposed results did not present significant difference between the groups in the 
considered assays, neither for photogrammetric analysis nor for rigidity analysis, being the average of the interfragmentary motion lesser that one millimeter on all of the studied groups. These data biomecanically demonstrate the applicability of the interlocking nail technique in medial third cominnutive femoral fractures in dogs, including, front to the necessity of the surgeon, the possibility to opt to any of the techniques of blockade studied.

Key words: Biomechanics; Fractures; Surgery; Dogs 


\section{LISTA DE FIGURAS}

Figura 4.1 - Imagem fotográfica de radiografia de fêmur esquerdo de cão, sendo mensurado o tamanho da haste a ser utilizado

- São Paulo - 2007

Figura 4.2 - Imagem fotográfica de exame radiográfico de fêmures de cão, identificando o correto posicionamento e bloqueios das hastes - São Paulo- 2007.

Figura 4.3 - Imagem fotográfica ilustrando preensão da epífise distal do fêmur canino por resina acrílica em copo oval com oito parafusos de fixação - São Paulo - 2007.

Figura 4.4 - Imagem fotográfica da máquina universal de ensaios mecânicos Kratos utilizada nos ensaios - São Paulo 2007.

Figura 4.5 - Imagem fotográfica ilustrando a disposição da máquina universal de ensaios mecânicos Kratos utilizada nos ensaios e o computador utilizado para captação dos dados - São Paulo - 2007.

Figura 4.6 - Imagem fotográfica do corpo de prova utilizado para os ensaios mecânicos - São Paulo - 2007.

Figura 4.7 - Imagem fotográfica de fêmur canino ostectomizado, cuja síntese foi realizada por haste bloqueada de $185 \mathrm{~mm}$ de comprimento, com intervalo de $25 \mathrm{~mm}$ em região média de sua diáfise, disposto em ensaio mecânico - São Paulo 2007.

Figura 4.8 - Desenho esquemático do ensaio de compressão excêntrica do fêmur sem o calibrador - São Paulo 2007.

Figura 4.9 - Imagem fotográfica do atuador cilíndrico acoplado à cabeça femoral para ensaio de compressão - São Paulo - 2007

Figura 4.10 - Desenho esquemático do ensaio de compressão excêntrica do fêmur como o calibrador e as câmeras São Paulo - 2007 
Figura 4.11 - Imagem fotográfica ilustrando disposição das câmeras fotográficas fixadas em travessão e anguladas a 45 graus entre si, no ensaio de compressão - São Paulo 2007.

Figura 4.12 - Seqüência de imagens fotográficas demonstrando o ensaio de compressão axial - São Paulo 2007

Figura 4.13 -Desenho esquemático do ensaio de encurvamento do fêmur sem o calibrador e as câmeras - São Paulo 2007

Figura 4.14- Desenho esquemático do ensaio de encurvamento do fêmur com o calibrador e as câmeras - São Paulo 2007.

Figura 4.15 - Seqüência de imagens fotográficas demonstrando o ensaio de encurvamento - São Paulo 2007.

Figura 4.16- Desenho esquemático do ensaio de torção do fêmur sem o calibrador e as câmeras - São Paulo 2007.

Figura 4.17- Imagem fotográfica ilustrando garra cilíndrica acoplada à epífise proximal para ensaio de rotação - São Paulo 2007.

Figura 4.18- Desenho esquemático do ensaio de torção do fêmur com o calibrador e as câmeras - São Paulo - 2007.

Figura 4.19 - Imagem fotográfica ilustrando disposição das câmeras fotográficas fixadas em travessão e anguladas a 45 graus entre si, nos ensaios de encurvamento e rotação- São Paulo - 2007

Figura 4.20 - Seqüência de imagens fotográficas demonstrando o ensaio de rotação - São Paulo - 2007.

Figura 5.1 - Gráfico de comparação das médias dos grupos estudados, obtidas no deslocamento em milímetros da porção superior dos corpos de prova, em relação ao momento inicial $(0 \mathrm{~N})$, segundo cada tempo de parada, durante o ensaio de compressão - São Paulo - 2007. 
Figura 5.2 - Gráfico de comparação das médias dos grupos estudados, obtidas no deslocamento em milímetros da porção superior dos corpos de prova, em relação ao momento inicial $(0 \mathrm{~N})$, segundo cada tempo de parada, durante o ensaio de encurvamento- São Paulo - 2007.

Figura 5.3 - Gráfico de comparação das médias dos grupos estudados, obtidas no deslocamento em milímetros da porção superior dos corpos de prova, em relação à porção inferior, segundo cada tempo de parada, durante o ensaio de rotação- São Paulo - 2007................................................ 


\section{LISTA DE TABELAS}

Tabela 5.1 - Valores obtidos, em N/mm, de rigidez dos corpos de prova, obtidos junto ao sistema lynx ${ }^{\circledR}$ modelo ads-2000, divididos nos grupos estudados, segundo os ensaios de compressão, encurvamento e rotação - São Paulo - 2007

Tabela 5.2 - Valores obtidos, em mm, de deslocamentos da porção superior dos corpos de prova em relação à situação inicial, em cada intervalo dos ensaios realizados, obtidos por análise fotogamétrica, divididos nos grupos estudados, segundo o ensaio de compressão- São Paulo - 2007...........

Tabela 5.3 - Valores obtidos, em mm, de deslocamentos da porção inferior dos corpos de prova em relação à situação inicial, em cada intervalo dos ensaios realizados, obtidos por análise fotogamétrica, divididos nos grupos estudados, segundo o ensaio de compressão- São Paulo - 2007...........

Tabela 5.4 - Valores obtidos, em mm, de deslocamentos da porção superior dos corpos de prova em relação à porção inferior, em cada intervalo dos ensaios realizados, obtidos por análise fotogamétrica, divididos nos grupos estudados, segundo o ensaio de compressão- São Paulo - 2007...........

Tabela 5.5 - Valores obtidos, em mm, de deslocamentos da porção superior dos corpos de prova em relação à situação inicial, em cada intervalo dos ensaios realizados, obtidos por análise fotogamétrica, divididos nos grupos estudados, segundo o ensaio de encurvamento- São Paulo - 2007........

Tabela 5.6 - Valores obtidos, em mm, de deslocamentos da porção inferior dos corpos de prova em relação à situação inicial, em cada intervalo dos ensaios realizados, obtidos por análise fotogamétrica, divididos nos grupos estudados, segundo o ensaio de encurvamento- São Paulo - 2007........

Tabela 5.7 - Valores obtidos, em mm, de deslocamentos da porção superior dos corpos de prova em relação à porção inferior, em cada intervalo dos ensaios realizados, obtidos por análise fotogamétrica, divididos nos grupos estudados, segundo o ensaio de encurvamento- São Paulo - 2007........ 
Tabela 5.8 - Valores obtidos, em mm, de deslocamentos da porção superior dos corpos de prova em relação à situação inicial, em cada intervalo dos ensaios realizados, obtidos por análise fotogamétrica, divididos nos grupos estudados, segundo o ensaio de rotação- São Paulo - 2007.

Tabela 5.9 - Valores obtidos, em mm, de deslocamentos da porção inferior dos corpos de prova em relação à situação inicial, em cada intervalo dos ensaios realizados, obtidos por análise fotogamétrica, divididos nos grupos estudados, segundo o ensaio de rotação- São Paulo - 2007....................

Tabela 5.10 - Valores obtidos, em mm, de deslocamentos da porção superior dos corpos de prova em relação à porção inferior, em cada intervalo dos ensaios realizados, obtidos por análise fotogamétrica, divididos nos grupos estudados, segundo o ensaio de rotação- São Paulo - 2007 ....................

Tabela 5.11 - Valores obtidos, em mm, de deslocamentos da porção superior dos corpos de prova em relação à situação inicial, em cada intervalo dos ensaios realizados, obtidos por análise fotogamétrica, segundo a coordenada espacial X, nos ensaios de compressão- São Paulo - 2007.

Tabela 5.12 - Valores obtidos, em mm, de deslocamentos da porção inferior dos corpos de prova em relação à situação inicial, em cada intervalo dos ensaios realizados, obtidos por análise fotogamétrica, segundo a coordenada espacial $\mathrm{X}$, nos ensaios de compressão- São Paulo - 2007

Tabela 5.13 - Valores obtidos, em mm, de deslocamentos da porção superior dos corpos de prova em relação à situação inicial, em cada intervalo dos ensaios realizados, obtidos por análise fotogamétrica, segundo a coordenada espacial $\mathrm{Y}$, nos ensaios de compressão- São Paulo - 2007

Tabela 5.14 - Valores obtidos, em $\mathrm{mm}$, de deslocamentos da porção inferior dos corpos de prova em relação à situação inicial, em cada intervalo dos ensaios realizados, obtidos por análise fotogamétrica, segundo a coordenada espacial $\mathrm{Y}$, nos ensaios de compressão- São Paulo - 2007 
Tabela 5.15 - Valores obtidos, em $\mathrm{mm}$, de deslocamentos da porção superior dos corpos de prova em relação à situação inicial, em cada intervalo dos ensaios realizados, obtidos por análise fotogamétrica, segundo a coordenada espacial Z, nos ensaios de compressão- São Paulo - 2007.

Tabela 5.16 - Valores obtidos, em $\mathrm{mm}$, de deslocamentos da porção inferior dos corpos de prova em relação à situação inicial, em cada intervalo dos ensaios realizados, obtidos por análise fotogamétrica, segundo a coordenada espacial Z, nos ensaios de compressão- São Paulo - 2007

Tabela 5.17 - Valores obtidos, em mm, de deslocamentos da porção superior dos corpos de prova em relação à situação inicial, em cada intervalo dos ensaios realizados, obtidos por análise fotogamétrica, segundo a coordenada espacial X, nos ensaios de encurvamento- São Paulo - 2007

Tabela 5.18 - Valores obtidos, em mm, de deslocamentos da porção inferior dos corpos de prova em relação à situação inicial, em cada intervalo dos ensaios realizados, obtidos por análise fotogamétrica, segundo a coordenada espacial X, nos ensaios de encurvamento- São Paulo - 2007.

Tabela 5.19 - Valores obtidos, em mm, de deslocamentos da porção superior dos corpos de prova em relação à situação inicial, em cada intervalo dos ensaios realizados, obtidos por análise fotogamétrica, segundo a coordenada espacial $\mathrm{Y}$, nos ensaios de encurvamento- São Paulo - 2007.

Tabela 5.20 - Valores obtidos, em mm, de deslocamentos da porção inferior dos corpos de prova em relação à situação inicial, em cada intervalo dos ensaios realizados, obtidos por análise fotogamétrica, segundo a coordenada espacial $\mathrm{Y}$, nos ensaios de encurvamento- São Paulo - 2007

Tabela 5.21 - Valores obtidos, em $\mathrm{mm}$, de deslocamentos da porção superior dos corpos de prova em relação à situação inicial, em cada intervalo dos ensaios realizados, obtidos por análise fotogamétrica, segundo a coordenada espacial Z, nos ensaios de encurvamento- São Paulo - 2007. 
Tabela 5.22 - Valores obtidos, em $\mathrm{mm}$, de deslocamentos da porção inferior dos corpos de prova em relação à situação inicial, em cada intervalo dos ensaios realizados, obtidos por análise fotogamétrica, segundo a coordenada espacial Z, nos ensaios de encurvamento- São Paulo - 2007.

Tabela 5.23 - Valores obtidos, em $\mathrm{mm}$, de deslocamentos da porção superior dos corpos de prova em relação à situação inicial, em cada intervalo dos ensaios realizados, obtidos por análise fotogamétrica, segundo a coordenada espacial X, nos ensaios de rotação- São Paulo - 2007.

Tabela 5.24 - Valores obtidos, em $\mathrm{mm}$, de deslocamentos da porção inferior dos corpos de prova em relação à situação inicial, em cada intervalo dos ensaios realizados, obtidos por análise fotogamétrica, segundo a coordenada espacial $\mathrm{X}$, nos ensaios de rotação- São Paulo - 2007

Tabela 5.25 - Valores obtidos, em $\mathrm{mm}$, de deslocamentos da porção superior dos corpos de prova em relação à situação inicial, em cada intervalo dos ensaios realizados, obtidos por análise fotogamétrica, segundo a coordenada espacial $\mathrm{Y}$, nos ensaios de rotação- São Paulo - 2007

Tabela 5.26 - Valores obtidos, em $\mathrm{mm}$, de deslocamentos da porção inferior dos corpos de prova em relação à situação inicial, em cada intervalo dos ensaios realizados, obtidos por análise fotogamétrica, segundo a coordenada espacial $\mathrm{Y}$, nos ensaios de rotação- São Paulo - 2007

Tabela 5.27 - Valores obtidos, em mm, de deslocamentos da porção superior dos corpos de prova em relação à situação inicial, em cada intervalo dos ensaios realizados, obtidos por análise fotogamétrica, segundo a coordenada espacial Z, nos ensaios de rotação- São Paulo - 2007.

Tabela 5.28 - Valores obtidos, em $\mathrm{mm}$, de deslocamentos da porção inferior dos corpos de prova em relação à situação inicial, em cada intervalo dos ensaios realizados, obtidos por análise fotogamétrica, segundo a coordenada espacial Z, nos ensaios de rotação- São Paulo - 2007. 


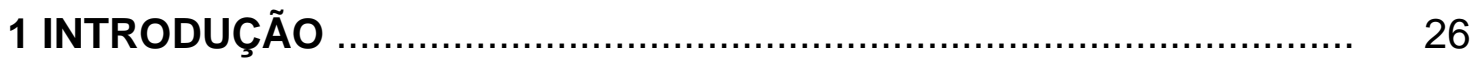

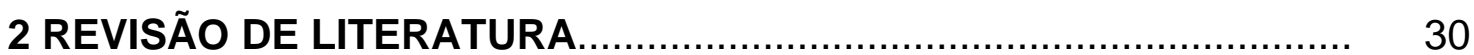

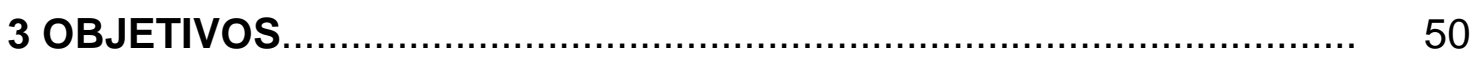

4 MATERIAL E MÉTODO.................................................................... 52

4.1 MATERIAL BIOLÓGICO........................................................... 53

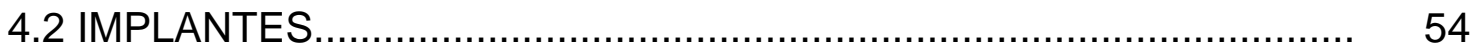

4.3 CORPOS DE PROVA................................................................. 55

4.3.1 Obtenção do Material Biológico.................................................. 55

4.3.2 Implantação das hastes.............................................................. 56

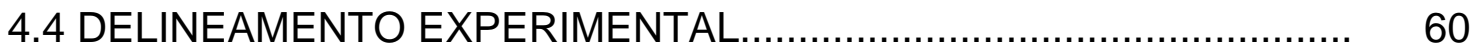

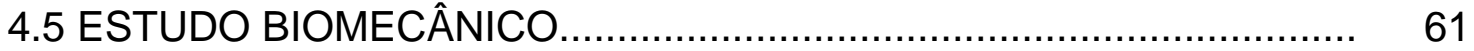

4.5.1 Acoplamento das peças à máquina ............................................ 61

4.5.2 Descrição dos ensaios mecânicos............................................. 62

4.5.2.1Ensaio de compressão axial......................................................... 67

4.5.2.2 Ensaio de encurvamento...................................................... 72

4.5.2.3 Ensaio de rotação.................................................................. 75

4.6 MÉTODO FOTOGRAMÉTRICO .................................................. 80

4.6.1 Parâmetros analisados......................................................... 80

4.7 ANÁLISE ESTATÍSTICA................................................................. 80

4.7.1 Níveis de Significância ............................................................... 81

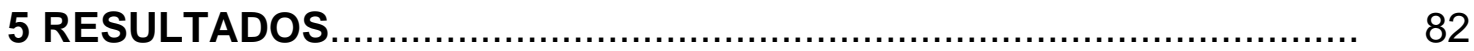

5.1 ANÁLISE DOS DADOS OBTIDOS PELO SISTEMA DE AQUISIÇÃO ANALÓGICA LYNX ${ }^{\circledR}$ MODELO ADS-2000........................................ 84

5.2 ANÁLISE FOTOGRAMÉTRICA..................................................... 86 
5.2.1 Análise das distâncias em relação a $0 \mathrm{~N}$

5.2.1.1 Ensaio de compressão...................................................... 86

5.2.1.2 Ensaio de Encurvamento............................................... 90

5.2.1.3 Ensaio de Rotação.............................................................. 94

5.2.2 Análise de deslocamento nos eixos $X, Y$ e $Z$ em relação a 0 N... $\quad 98$

5.2.2.1 Ensaio de compressão.................................................... 98

5.2.2.2 Ensaio de encurvamento............................................... 105

5.2.2.3 Ensaio de Rotação.............................................................. 112

5.3 GRÁFICOS DE COMPARAÇÃO DAS MÉDIAS OBTIDAS NO DESLOCAMENTO............................................................... 119

5.3.1 Ensaio de Compressão...................................................... 119

5.3.2 Ensaio de Encurvamento................................................ 120

5.3.3 Ensaio de Rotação............................................................. 121

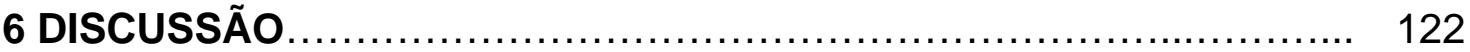

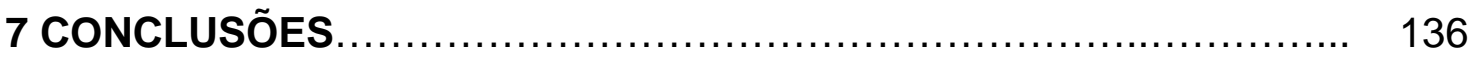

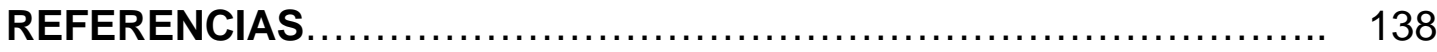




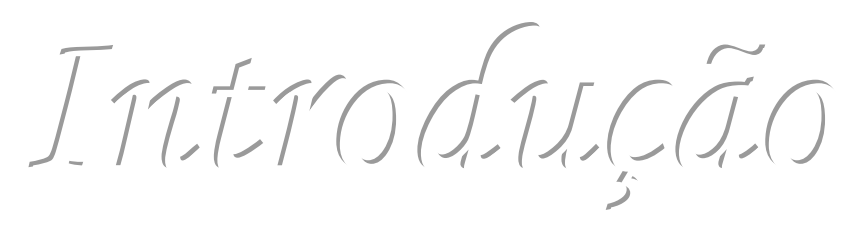




\section{INTRODUÇÃO}

O mundo moderno, principalmente nos grandes centros urbanos, tem provocado significativa mudança no comportamento dos seres humanos, com reflexos no perfil das famílias. Questões econômicas, de segurança, de disponibilidade de tempo e outros fatores, acabaram por modificar o cotidiano das pessoas. A opção por famílias cada vez menos numerosas fez com que os indivíduos buscassem, com grande intensidade, a companhia de pequenos animais como forma de preencher um espaço em suas vidas. Neste contexto, os animais de companhia vêm, gradativamente, ao longo dos anos, conquistando um status cada vez mais importante. Diante do fato, o zelo e os cuidados dispensados aos animais têm aumentado de forma exponencial, obrigando os veterinários a desenvolver e especializar a ars veterinária, cuja evolução, em breve relato, é descrita.

Do início dos quadros de "cura", nos primórdios da história, chega-se aos primeiros processos cirúrgicos em animais, confundidos mesmo com o início da cirurgia em humanos, pois os instrumentos e técnicas eram os mesmos. A primeira cirurgia que se tem conhecimento é a trepanação, para dar vazão aos "maus espíritos".

O século XVIII reflete, sem dúvida, o início da medicina veterinária moderna, com a fundação da Escola Veterinária de Lion (1762) e Alfort (1765), como marco do segundo período da história veterinária: o período educacional. Nesta época os cirurgiões surgem como os primeiros grandes mestres da veterinária. Lafosse se projeta como anatomista e cirurgião de renome. Na Alemanha, Wolstein se destaca com suas publicações e, na Inglaterra, funda-se o Colégio 
de Veterinária de Londres (1791). É nesse período que John Hunter (17281793) tem grande projeção. Trabalhando com fraturas e crescimento ósseo, muito do qual aprendido com estudos em animais, estabelece-se como pioneiro em ortopedia.

O século XIX surge com novidades em termos de fixação e redução de fraturas, na tentativa de se prevenir a formação de seqüelas indesejáveis. Em cães, Blaine (1824) aplica imobilizações de madeira, fixadas por tiras de couro. A descoberta dos raios-X por Röentger (1895) foi o avanço mais notável desta época, permitindo melhor avaliação dos quadros mórbidos e conseqüente explicação dos insucessos de até então.

No século passado, a grande evolução da ortopedia veterinária data dos anos 50, com o início de seu processo de especialização, seguindo os padrões da medicina humana, intensificada após criação do grupo internacional AO/ASIF, que norteia as atividades dos especialistas desta área. A este fato, seguiu-se a difusão mundial de novos conceitos de tratamento e desenvolvimento de implantes e técnicas que permitam ao paciente o retorno de suas atividades normais através da deambulação precoce, ativa e indolor.

Em relação às novas metodologias, surge, derivado de análogo utilizado em medicina humana, novo conceito de tratamento de fraturas cominutivas de úmero, fêmur e tíbia, a técnica de "Interlocking nail". O termo, mundialmente conhecido e aceito, encontra na literatura nacional nomenclatura de Haste Bloqueada, embora nenhuma oposição seja feita à utilização da forma original. Sua filosofia baseia-se na derivação das hastes de Kuntscher, que tem por função bloquear as forças de compressão axial, encurvamento e rotação, 
atuantes nos quadros de fratura, possibilitando o adequado processo de reparação óssea.

A técnica consiste em redução da fratura por haste intramedular, bloqueada por quatro parafusos, alocados transversalmente em orifícios existentes na haste, dispostos em posições fixas a 11 ou $22 \mathrm{~mm}$ de distância entre si, sendo dois no segmento proximal da haste, e dois em seu segmento distal.

Para sua adequada aplicação, a haste deve preencher a maior parte do canal medular, tanto em diâmetro, quanto em comprimento, e todos os bloqueios devem ser efetuados.

Sabe-se no entanto, que determinadas situações impossibilitam o bloqueio de todos os orifícios, tais como fraturas de alta cominução, em região de terço proximal ou distal dos ossos em questão. Soma-se a este fato, a carência de dados publicados em relação ao comportamento biomecânico das hastes quando utilizadas em fraturas múltiplas e cominutivas.

O cenário descrito torna as Hastes Bloqueadas pouco utilizadas nos tratamentos dos quadros mórbidos em questão, muito embora a facilidade da técnica, se comparada à colocação de placas e parafusos justificasse sua escolha.

Estes fatos motivaram a elaboração deste trabalho que visou a análise biomecânica da micromovimentação interfragmentária de fraturas cominutivas submetidas à osteossíntese com hastes bloqueadas, para que os dados obtidos possam subsidiar novas pesquisas e o desenvolvimento de metodologias que tornem esta técnica exeqüível aos casos em questão. 


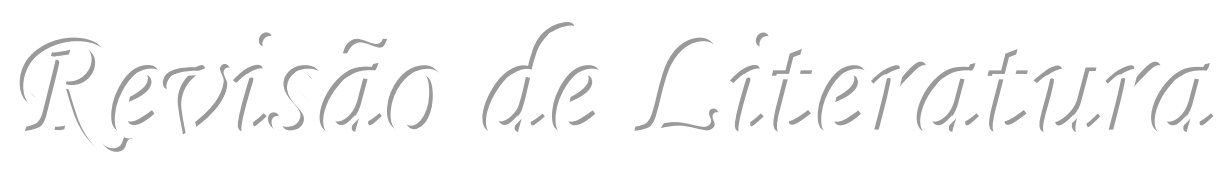




\section{REVISÃO DE LITERATURA}

O osso é o elemento estrutural básico do corpo de qualquer mamífero. No entanto, pouca pesquisa é disponível referente às propriedades mecânicas básicas de ossos longos de cães. Estes dados não somente explicam melhor as características das fraturas, como são necessários para o desenvolvimento de qualquer técnica de fixação (MARKEL et al., 1994).

Os ossos apresentam geometria complexa e são submetidos a grupos de força igualmente complexos, responsáveis pela geração de fatores de estresse e deformação ao longo de toda a estrutura óssea (CARTER; SPENGLER, 1977). A relação entre estresse sofrido e deformação apresentada gera curva exponencial de resposta, que reflete o comportamento mecânico da estrutura óssea. As forças mencionadas geram cargas de compressão axial, torção e encurvamento. Ossos longos in vivo estão sempre sofrendo ação combinada das forças de compressão e encurvamento. Como resultado desta ação combinada, cria-se força de compressão excêntrica, com maior estresse distribuído no lado contrário da aplicação da força. Além desta, a força de torção gera tendência de rotação do osso pelo eixo axial, provocando deformações evidentes em sua superfície. (SUMNER-SMITH, 2002).

Reilly et al.(1974) descreveram a ação conjunta destas forças em ossos longos, demonstrando que, por sua característica cilíndrica, apresentam maior deformação longitudinal que transversal. Por esta deformação explica-se o fato dos ossos serem estruturas tubulares e não cilíndricas sólidas. Estruturas tubulares apresentam momento de área de inércia muito maior que as sólidas. Tal fato permite ao osso resistir duas vezes mais às forças de compressão e 
quatro e meia vezes mais às forças de encurvamento e rotação (SUMNERSMITH; 2002, FERRIGNO; PEDRO, 2006).

Segundo Markel et al.(1994), fêmur e úmero sofrem maior atuação de forças de rotação, quando comparados à rádio e tíbia. A resposta gerada por estas forças está relacionada com a área cortical existente nestes ossos, resultando em maior momento polar de inércia dos ossos proximais em relação aos distais (FERRIGNO; PEDRO, 2006).

Este aumento de forças e momentos é basicamente resultante da soma dos vetores atuantes na porção proximal do osso. Estas forças e momentos são determinados por fatores físicos, como forças musculares usadas para locomoção e resistência à força da gravidade (MARKEL et al., 1994).

Em estudo biomecânico de osso íntegro, Markel et al.(1994) demonstraram não haver diferença estatística significativa entre os membros direito e esquerdo, quando comparadas suas reações em relação às forças de atuação. Demonstraram também que a energia absorvida por toda a diáfise do osso íntegro é maior que aquela absorvida pela região média desta diáfise. Existe portanto uma dissipação das forças ao longo do eixo longitudinal do osso. Dáse a esta dissipação o nome de braço de força.

Fraturas ocorrem quando a carga aplicada sobre determinada região do osso superam sua capacidade de resistência. Em osso fraturado, o braço de força acaba produzindo maior concentração do vetor no ponto da fratura que, ao apresentar momento de inércia diminuído, tende a movimentar com maior facilidade (HULSE et al., 1997).

Fraturas de ossos longos são, sem dúvida, um dos principais pontos de tratamento ortopédico na medicina veterinária. Destas, as fraturas de fêmur são 
responsáveis por aproximadamente 20 a 25\% do total de casos apresentados por cães e gatos (LARIN et al., 2001). Harasen (2003) apresenta estudo retrospectivo em que $45 \%$ (128/282) do total de fraturas de ossos longos atendidas correspondiam ao fêmur, enquanto $26 \%$ eram fraturas tibiais. Estas fraturas geralmente ocorrem por acidentes automobilísticos, quedas ou acidentes com armas de fogo (LARIN et al., 2001). Estes dados provavelmente estão ligados a maior taxa de sobrevida dos animais que sofrem traumatismos de membros pélvicos, se comparados àqueles que sofrem trauma em regiões mais craniais, com o envolvimento quase que inevitável de regiões anatômicas nobres como o crânio e tórax (HARASEN, 2003).

Segundo Schatzker e Houlton (2002), o osso é tecido capaz de se adaptar rapidamente à aplicação contrária de força, pois consegue armazenar energia em seu interior. No entanto, em quadros de fraturas, perde-se a integridade estrutural e, em frações de segundo, a energia armazenada é dissipada aos tecidos adjacentes. O grau de energia liberado é diretamente responsável tanto pelo número de fragmentos ósseos produzidos, como pelo dano tissular regional, com criação de cavitações de grau variado. Corroborando estes dados, Harris et al.(2006) demonstram a alta incidência de complicações com desvitalização de tecidos moles como primárias à fraturas tibiais cominutivas em seres humanos, decorrentes de trauma agudo de alta energia.

Berkson e Virkus (2006) descrevem a severidade da fratura e o grau de complexidade de seu tratamento como sendo diretamente relacionados à intensidade do trauma original. Citam que fraturas originadas por traumas de baixo impacto têm características de depressão unilateral, enquanto aquelas geradas por traumas de alto impacto, apresentam características cominutivas. 
Sob este aspecto, Beardsley et al.(2005) descrevem correlação linear entre o número de fragmentos ósseos e absorção de energia.

Pela descrição acima, a presença de alto grau de cominução destas fraturas femorais denota escolha criteriosa da técnica de reparação. Saravanian et al.(2002a) descrevem esta cominução como a presença de uma ou mais esquírolas ósseas, associadas à fragmentos menores, tornando especialmente difíceis os procedimentos de alinhamento e estabilização. Estas fraturas requerem técnicas de reparação capazes de resistir às forças de compressão, torção e encurvamento, apresentando formação de calo ósseo e consolidação adequada.

Segundo Roe (1998), vários estágios de maturação do calo ósseo são influenciados por fatores humorais locais e físicos. A variação de estresse e deformação sobre estes tecidos formadores do calo ósseo é que farão sua organização e diferenciação. Conforme a deposição de matriz cartilaginosa, menor a resistência celular à deformação é permitida. Por este fator, é consenso entre os autores a necessidade de osteossíntese baseada em técnica que bloqueie as forças atuantes, impedindo a movimentação do foco da fratura.

Em estudo utilizando osteoblastos em meio de cultura submetida à deformação, Hulse et al.(1997) descrevem a maior proliferação celular em cultura submetida à deformação de $1 \%$, se comparados àqueles cuja cultura fora submetida à deformação de 5\%. Corroborando estes dados, Cheal et al.(1991) descrevem que altos graus de movimentação favorecem a reabsorção óssea e conseqüente desenvolvimento de quadros de não união óssea. 
A atuação de todos estes fatores humorais é altamente beneficiada através de movimentação ativa, precoce e indolor do membro afetado que, segundo Schatzker e Houlton (2002), geram normalização do suporte vascular tanto ósseo quanto de tecidos moles, aumentando a nutrição celular e diminuindo a osteoporose pós-traumática, por restabelecimento do equilíbrio entre formação e reabsorção ósseas.

Esta tríade "movimentação ativa, precoce e indolor" é premissa básica do grupo AO/ASIF (Arbeistsgemeinschft für Osteosynthesefragen / Association for the Study of Internal Fixation), descrita por Miller (1998) como associação criada na década de 50, em resposta à inaceitável incidência de doenças da fratura decorrentes do uso de técnicas de fixação e imobilização incorretas. Este grupo definiu diretrizes para o rápido retorno funcional após intervenção ortopédica que, segundo Sumner-Smith (2002), consistia em redução anatômica dos fragmentos ósseos, especialmente relativos às superfícies articulares, cirurgia atraumática, fixação rígida, respeitando os padrões biomecânicos, e movimentação ativa, precoce e indolor, evitando a doença da fratura. Nos dias atuais, segundo Miller (1998), algumas premissas foram revistas, sendo a osteossíntese estável, com preservação da biologia do foco de fratura, o item mais relevante, sempre respeitando os demais itens mencionados.

A meta da redução anatômica é, segundo Schatzker e Houlton (2002), a consolidação óssea primária, sendo importante por vários aspectos, como congruência articular, correto alinhamento entre metáfise e diáfise e maior resistência às forças atuantes. 
Dickson et al.(2001) descrevem o tratamento de fratura cominutiva de tíbia em pacientes humanos através de redução anatômica, com $81 \%$ de resultados considerados bons a excelentes.

Johnston et al.(1991) e Hulse et al.(1997) descrevem que os principais problemas da redução anatômica das fraturas cominutivas são decorrentes da falhas dos implantes por formação de intervalos entre as esquírolas ósseas, provocando micro movimentação e instabilidade, com deformação interfragmentária.

Nos dias atuais, adotou-se em substituição à redução anatômica, a osteossíntese biológica, descrito por Frigg e Ulrich (2003) como novo paradigma da cirurgia ortopédica.

O conceito de recuperação biológica das fraturas foi introduzido no intuito de preservar, o máximo possível, a integridade vascular dos fragmentos ósseos e, ao mesmo tempo, prover fixação capaz de manter o alinhamento e o comprimento ósseos durante o período de reparação (WOO et al. 1984; PERREN, 1991; ARON et al., 1995; BERARDÉ et al., 2002; STIFFLER, 2004). Fraturas tratadas por este método são reduzidas e estabilizadas a céu fechado, utilizando, em medicina humana, apenas fluoroscopia e pequenas incisões para colocação dos implantes. O alinhamento dos fragmentos ósseos maiores e articulações predominam sobre a reconstrução anatômica. Em medicina veterinária, pelo pouco acesso aos exames fluoroscópicos (HORSTMAN et al., 2004), foi instituída a técnica do "abra, mas não toque", que consiste em mínimas incisões, com o menor contato possível com os tecidos moles adjacentes ao foco de fratura, exclusivamente para observar a disposição dos fragmentos ósseos e realizar a osteossíntese (MC LAUGHLIN, 1999; PALMER, 
1999; HORSTMAN et al., 2004). Esta abordagem preserva o potencial osteogênico do hematoma provocado pela fratura (BERNARDE et al., 2001), minimiza a perda de vascularização, reduz o tempo cirúrgico e minimiza a possibilidade de infecção pós-operatória (MCCLURE, et al., 1998; LOPEZ, et al., 1999; HORSTMAN, et al., 2004). Pospula et al.(2003) mencionam o uso de mínimo acesso para correção de fraturas cominutivas de fêmur e tíbia, com 100\% de recuperação (16/16) de seus pacientes.

White et al.(2006) citam, em pacientes humanos, o desenvolvimento de fatores depressores cardiovasculares e embolismo transcardíaco, decorrente de ativação de sistema de coagulação, em procedimentos cirúrgicos de longo período, em pacientes poli-traumatizados. Deste modo, citam a utilização de hastes bloqueadas como forma de minimizar o tempo cirúrgico das osteossínteses, diminuindo o aparecimento dos eventos descritos.

Hotz (2003) descreve o uso da técnica de osteossíntese biológica em crianças, após redução fechada da fratura e visualização do resultado por análise radiográfica. Cita, no entanto, necessidade de aparelhos adequados e extrema habilidade e experiência do cirurgião.

Gautier e Sommer (2003) indicam uso de placas bloqueadas como método de osteossíntese biológica, por manter a biologia do hematoma fraturário e ainda assim realizar osteossíntese rígida. Sobre este ponto, Parren et al.(2003) indicam a facilidade da utilização de placas bloqueadas, pois ao travarem na placa, os parafusos, mesmo monocorticais, conferem à rigidez adequada ao implante preservando a vascularização periosteal.

Investigações clínicas são escassas em veterinária, em termos de comparação entre osteossíntese anatômica e biológica. Dudley et al.(1997) compararam 
osteossíntese com redução aberta e utilização de placas ósseas com redução fechada e fixação esquelética externa em fraturas cominutivas de tíbia em cães. Os resultados não apresentam diferenças estatísticas significativas em termos de união óssea. No entanto, demonstram diferença em termos de tempo de intervenção cirúrgica e complicações maiores no pós-operatório (osteomielite, união retardada e falha de implante), menores no grupo de redução fechada.

Johnson et al.(1996) estudaram, em fraturas cominutivas de fêmur, o uso de placas ósseas através de técnica aberta e redução anatômica e técnica fechada e redução por ponteamento. Demonstraram que o tempo cirúrgico e de processo de reparação óssea foram menores no grupo de redução fechada.

Horstman et al.(2004) compararam a reparação de fraturas por osteossíntese biológica e redução anatômica, utilizando hastes bloqueadas, apresentando como resultado o menor tempo de reparação da fratura dos pacientes submetidos ao método biológico (90\% do grupo de osteossíntese biológica apresentaram reparação em 8 semanas, contra apenas 65\% do grupo de osteossíntese anatômica). Demonstraram também que a manutenção da biologia do foco de fratura provê subsídios adequados para a reparação óssea, uma vez que citam não haver diferença estatística significativa dentro do grupo de osteossíntese biológica para os pacientes que receberam enxertos esponjosos em relação àqueles que não receberam.

Em relação às técnicas utilizadas para síntese de fraturas cominutivas em cães, alvo maior deste trabalho, Larin et al.(2001) citam que muitas técnicas são descritas para seu tratamento, incluindo uso de hastes intramedulares, fios de cerclagem, fixadores externos e placas parafusadas, ou suas combinações. 
Pinos intramedulares têm sido usados devido a sua praticidade e baixo custo em termos de estabilização de fraturas diafisárias de cães e gatos (PRESNEL, 1978). No entanto, são comuns as complicações cirúrgicas decorrentes da instabilidade do foco de fratura, migração do implante, rotação e encurtamento do osso afetado (DUHAUTOIS, 2003).

Saravanian et al.(2002a) compararam a osteossíntese de fraturas cominutivas de fêmur utilizando pinos intramedulares e placas ósseas de neutralização. Através do uso de pinos intramedulares, observaram a formação tardia de calo ósseo, com presença de sinais de osteomielite na maioria dos pacientes, como reação periosteal extensa e área de lise ao redor dos pinos. Descrevem ainda a presença de intervalo de fratura evidente aos 60 dias de pós-operatório, com instabilidade rotacional. Como conclusão, relatam que esta forma de osteossíntese deve ser evitada em fraturas cominutivas, pois tende ao colapso do sistema e falha de técnica. Indicam portanto a utilização de placas ósseas de neutralização, descrevendo a formação adequada de calo ósseo e reparação da fratura.

Placas ósseas apresentam variedade de formas e funções dentro da cirurgia ortopédica. Sua atuação primária remete o cirurgião à redução anatômica e osteossíntese rígida, através da compressão interfragmentária (MILLER, 1998; SCHATZKER e HOULTON , 2002). No entanto, os mesmos autores citam seu emprego em osteossínteses biológicas. Através de mínimo acesso e realinhamento dos segmentos ósseos maiores, pode-se utilizar as placas ósseas em técnica denominada como ponteamento, bloqueando o orifícios proximais e distais à fratura (KESEMENELI et al., 2002). 
Hulse et al.(1997) citam que a presença de intervalos entre os fragmentos e as placas ósseas não permitem, no paciente, a atuação de cargas fisiológicas de força no momento pós-operatório. Tal fato se deve à diminuição da área de contato entre placa e osso e aumento da força de encurvamento, através do aumento da ação do braço de força e diminuição do momento de inércia. Para minimizar estes fatores, descrevem a utilização combinada de pinos intramedulares que ocupem $50 \%$ do canal medular e placas ósseas, diminuindo em cerca de $50 \%$ a força sobre a placa óssea. No entanto, mostram como possível causa de falha do sistema a necessidade de bloqueio da placa por parafusos monocorticais, devido ao preenchimento do canal medular pelo pino. Tal bloqueio torna a placa mais instável e sujeita a deslocamentos.

Outra modalidade de placa óssea que surge como forma de realização de osteossíntese rígida, com preservação do mecanismo biológico de reparo da fratura é a denominada placa bloqueada, ou LCP. Através de parafusos autoperfurantes ou auto-macheantes, que travam diretamente na placa, permitem formação de intervalo entre seu corpo e o osso fraturado além de mínima manipulação cirúrgica para implantação (AGUILA et al., 2005; GAUTIER e SOMMER, 2003). Mesmo o uso monocortical dos parafusos bloqueados é possível, sem perda da resistência do implante (PERREN et al., 2003), fato este que não se repete para os parafusos corticais comuns (DAVENPORT et al., 1988).

Aguila et al., 2005 descrevem estudo comparativo entre as placas de compressão e LCP em fraturas diafisárias de fêmur em cão. A placa bloqueada demonstrou a mesma resistência às forças de compressão axial e torção, sendo significativamente mais resistente no ensaio de encurvamento. 
$\mathrm{Na}$ tentativa de desenvolver técnica que alie a facilidade e vantagens biomecânicas dos pinos intramedulares, com a rigidez e bloqueio das forças atuantes oferecidas pelas placas parafusadas, foi descrito por Modney (DUELAND et al., 1999, GUPTA, 2001), na década de 50, a técnica de Interlocking nail (IN). Hastes intramedulares, derivadas das hastes de Kuntscher (DUELAND et al., 1996) com orifícios transversais posicionados em distâncias padronizadas, permitindo, por entre os mesmos, realizar bloqueio dos movimentos rotacionais e axiais, através de parafusos.

A haste de IN é colocada de forma intramedular e os parafusos são fixados proximal e distalmente à fratura. Além de prevenir os movimentos responsáveis pelas complicações descritas para fixação com pinos intramedulares, o uso de IN é biomecanicamente vantajoso em relação às técnicas de imobilização por placa parafusada, por atuar ao longo do eixo mecânico central do osso (MOSES et al., 2002), além de preservar os conceitos de padrões biológicos de osteossíntese (DUHAUTOIS, 2003; FERRIGNO; PEDRO, 2006).

Em pacientes humanos, a fixação por IN tem suplantado o uso de placas parafusadas em muitas fraturas diafisárias de fêmur, tíbia e úmero, pela facilidade de aplicação, manutenção da vascularização dos fragmentos e segurança de técnica, uma vez que é aplicada com auxílio de fluoroscopia na colocação dos parafusos transcorticais, o que minimiza o acesso cirúrgico e torna efetivamente precisa a técnica, diminuindo também a morbidade póscirúrgica (MOSES et al., 2002). Suas indicações incluem fraturas diafisárias fechadas ou abertas, simples ou cominutivas, pseudoartroses, contaminadas ou não, além de osteotomias corretivas de alongamento, encurtamento ou derrotacionais. 
Como forma de manter o mecanismo biológico de reparação de fraturas, grande quantidade de artigos são publicados em medicina humana, apontando as hastes bloqueadas como as mais vantajosas no tratamento de fraturas diafisárias de ossos longos (WISS et al., 1990; JUBEL et al., 2002; WHITE et al., 2006).

Este sistema foi adaptado à necessidade da medicina veterinária por Dueland, em 1989, e comercializado pela Innovative Animal Products ${ }^{\circledR}$, desde 1994. O sistema veterinário utiliza guia acoplado à extremidade proximal da haste intramedular, para localização exata dos locais de inserção dos parafusos, permitindo sua aplicação sem a utilização de fluoroscópios (MCLAUGHLIN, 1999).

Cinco gerações de IN já foram desenvolvidas, sendo que a última consiste em hastes de 4.0, 4.7, 6.0, 8.0, 10 e 13 mm de diâmetro, com diferentes comprimentos (variando de 60 a $235 \mathrm{~mm}$ ), apresentando 2 orifícios proximais e 2 distais para bloqueio com parafusos de 2,0, 2,7 3,5 ou 4,5 mm, dependendo do seu diâmetro. Estes orifícios estão localizados a uma distância fixa de 11 ou $22 \mathrm{~mm}$ entre si.

Na porção proximal da haste, existe fenda para alocação do extensor, que pode ser de 80 ou $120 \mathrm{~mm}$ de comprimento. O extensor mais curto é utilizado em tratamento de fraturas de úmero e fêmur, enquanto o mais longo é utilizado em fraturas de tíbia, para evitar qualquer contato do equipamento com os côndilos da tróclea do fêmur ou patela.

A haste, previamente escolhida pelo comprimento do osso visualizado em radiografia, através de modelo específico impresso em folha transparente, colocado por sobre o filme radiográfico, é inserida por via normógrada ou 
retrógrada; o extensor é então disposto e neste o guia com as marcações específicas de perfuração é fixado. Baseando-se nestas marcações, são realizados os procedimentos de perfuração, macheamento e bloqueio dos orifícios da haste (DUELAND et al., 1999).

Alguns outros modelos de hastes bloqueadas são produzidos em comercializados em âmbito mundial (ENDO et al., 1998; DIAZ-BERTRANA et al., 2005), sendo o modelo descrito, no entanto, o mais aceito, estudado e comercializado mundialmente (DUELAND et al., 1999).

Várias descrições já são encontradas quanto ao uso desta técnica em animais. Dueland et al.(1999) descrevem a aplicação de IN em tratamento de diferentes fraturas diafisárias em 134 cães, sendo 92 fraturas de fêmur, 23 de tíbia e 19 de úmero, 70 destas classificadas como instáveis. Como resultados, 83\% dos quadros foram tratados sem nenhuma complicação e apenas 1 caso não apresentou consolidação óssea. Moses et al.(2002) descreveram o tratamento de 21 fraturas de úmero com utilização da técnica, com $86 \%$ de recuperação sem complicações. Langley-Hobbs e Friend (2002) descrevem o tratamento de fratura de fêmur em peru, com formação de calo ósseo e retorno da função do membro após duas semanas de confinamento.

O uso desta modalidade tem sido mais efetivo na reparação de fraturas diafisárias altamente cominutivas, em relação às demais técnicas propostas. A neutralidade da colocação da haste, tanto quanto sua geometria promovem a rigidez necessária ao bloqueio das forças, diminuindo a fatiga provocada pelas mesmas sobre o material (RADCLIFFE et al., 2001; WIDJAJA e HARTUNG, 2001). A utilização de placas parafusadas em fraturas cominutivas causa aumento da fatiga no implante por sua alocação em posição excêntrica, 
tornando maiores as forças de encurvamento e deslocamento lateral. Além disso, as hastes de IN podem ser implantadas através de acessos cirúrgicos menores que as placas, minimizando assim a manipulação e incisão de tecidos moles adjacentes, implicando na manutenção da integridade biológica do foco da fratura (SCHMAEDECKE et al., 2005).

Em relação ao uso de fixadores externos, o uso de hastes de IN apresenta vantagens ainda maiores, pois não necessita de manejo ambulatorial freqüente. Se comparado ao uso de pino intramedular e cerclagem associados, técnica de IN apresenta resultados consideravelmente melhores, uma vez que é freqüente a perda da cerclagem por quebra do fio além da pouca estabilidade rotacional promovida por esta associação (DUELAND et al., 1999, FERRIGNO; PEDRO , 2006).

Woodard et al.(1988) compararam, após osteotomia femoral, várias técnicas, por períodos determinados, até 1 ano de pós-operatório. Concluíram que vários métodos são efetivos para a reparação da fratura. No entanto, citam o IN como mais efetivo por apresentar rigidez torsional maior em relação às demais técnicas, com mínima destruição da vascularização e conseqüente manutenção da biologia do hematoma fraturário.

Saravanan et al.(2002b) desenvolveram estudo histopatológico da formação de calo ósseo após diferentes formas de fixação interna de fraturas altamente cominutivas em cães, tendo apresentado como resultado a incapacidade de estabilização óssea inerente à utilização de pino intramedular associado a fios de cerclagem, enquanto resultados satisfatórios foram observados no grupo testado após implantação de hastes bloqueadas de IN. 
Mesmo o tratamento de quadros ortopédicos mais complexos já foi descrito através da utilização de hastes bloqueadas. El Shafie et al. (2001) descreveram o uso desta modalidade em correção de fratura ipsiateral de diáfise e colo femoral em nove pacientes humanos, tendo apresentado bons resultados em 8 e união retardada em apenas 1 caso.

Dueland et al.(1996) demonstram ser desnecessária a remoção das hastes de IN, uma vez que, após o remodelamento ósseo, retiram o estresse do osso íntegro.

Embora apresente resultados expressivamente melhores se comparadas às demais técnicas já consagradas para o tratamento de fraturas cominutivas, algumas restrições foram relatadas. Gupta (2001) indica que, apesar de promover excelente bloqueio contra as forças de rotação, compressão e encurvamento, esta técnica impede micromovimentações do foco de fratura, o que em alguns casos dificultaria o desenvolvimento do calo ósseo.

Khan et al. (1995) descrevem o desenvolvimento iatrogênico de fratura de colo femoral como complicação do uso deste procedimento, por técnica inadequada.

A utilização da técnica de IN em fêmur de pacientes humanos gera discussão principalmente no tocante à necessidade de fresagem do canal medular. Cheung et al.(2004) estabelecem pontos críticos da relação entre IN e osso em pacientes humanos, demonstrando a necessidade de maior superfície de contato entre ambos para dissipar as forças atuantes, principalmente em relação aos bloqueios distais (LIN et al., 2001). Para tanto, Fairbank et al.(1995) indicam a necessidade da fresagem do canal medular para homogeneização de seu diâmetro e adequação da haste em seu interior. No 
entanto, Frolke et al.(2003) citam o aumento da temperatura provocada pela fresagem como fator desencadeante de severas complicações da técnica, desde quadros de não união até processos de tromboembolismo. Para evitar o desenvolvimento destes quadros, Abbas et al.(2000), em oposição ao exposto por Fairbank et al.(1995), referem como segura a utilização de haste de diâmetro menor, através de técnica onde não é utilizada fresagem.

Embora plenamente reconhecido pelos bons resultados clínicos apresentados, pouca referência em literatura existe em relação ao comportamento biomecânicos das hastes de IN. Tais estudos se tornam ainda mais escassos, quando toma-se a análise da micromovimentação interfragmentária como foco. Gupta (2001) descreve que a técnica impede micromovimentação, sem no entanto avaliar este dado por estudo biomecânico.

Estudos biomecânicos determinam informações básicas que proporcionam conhecimento necessário para o entendimento de suas influências sobre 0 processo de reparação óssea. Em ensaios biomecânicos de compressão axial, encurvamento e rotação envolvendo hastes bloqueadas, não bloqueadas e placas ósseas, Dueland et al.(1996) demonstraram não haver diferença significativa entre o fêmur intacto e o osteotomizado e reduzido por haste bloqueada de $8 \mathrm{~mm}$ e parafusos de $4,5 \mathrm{~mm}$, no ensaio de máximo torque. Demonstraram ainda que as hastes de $8 \mathrm{~mm}$ apresentam 165\% mais resistência ao torque que as de $6 \mathrm{~mm}$. No mesmo trabalho, os autores demonstram a dificuldade de comparação com outras pesquisas semelhantes, pela pouca estruturação da metodologia e baixa qualidade dos resultados obtidos. 
De forma geral é demonstrado pelos autores que as hastes bloqueadas apresentam melhor resistência a forças atuantes se comparadas às placas parafusadas (JOHNSTON et al., 1991; BANKSTON et al., 1992). Tal fato se aplica por apresentar aumento da resistência ao encurvamento, compressão e rotação por atuar no centro do eixo ósseo, aumentando seu momento de inércia se comparadas às placas.

Dueland et al.(1996) demonstraram que as hastes bloqueadas são mais resistentes ao encurvamento cranio-caudal, em comparação ao latero-medial. Tal fato se faz importante uma vez que estudos de Carter et al.(1981) e Matushek et al.(1989) comprovam que o fêmur e a tíbia estão mais sujeitos ao encurvamento cranio-caudal durante a marcha.

Bernardé et al.(2002) tenham provavelmente desenvolvido o mais completo teste biomecânico comparativo entre Interlocking nail e placas parafusadas até então. Em quatro grupos distintos, analisaram de forma não destrutiva o comportamento dos implantes segundo as forças de compressão excêntrica e encurvamento. O modelo experimental consistiu de fêmures caninos, osteotomizados, onde fora criado intervalo de $25 \mathrm{~mm}$ na região média de sua diáfise, mimetizando fratura cominutiva. Tal intervalo, segundo os autores, foi tomado para que, nos ensaios de encurvamento, não existisse qualquer possibilidade de contato entre os fragmentos. Utilizando métodos optoeletrônicos, com erro de 0,1 mm, a qual descreveram como ideal, apresentaram como resultados maior fragilidade dos parafusos na região proximal do intervalo e rigidez dos parafusos mais distais, quando analisadas as placas parafusadas. Em relação às hastes bloqueadas, demonstraram a mesma fragilidade do parafuso proximal ao intervalo. Pelos estudos realizados, 
não foi possível descrever quaisquer deformações ósseas no ponto de bloqueio dos parafusos. Em relação às hastes bloqueadas, observaram importantes deformações no parafuso proximal ao intervalo criado.

Durall et al.(2004) demonstram através de estudo in vivo a utilização de Interlocking nail associado à fixação esquelética externa, como forma de minimizar os riscos de quebra do parafuso, o que, segundo os autores, é importante forma de perda do sistema e falha da osteossíntese. Descrevem ainda forma de dinamização do sistema, através de remoção da fixação externa e dos pinos de fixação distal após quatro semanas. Como resultados, descrevem que o modelo estático apresentou média de consolidação em tempo menor que o grupo com modelo dinamizado. Em relação à formação de calo ósseo, demonstraram não haver diferença significativa entre os dois grupos em relação à sua qualidade, mas sim em relação ao tempo de remodelamento.

Reems et al.(2006) compararam, utilizando haste bloqueada de $8,0 \mathrm{~mm}$ de diâmetro, modelo 11, em fêmur canino como modelo experimental, em ensaio cíclico de torção, as propriedades estruturais do bloqueio de um ou dos dois orifícios distais da haste. Como resultados, apontam o significativo aumento de resistência da haste quando bloqueados os dois orifícios.

McDuffee et al.(2000) descrevem ensaio biomecânico das hastes bloqueadas em osteossíntese de tíbia de eqüinos, apresentando como resultados a maior resistência às forças de compressão axial e encurvamento do que as esperadas para o implante em animal vivo. No entanto, apresentaram resistência às forças de rotação menores que as encontradas em animal vivo, 
descartando este modelo para o uso isolado no tratamento de fraturas tibiais em eqüinos.

Lopez et al.(1999) compararam, utilizando o terceiro metacarpiano eqüino como modelo experimental, a utilização de hastes bloqueadas em um grupo, e duas placas parafusadas dispostas em projeção ortogonal em outro grupo. Do mesmo modo que o estudo descrito anteriormente, as hastes bloqueadas apresentaram piores resultados mediante as forças de rotação. Os autores encorajam, no entanto, o uso de IN para osteossíntese de terceiro metacarpeano, por apresentarem a mesma resistência às forças de compressão e encurvamento que o grupo da dupla placa, apresentando inúmeras vantagens em termos de aplicação da técnica, comparativamente. Corroboram estes dados os apontamentos de Galuppo et al(2002), indicando a técnica para tratamento de fraturas de terceiro metacarpeano em eqüinos adultos.

O presente estudo visou magnificar a avaliação de comportamento biomecânico das hastes bloqueadas, pois é consenso entre os autores à carência de dados publicados em relação a estes parâmetros, razão pela qual podem ser explicadas muitas das falhas descritas em estudos in vivo (KHAN et al., 1995; GUPTA, 2001). Não há, na literatura pesquisada, trabalhos utilizando análise fotogramétrica da micromovimentação interfragmentária do foco da fratura em osteossínteses com IN. Tal metodologia permite, segundo Chadwick (1992), através da captação e análise de imagens por câmeras em angulação definida, estabelecer em três dimensões, o comportamento dinâmico do objeto em estudo. Os dados obtidos por este estudo certamente fornecerão maiores subsídios para o desenvolvimento e aperfeiçoamento desta técnica. 
ofojetiosos 


\section{OBJETIVOS}

O objetivo do presente estudo é avaliar o comportamento das hastes bloqueadas, em análise in vitro, em relação a quatro diferentes possibilidades de bloqueio transcortical (4 bloqueios, realizados a $22 \mathrm{~mm}$ entre si; 3 bloqueios, sendo 2 distais, realizados a $22 \mathrm{~mm}$ entre si e 1 proximal, realizado no orifício próximo à linha da ostectomia; 3 bloqueios, sendo 2 distais, realizados a 22 $\mathrm{mm}$ entre si e 1 proximal, realizado no orifício mais distante à linha da ostectomia e 4 bloqueios, realizados a $11 \mathrm{~mm}$ entre si), quando submetidas às forças de compressão axial, encurvamento e rotação, mimetizando cenário de reparação de fratura cominutiva em fêmur de cão.

Da mesma forma, avaliar o comportamento de haste de comprimento menor ao ideal, submetida aos mesmos testes biomecânicos, através de análise fotogramétrica e confrontamento de dados aos obtidos pela máquina universal de ensaios mecânicos Kratos ${ }^{\circledR}$ modelo 5002 dotada de célula de carga de 981 N (100 kgf). 


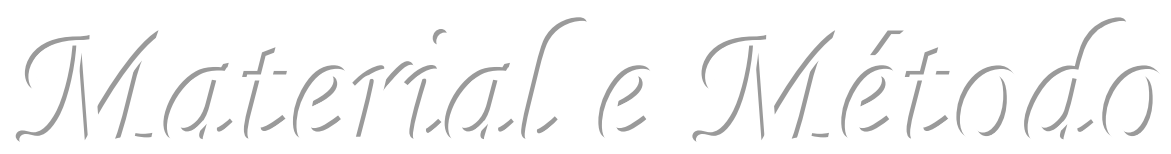




\section{MATERIAL E MÉTODO}

Foram realizados estudos biomecânicos em relação às diferentes possibilidades de bloqueio transcortical e diferentes tamanhos de hastes bloqueadas, utilizando fêmur de cães como material biológico padrão.

\subsection{MATERIAL BIOLÓGICO}

Foram utilizados 30 fêmures provenientes de 15 cadáveres de cães, com idade variando entre 3 e 6 anos, mortos ou eutanaziados por outras causas, oriundos da rotina do Hospital Veterinário do Centro Universitário de São José do Rio Preto/SP. Somente foram utilizados fêmures que, avaliados por exame radiográfico, não apresentarem sinais de osteopenia e cujas hastes ideais medissem 185 mm de comprimento e 8 mm de diâmetro.

As peças foram obtidas por dissecção romba do local, com auxílio de lâmina e cabo de bisturi, tesoura de Mayo, pinças hemostáticas e dente de rato, sendo retirados todos os tecidos moles adjacentes ao osso, liberado de suas inserções articulares.

Todo material biológico foi obtido imediatamente após morte ou eutanásia do animal, sendo submetidos à conservação em freezer convencional, com temperatura de $-24^{\circ} \mathrm{C}$. No momento da implantação das hastes bloqueadas, este material foi previamente descongelado em água corrente.

Após descongelamento, os fêmures foram ostectomizados, com formação de intervalo de $25 \mathrm{~mm}$ em terço médio de da diáfise femoral, com auxílio de serra 
oscilatória pneumática (Projeto FAPESP nº 02/10674-4), mimetizando intervalo gerado em fraturas cominutivas (BERNARDÉ et al., 2002).

Após implantação das hastes, o material, denominado como corpo de prova, foi embalado em filmes plásticos e resfriado em recipiente térmico contendo cubos de gelo, até o momento da análise. Tal procedimento foi realizado para se evitar novo congelamento do material e conseqüente variação estrutural dos corpos de prova.

\subsection{IMPLANTES}

Foram utilizadas 30 hastes bloqueadas de aço 316 L, com diâmetro de 8,0 mm, sendo 25 com comprimento de $185 \mathrm{~mm}$ e cinco com comprimento de $160 \mathrm{~mm}$. Todas as hastes apresentam quatro orifícios transversais de bloqueio, sendo dois proximais e dois distais. As hastes com diâmetro de $160 \mathrm{~mm}$ apresentam orifícios transversais dispostos a $22 \mathrm{~mm}$ entre si. Já em relação às hastes de $185 \mathrm{~mm}, 20$ apresentam orifícios dispostos a $22 \mathrm{~mm}$ entre si, e cinco, orifícios dispostos a $11 \mathrm{~mm}$ entre si, sendo utilizadas conforme o grupo analisado.

Para implantação das hastes, foi utilizado kit de instrumental específico, composto por extensor de fêmur, guia e rosca de fixação, fresa, guias de broca e de macheador, macheador e brocas ${ }^{1}$, além de material cirúrgico ortopédico convencional, como furadeira, chave sextavada e parafusos corticais de 3,5 $\mathrm{mm}$.

\footnotetext{
${ }^{1}$ Innovative Animal Products ${ }^{\circledR}$
} 


\subsection{CORPOS DE PROVA}

\subsubsection{Obtenção do Material Biológico}

Os cadáveres tiveram seus fêmures radiografados. Com auxílio de template padrão que acompanha o kit de hastes bloqueadas ${ }^{2}$, feito em filme de transparência, e alocado por sobre a radiografia, definiram-se os tamanhos ideais de hastes utilizadas em cada caso. Somente fêmures cujas hastes ideais medissem $185 \mathrm{~mm}$ foram utilizados, no intuito de excluir que quaisquer resultados discrepantes referentes ao tamanho das hastes fossem analisados (Figura 4.1).

Após escolha dos fêmures, as peças foram preparadas através de dissecção romba, sendo liberados de suas inserções musculares, ligamentares e vásculonervosas. Seqüencialmente a isso, foram embaladas em sacos plásticos e criopreservadas em temperatura de $-24^{\circ} \mathrm{C}$.

No momento da composição dos corpos de prova, as peças foram submetidas ao descongelamento em água corrente, até atingir a temperatura ambiente.

Após adequação de temperatura, em cada peça foi realizada ostectomia femoral, sendo criado intervalo de $2,5 \mathrm{~cm}$ entre as margens, com auxílio de serra oscilatória pneumática.

Para a obtenção do posicionamento ideal do intervalo, foi tomada medida do comprimento de cada fêmur, iniciando-se no trocânter maior, seguindo-se até o côndilo femoral lateral, com auxílio de paquímetro metálico. Obteve-se o ponto médio deste comprimento, e traçaram-se duas linhas paralelas e eqüidistantes

\footnotetext{
2 Innovative Animal Products ${ }^{\circledR}$
} 
a $12,5 \mathrm{~mm}$ deste ponto, obtendo-se na porção média da diáfise femoral 0 intervalo desejado.

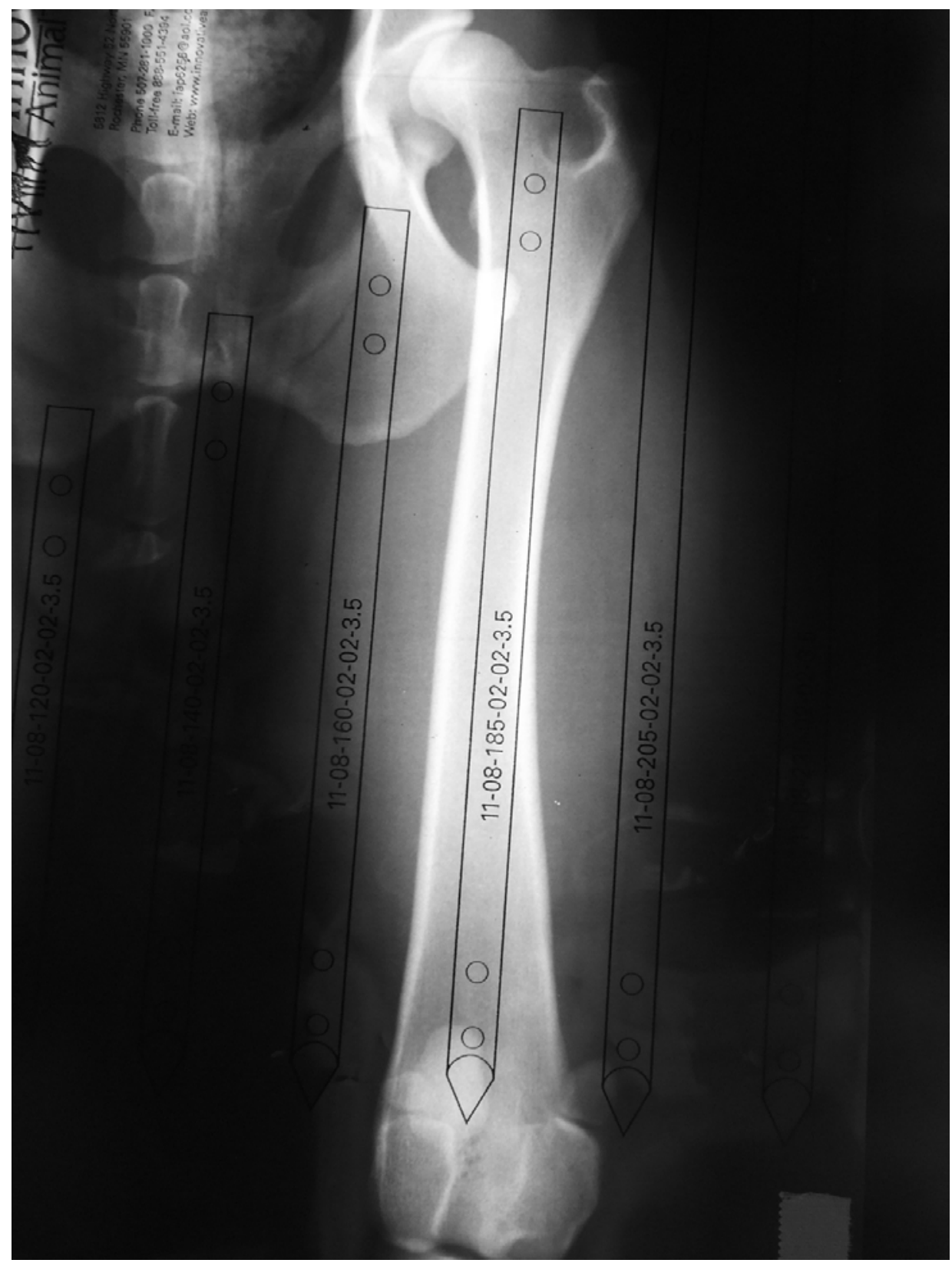

Figura 4.1 - Imagem fotográfica de radiografia de fêmur esquerdo de cão, sendo mensurado o tamanho da haste a ser utilizado - São Paulo - 2007

\subsubsection{Implantação das hastes}

A haste utilizada devia preencher toda a extensão do canal medular, tendo seu diâmetro que ocupar a maior parte do mesmo. O osso foi previamente fresado 
com auxílio de fresa manual, presente no conjunto de instrumentos específicos $^{3}$, para que, além da remoção de toda estrutura não óssea, nenhuma força adicional fosse necessária durante a introdução da haste.

Para cada corpo de prova, tomou-se o segmento proximal do fêmur ostectomizado e, com auxílio de furadeira, foi introduzido pino intramedular de 6,0mm de diâmetro, por via retrógrada, em direção ao colo femoral. Após abertura de orifício inicial, foi retirado o pino intramedular e, sequencialmente, introduzida manualmente a haste, de $8 \mathrm{~mm}$ de diâmetro, com auxílio de extensor de fêmur e chave próprios ${ }^{3}$. Após adequação do segmento proximal, tomou-se a porção distal do fêmur ostectomizado, seguindo manualmente a introdução da haste, até que fosse observada resistência ao procedimento. Neste momento, ambos os segmentos foram corretamente alinhados e, com auxílio de paquímetro metálico, foi conferido o intervalo de $25 \mathrm{~mm}$ entre os segmentos. A rotação da haste se deu até que os furos estivessem alinhados em disposição látero-medial. Neste momento, a guia dos orifícios foi encaixada e fixada à haste por meio de extensor e rosca específicos ${ }^{3}$ acoplado à sua borda superior. Esta guia apresenta marcações laterais, indicando o correto posicionamento dos orifícios, tanto para hastes de $11 \mathrm{~mm}$, como para as de $22 \mathrm{~mm}$.

Em relação aos bloqueios, foram utilizadas as marcações específicas do guia, adequadas para cada grupo de testes. Com auxílio de manga de broca ${ }^{3}$, inserido no local indicado pelo guia, foi alinhada a furadeira ao ponto exato de fixação transcortical. A perfuração foi feita através das duas corticais, com a broca alcançando a cortical distal por transposição do orifício existente na

\footnotetext{
${ }^{3}$ Innovative Animal Products ${ }^{\circledR}$
} 
haste. Após a verificação do comprimento do parafuso a ser utilizado, as corticais foram macheadas, e o parafuso fixado, bloqueando a haste. Para todos os corpos de prova, este procedimento foi realizado primeiramente para o segmento distal, bloqueando primeiramente o orifício mais distante à linha de ostectomia e, em seguida, o mais próximo. Após verificação do correto posicionamento do segmento proximal, respeitando o intervalo de $25 \mathrm{~mm}$ de distância entre as linhas da ostectomia, o procedimento foi repetido para seus bloqueios, realizando primeiramente o bloqueio do orifício próximo à ostectomia, para em seguida, bloquear o orifício mais distante. As variações de bloqueio foram realizadas no segmento proximal, descritas no sub-capítulo seguinte. O guia e o extensor foram então removidos. Após o término deste procedimento, as peças foram novamente radiografadas para a certificação do correto posicionamento das hastes e adequada aplicação da técnica (Figura 4.2). 


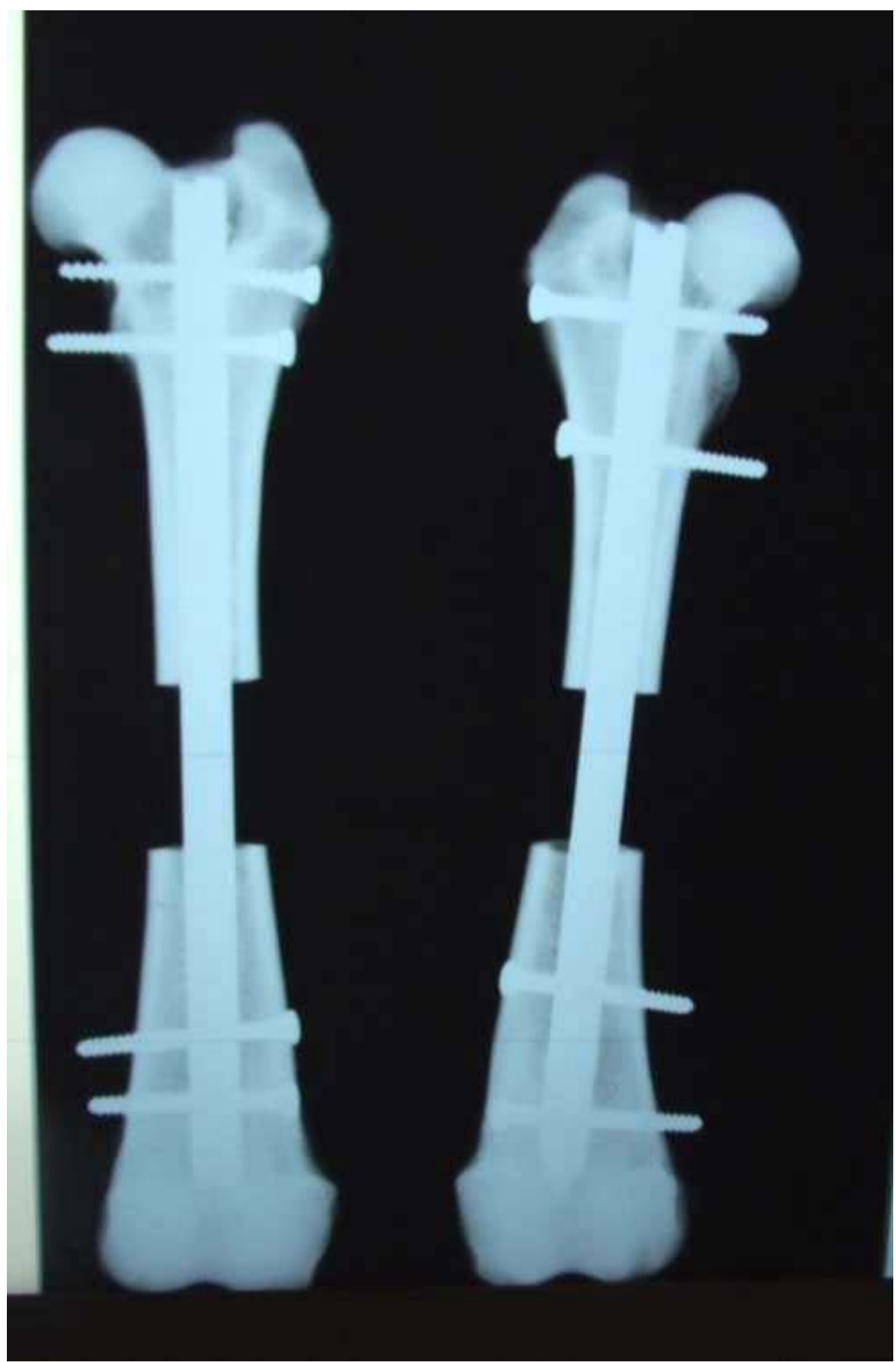

Figura 4.2 - Imagem fotográfica de exame radiográfico de fêmures de cão, identificando o correto posicionamento e bloqueios das hastes São Paulo- 2007 


\subsection{DELINEAMENTO EXPERIMENTAL}

Os fêmures dissecados e com as hastes devidamente alocadas foram divididos em grupos não pareados, com 6 elementos cada, para comparação dos resultados dentro do próprio grupo e entre os diferentes grupos.

Foram criados 5 grupos, assim discriminados:

Grupo 1: hastes de 185 mm, com 4 bloqueios, realizados a 22 mm entre si;

Grupo 2: hastes de $185 \mathrm{~mm}$, com 3 bloqueios, sendo 2 distais, realizados a 22 $\mathrm{mm}$ entre si e 1 proximal, realizado no orifício próximo à linha da ostectomia;

Grupo 3: hastes de $185 \mathrm{~mm}$, com 3 bloqueios, sendo 2 distais, realizados a 22 $\mathrm{mm}$ entre si e 1 proximal, realizado no orifício mais distante à linha da ostectomia;

Grupo 4: hastes de $185 \mathrm{~mm}$, com 4 bloqueios, realizados a $11 \mathrm{~mm}$ entre si;

Grupo 5: hastes de $160 \mathrm{~mm}$, com 4 bloqueios, realizados a $22 \mathrm{~mm}$ entre si; este grupo tem por finalidade examinar o comportamento de haste de tamanho menor, ou seja, tal haste foi implantada em fêmur cujo padrão seria a de $185 \mathrm{~mm}$.

Os fêmures de cães de cada grupo estudado foram submetidos, em tempos diferentes, a três tipos de ensaios não destrutivos definidos como ensaio de compressão excêntrica, ensaio de encurvamento e ensaio de rotação. 


\subsection{ESTUDO BIOMECÂNICO}

\subsubsection{Acoplamento das peças à máquina}

Para o adequado posicionamento junto à máquina, os côndilos femorais foram ostectomizados, não interferindo na conformação original do ensaio. No momento do ensaio, cada fêmur foi fixado à máquina em copo oval de $5 \mathrm{~cm}$ de profundidade, que era preenchido por resina acrílica (Figura 4.3). A esta composição deu-se o nome de corpo de prova. Após a polimerização e resfriamento da base acrílica, esta foi firmemente aprisionada por 8 parafusos, que transfixavam o copo, em duas filas de quatro, posicionados ortogonalmente entre si. Tal procedimento foi tomado para que a peça não se deslocasse durante o ensaio, tornando inverídicos os resultados obtidos. 


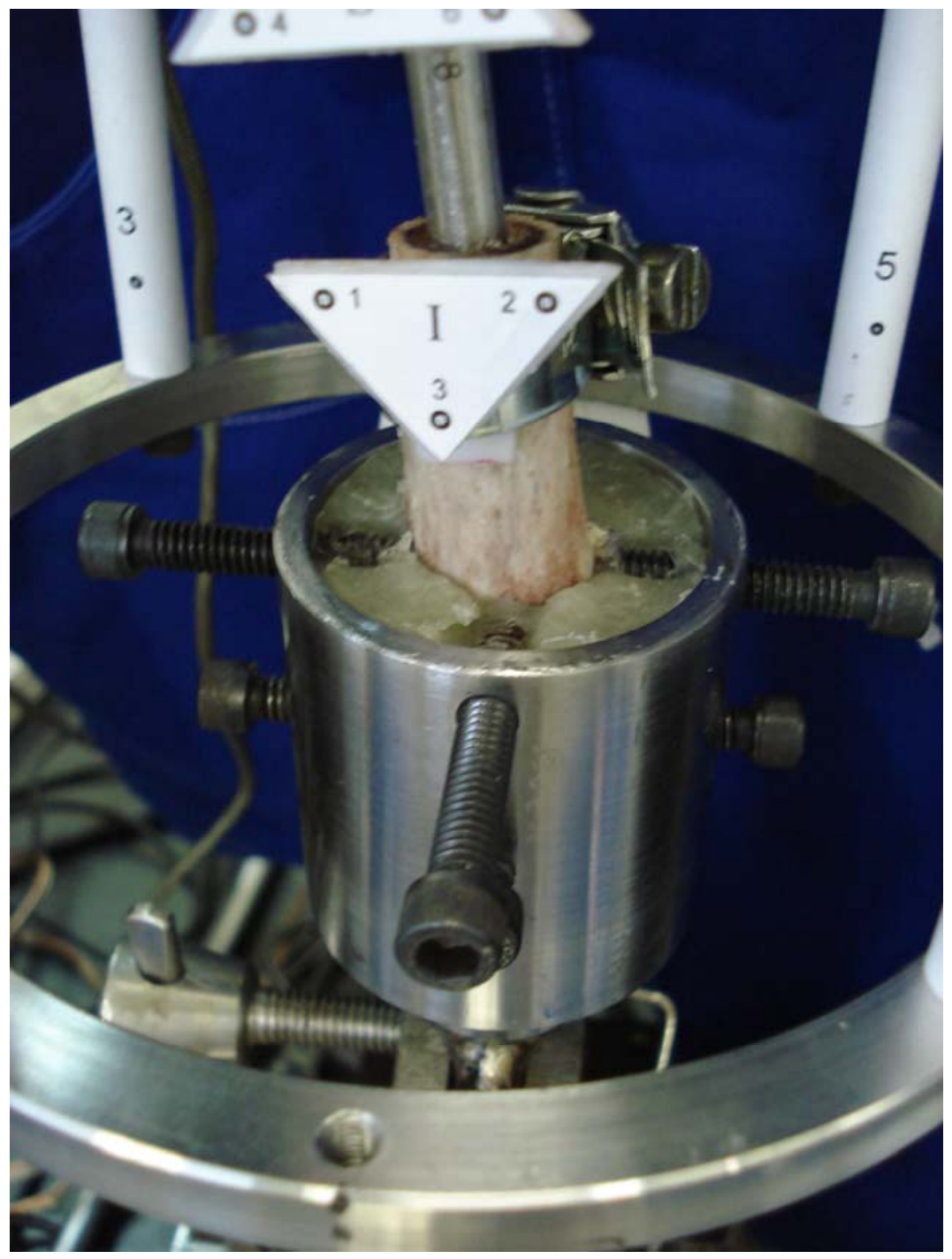

Figura 4.3 - Imagem fotográfica ilustrando preensão da epífise distal do fêmur canino por resina acrílica em copo oval com oito parafusos de fixação - São Paulo - 2007

\subsubsection{Descrição dos ensaios mecânicos}

Os ensaios mecânicos foram realizados utilizando máquina universal de ensaios mecânicos $\operatorname{Kratos}^{\circledR}$ modelo 5002 dotada de célula de carga de $981 \mathrm{~N}$ (100 kgf) com uma velocidade de ensaio de $20 \mathrm{~mm} / \mathrm{min}$ (Figura 4.4). Os parâmetros força e deformação foram enviados ao computador IBM ${ }^{\circ}-\mathrm{PC}$ através de um sistema de aquisição analógica Lynx® modelo ADS-2000 permitindo a gravação dos parâmetros para posterior análise (Figura 4.5). 
O corpo de prova foi composto por fêmur canino ostectomizado na região central de sua diáfise e por uma síntese óssea (haste bloqueada) mantendo um afastamento de $25 \mathrm{~mm}$ entre os fragmentos ósseos. ( Figura 4.6)

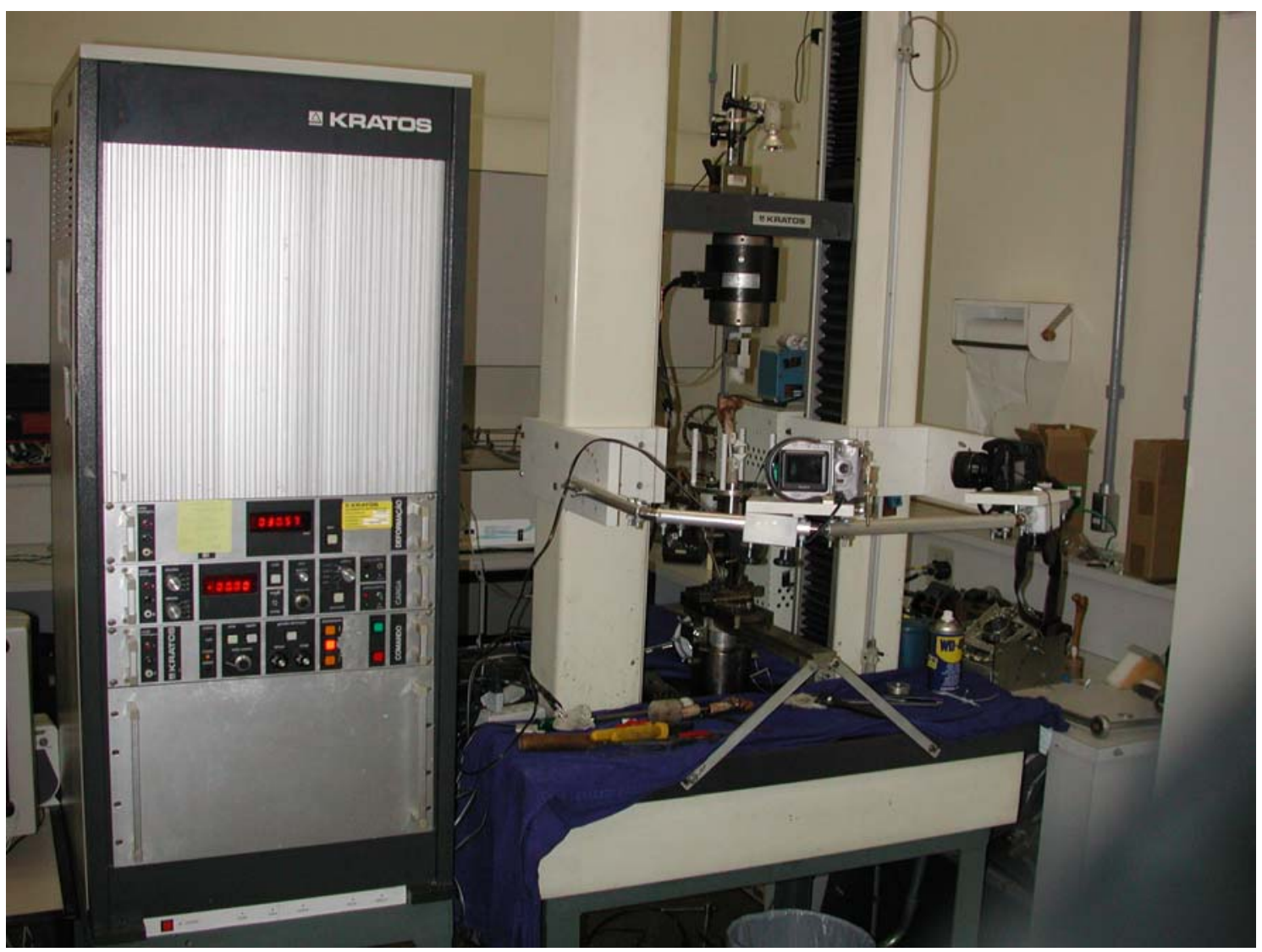

Figura 4.4 - Imagem fotográfica da máquina universal de ensaios mecânicos Kratos utilizada nos ensaios - São Paulo - 2007 


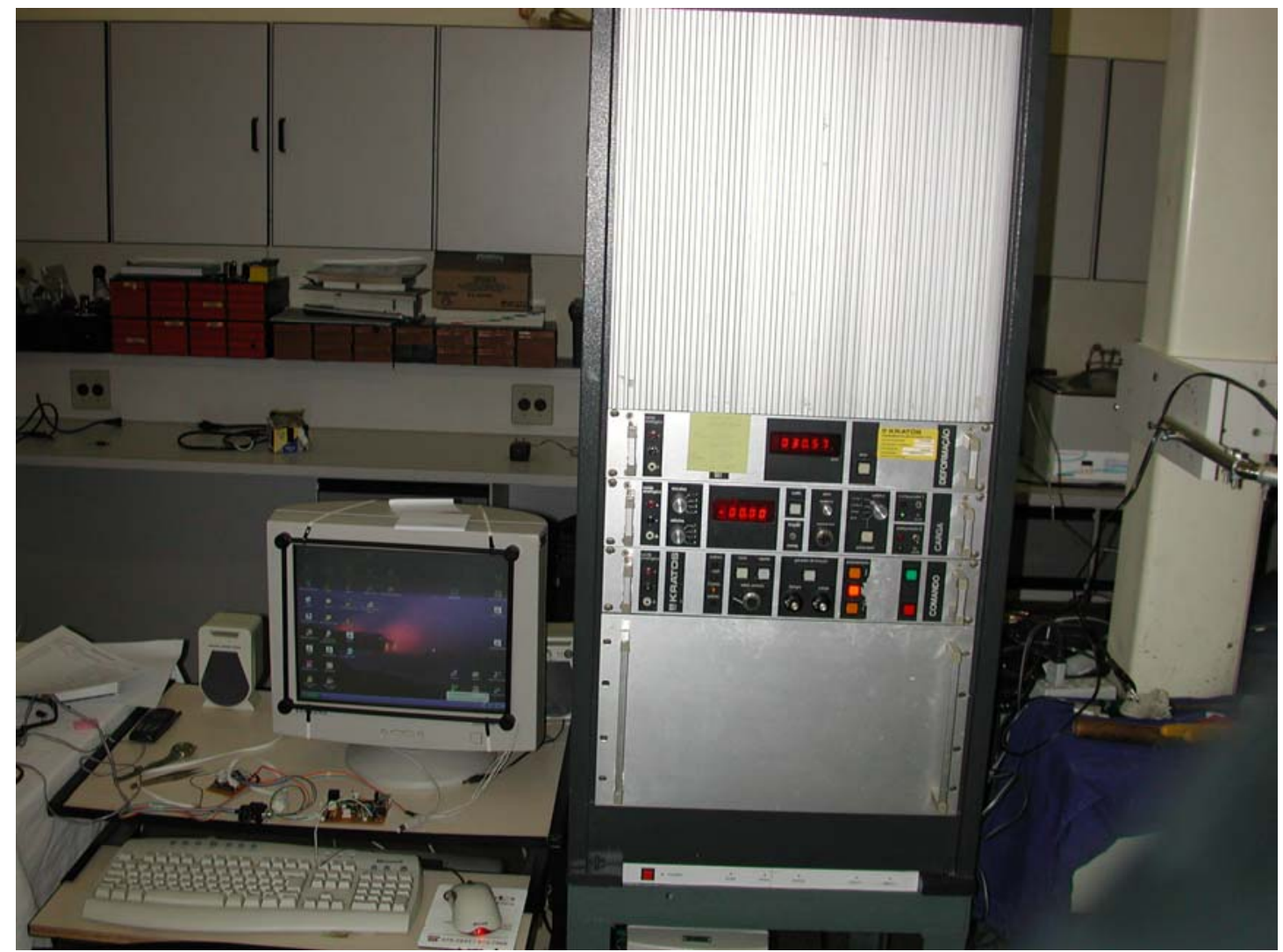

Figura 4.5 - Imagem fotográfica ilustrando a disposição da máquina universal de ensaios mecânicos Kratos utilizada nos ensaios e o computador utilizado para captação dos dados - São Paulo 2007 


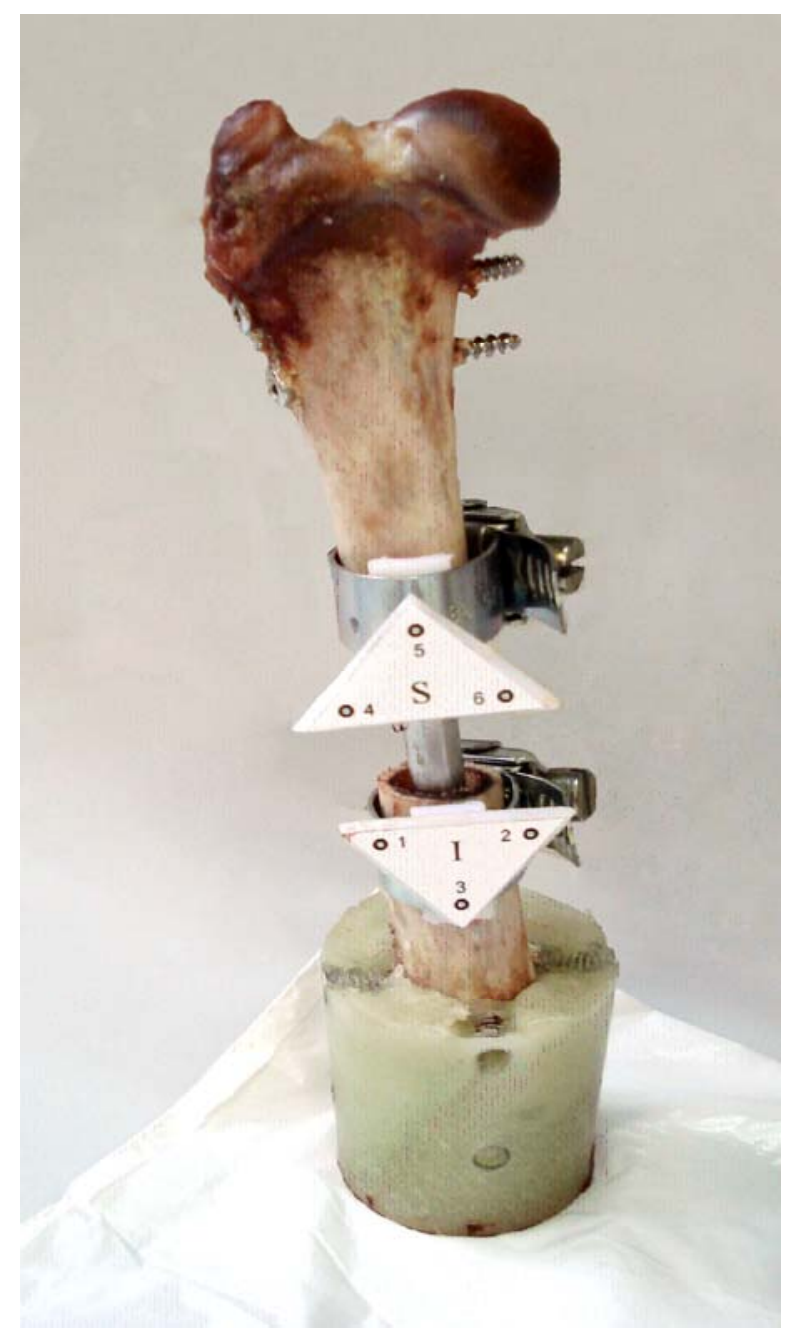

Figura 4.6 - Imagem fotográfica do corpo de prova utilizado para os ensaios mecânicos - São Paulo - 2007

Em todos os ensaios os deslocamentos lineares e angulares relativos do segmento distal em relação ao segmento proximal foram medidos através de fotogrametria em três dimensões pelo método matemático DLT (Direct Linear Transformation) (ABDEL-AZIZ e KARARA, 1971), com a utilização de duas máquinas fotográficas digitais calibradas com resolução de 3,3 Mpixel, um calibrador com $80 \mathrm{~mm}$ de altura, $100 \mathrm{~mm}$ de largura e $100 \mathrm{~mm}$ de profundidade, dois marcadores triangulares contendo três pontos circulares com diâmetro de $5 \mathrm{~mm}$ (um fixado no segmento proximal e um no segmento distal junto ao intervalo de $25 \mathrm{~mm}$ ) (figura 4.7-A), associados a programa de 
computador que permita medir através das fotos digitais, as coordenadas $\mathrm{X}, \mathrm{Y}$ e Z de cada marcador.

O calibrador consistiu em 8 pontos distribuídos em quatros hastes. Cada ponto é formado por um circulo preto com uma marca em cruz na cor branca (figura 4.7-B). As distâncias dos 7 pontos em relação a um ponto de referência foram medidas por um equipamento digitalizador em 3 dimensões.

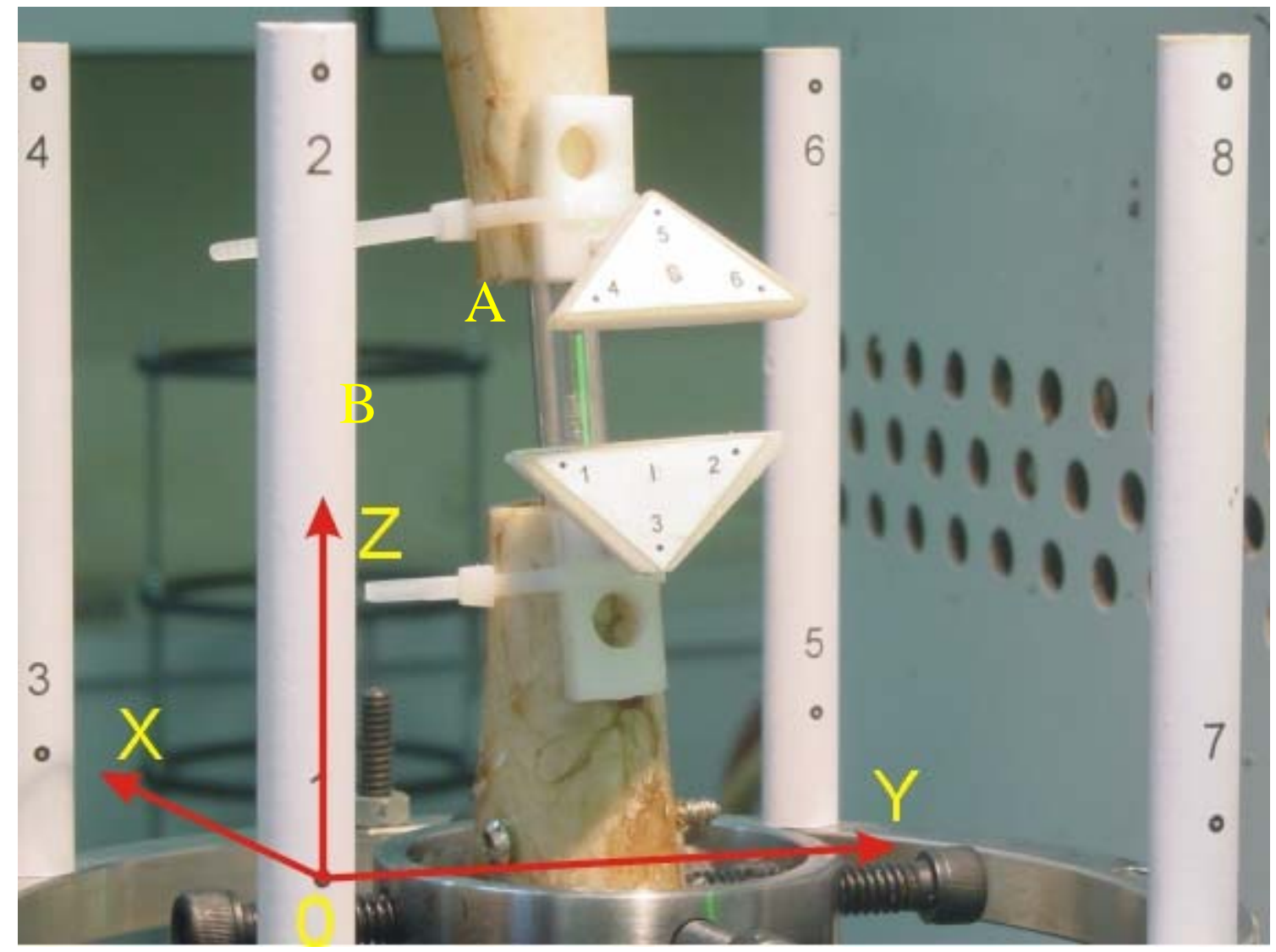

A - Marcadores esféricos presos às extremidades da ostectomia do fêmur $B$ - Calibrador $\mathrm{X}, \mathrm{Y}$ e Z - coordenadas espaciais.

Figura 4.7 - Imagem fotográfica de fêmur canino ostectomizado, cuja síntese foi realizada por haste bloqueada de $185 \mathrm{~mm}$ de comprimento, com intervalo de $25 \mathrm{~mm}$ em região média de sua diáfise, disposto em ensaio mecânico - São Paulo - 2007

Os três ensaios foram realizados sobre cada campo de prova, seguindo a mesma seqüência: compressão axial, encurvamento e rotação. Cada ensaio 
mensurado, foi precedido por aplicação da mesma carga, sem análise fotogramétrica, no intuito de eliminar qualquer variação referente à acomodação do campo de prova junto à máquina.

\subsubsection{Ensaio de compressão axial}

A carga foi aplicada na cabeça do fêmur através de atuador cilíndrico (Figuras 4.8-A e 4.9) com superfície de contato côncava, no sentido superior para inferior, com o fêmur (Figura 4.8-B) posicionado verticalmente, utilizando, para isso, dispositivo mecânico regulável (Figura 4.8-E).

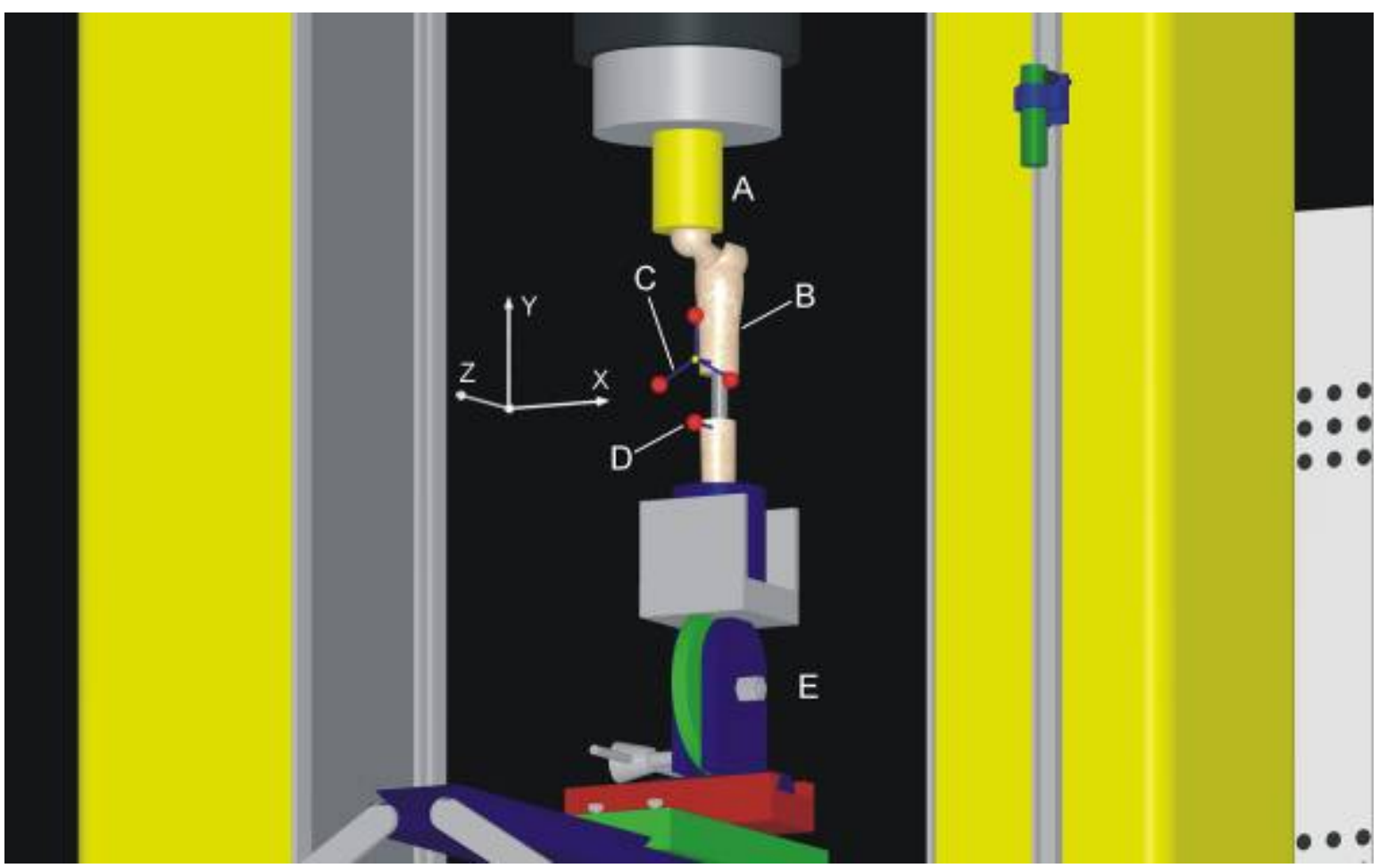
A - Atuador cilíndrico
B - Fêmur
C - Marcadores esféricos presos à extremidade proximal do fêmur
D - Marcador esférico preso à extremidade inferior do fêmur
E - Dispositivo mecânico
$\mathrm{X}, \mathrm{Y}$ e $\mathrm{Z}$ - Coordenadas espaciais

Figura 4.8 - Desenho esquemático do ensaio de compressão excêntrica do fêmur sem o calibrador - São Paulo - 2007 


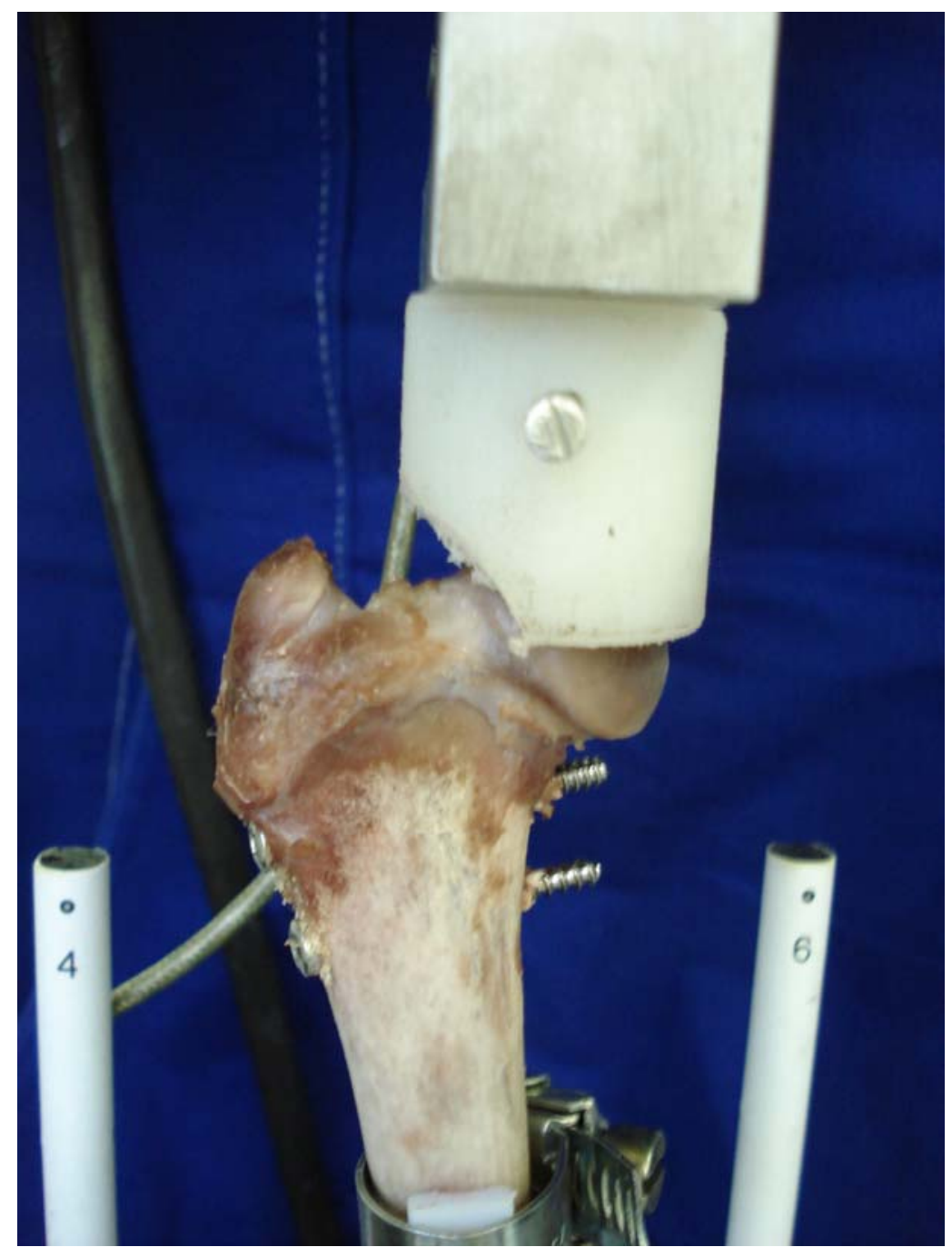

Figura 4.9 - Imagem fotográfica do atuador cilíndrico acoplado à cabeça femoral para ensaio de compressão - São Paulo - 2007

O calibrador (Figura 4.10-D) foi conectado ao dispositivo mecânico e as máquinas fotográficas (Figura 4.10-F) foram posicionadas de modo que enquadrasse todos os pontos do calibrador e os marcadores. As máquinas ficaram a $50 \mathrm{~cm}$ do centro do calibrador e defasadas $45^{\circ}$ entre elas. As faces do calibrador foram posicionadas em relação ao eixo anatômico do fêmur de modo que o plano horizontal correspondesse ao plano $X-Z$ do calibrador, plano frontal ao plano X-Y e plano sagital referente ao plano Z-Y (Figura 4.11) . 


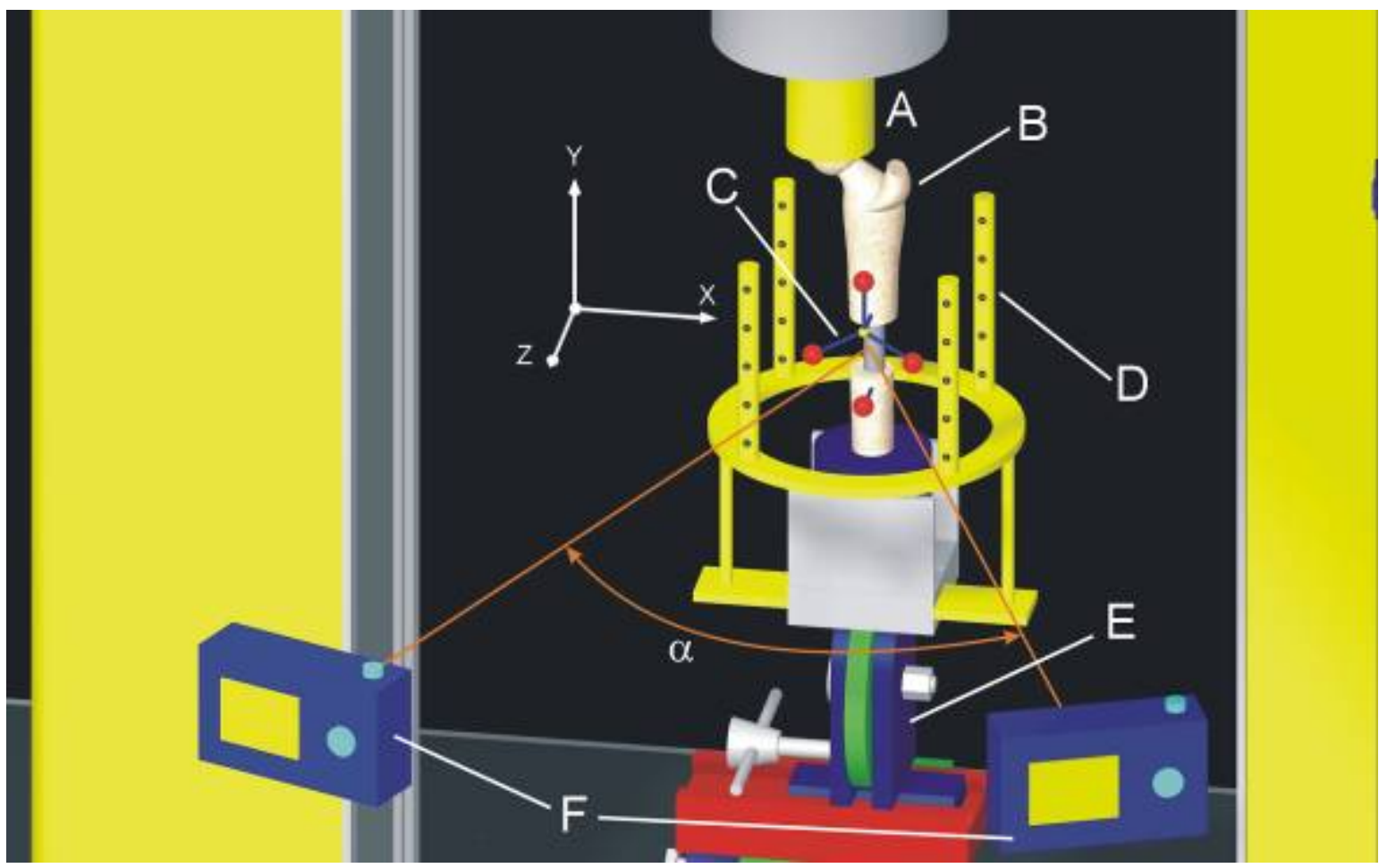

A - Atuador cilíndrico

B - Fêmur

C - Marcadores esféricos presos ao fêmur

D - Calibrador

E - Dispositivo mecânico

F - Duas máquinas fotográficas digitais

- Ângulo formado entre as câmeras (aproximadamente $45^{\circ}$ )

$\mathrm{X}, \mathrm{Y}$ e $\mathrm{Z}$ - Coordenadas espaciais

Figura 4.10 - Desenho esquemático do ensaio de compressão excêntrica do fêmur como o calibrador e as câmeras - São Paulo - 2007 


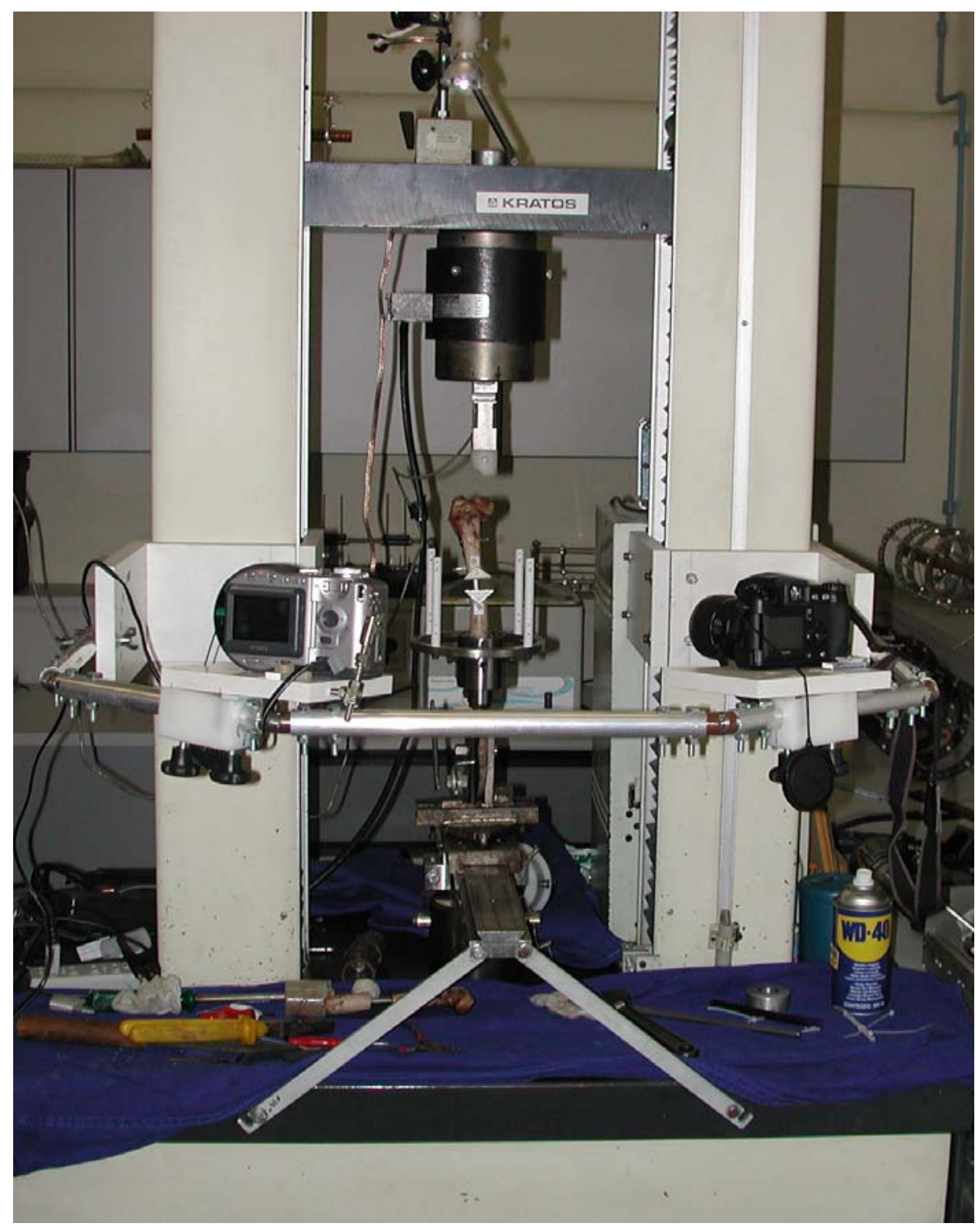

Figura 4.11 - Imagem fotográfica ilustrando disposição das câmeras fotográficas fixadas em travessão e anguladas a 45 graus entre si, no ensaio de compressão - São Paulo - 2007

Os ensaios foram feitos de forma descontínua, ou seja, a máquina aplicou forças com incrementos de $40 \mathrm{~N}$ com paradas de 20 segundos até o valor de 200 N (BERNARDÉ et al., 2002). Foram tiradas, no mesmo instante, duas fotos antes do inicio do ensaio e tiradas duas fotos 10 segundos após cada parada da máquina, totalizando cinco paradas e 12 fotos (figura 4.12). 


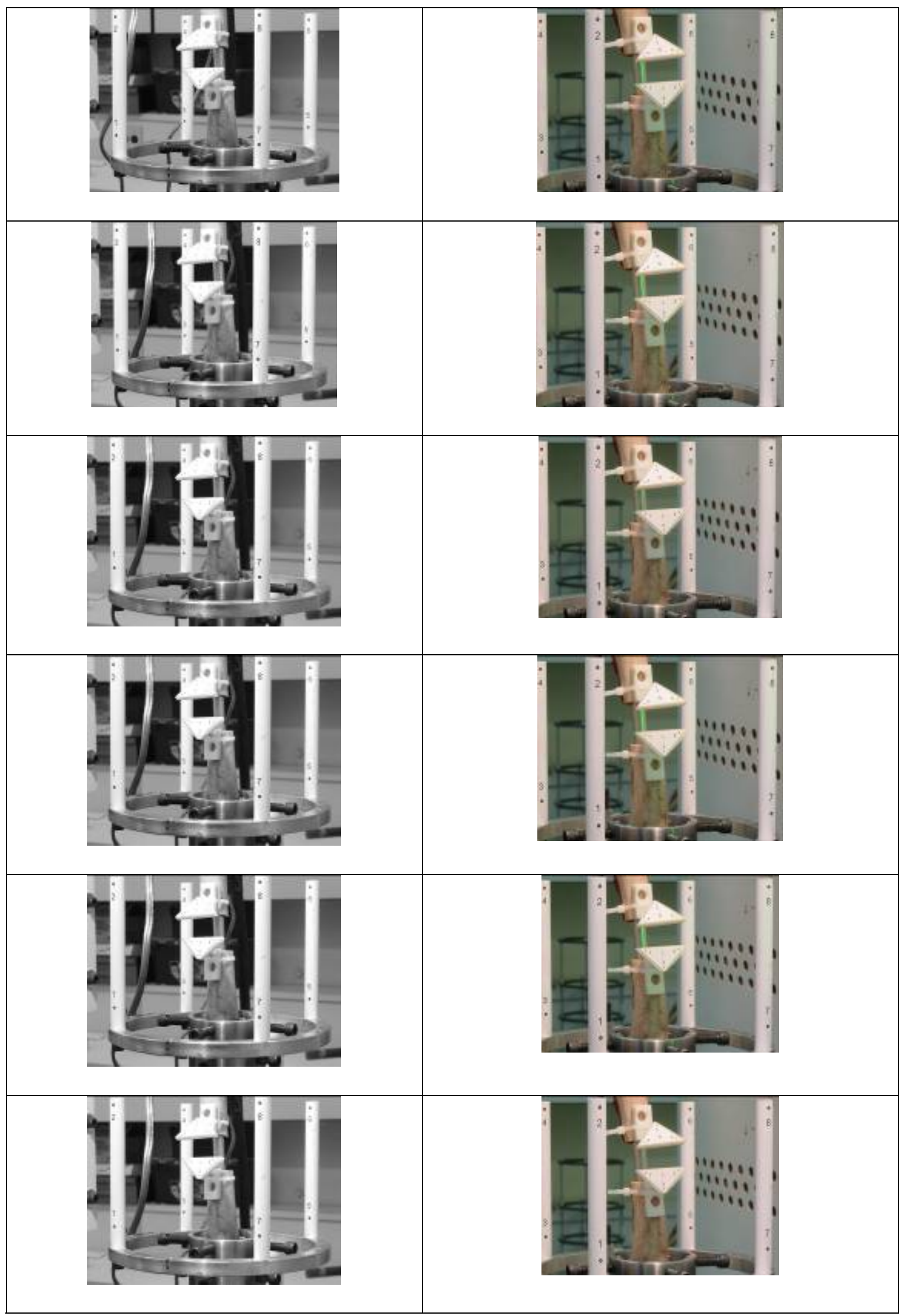

Figura 4.12 - Seqüência de imagens fotográficas demonstrando o ensaio de compressão axial - São Paulo - 2007 


\subsubsection{Ensaio de encurvamento}

A carga foi aplicada na cabeça do fêmur através de atuador cilíndrico (Figura 4.13-A) com superfície de contato côncava, no sentido anterior para superior, com o fêmur (Figura 4.13-B) posicionado horizontalmente, utilizando, para isso, dispositivo mecânico regulável (Figura 4.13-D).

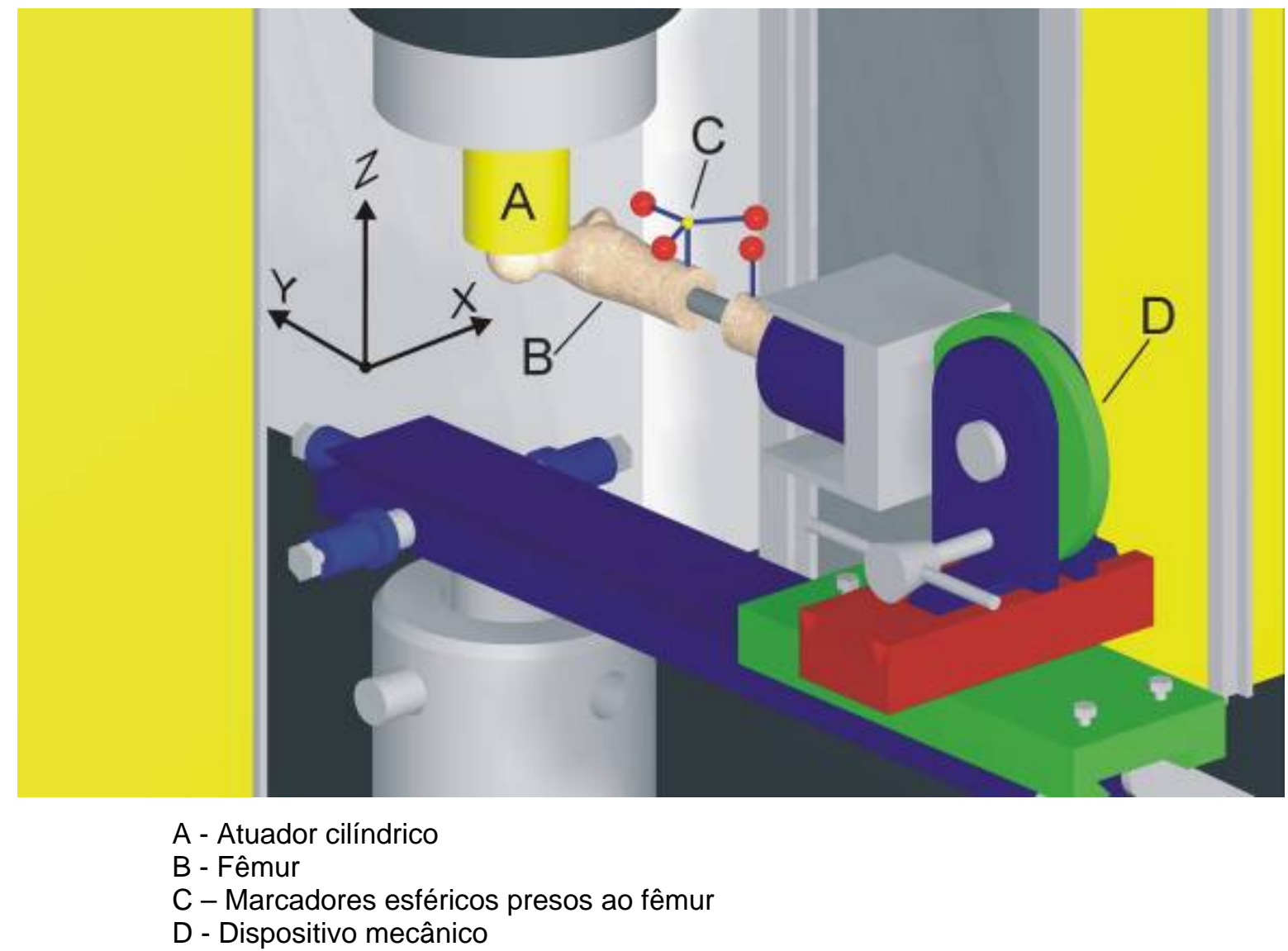

Figura 4.13 -Desenho esquemático do ensaio de encurvamento do fêmur sem o calibrador e as câmeras - São Paulo - 2007

O calibrador e as câmeras (Figura 4.14) foram montados como descrito anteriormente no ensaio de compressão, porém defasados $90^{\circ}$ em relação ao plano horizontal da máquina de ensaios. O ensaio foi feito de forma descontínua, com incrementos de $12 \mathrm{~N}$ com paradas de 20 segundos até 0 
valor de $60 \mathrm{~N}$. Foram tiradas, no mesmo instante, duas fotos antes do inicio do ensaio e tiradas duas fotos 10 segundos após cada parada da máquina, totalizando cinco paradas e 12 fotos (Figura 4.15).

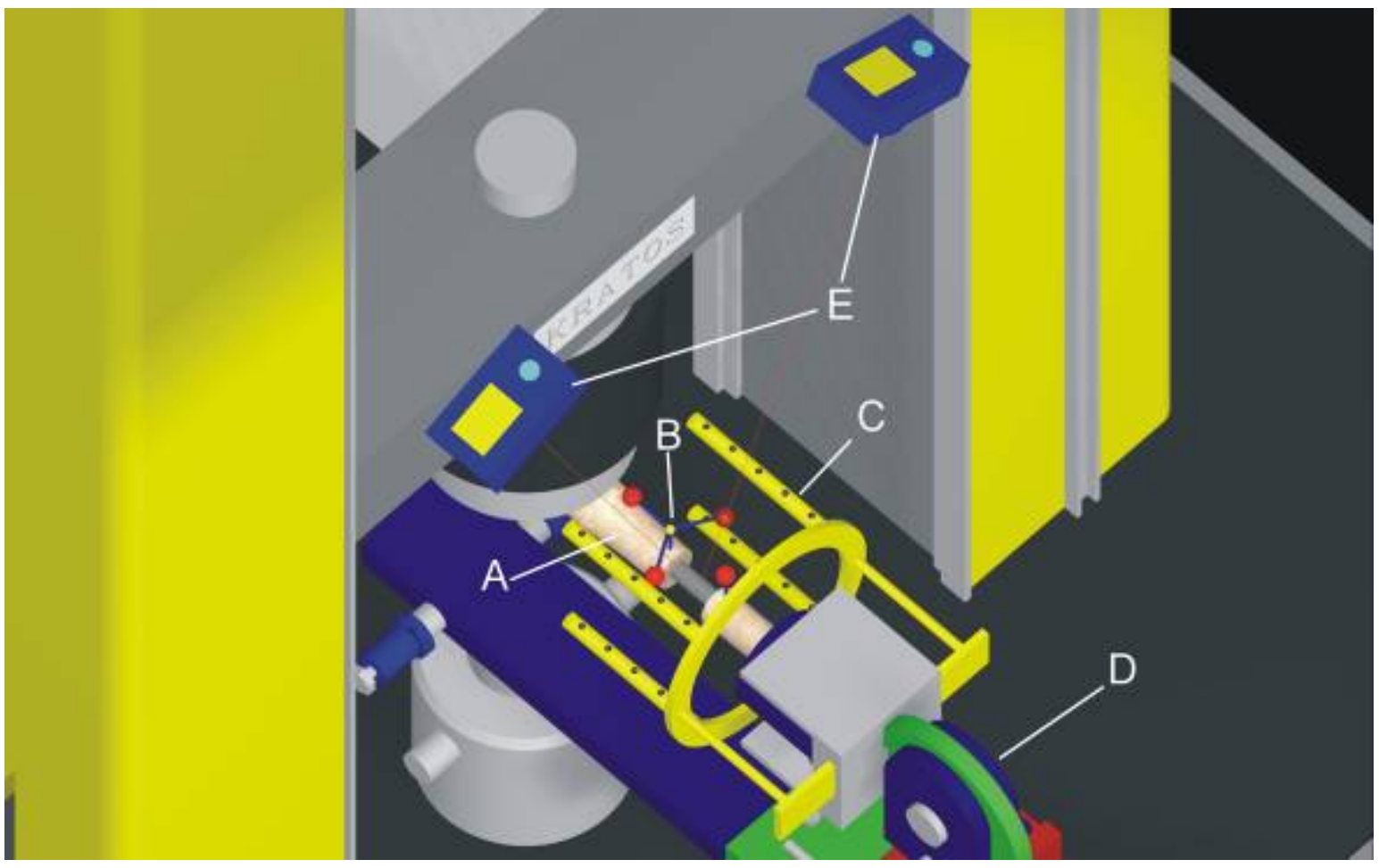

A - Fêmur

B - Marcadores esféricos

C - Calibrador

D - Dispositivo mecânico

E - Máquina fotográfica digital

Figura 4.14- Desenho esquemático do ensaio de encurvamento do fêmur com o calibrador e as câmeras - São Paulo - 2007 


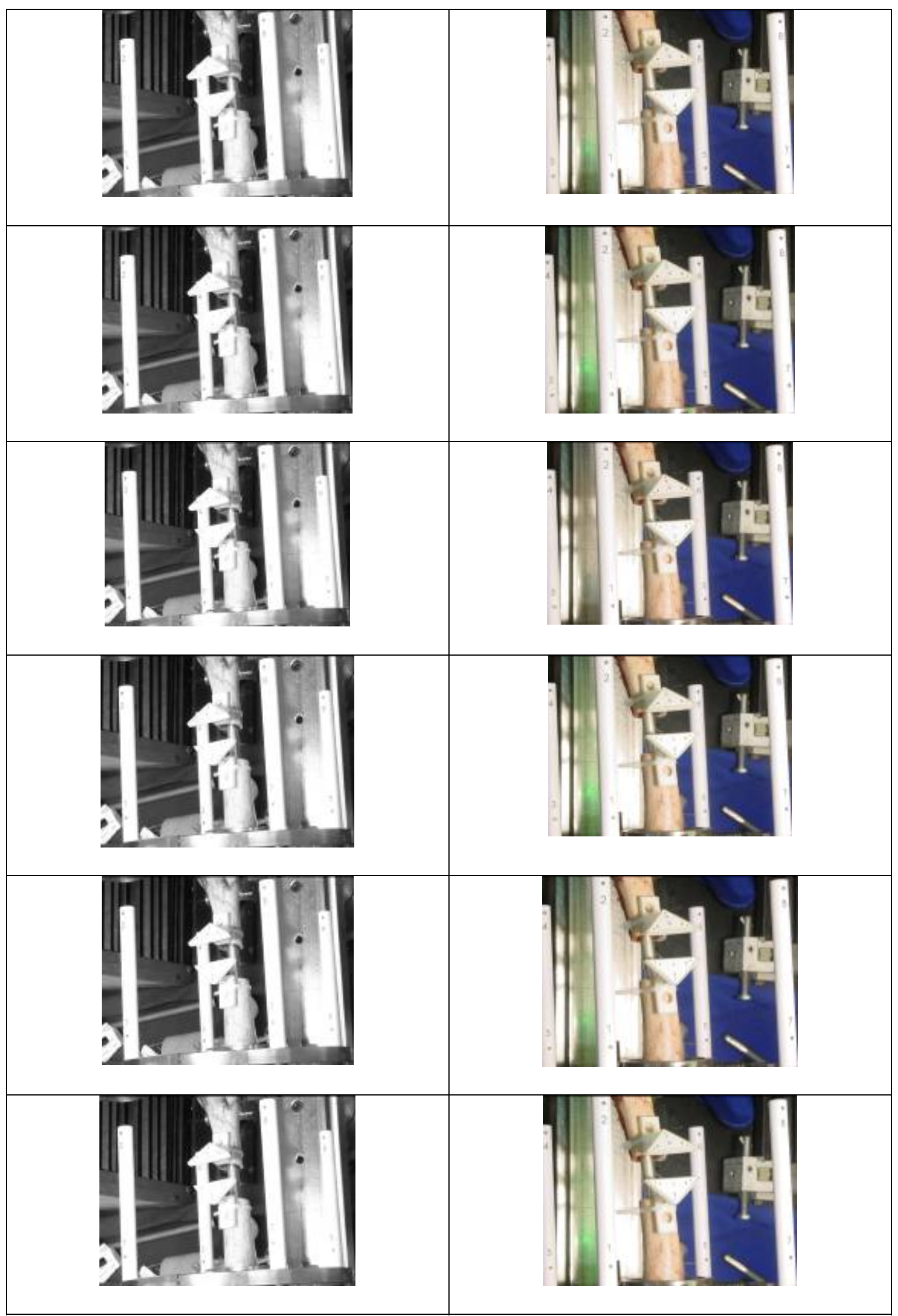

Figura 4.15 - Seqüência de imagens fotográficas demonstrando o ensaio de encurvamento - São Paulo - 2007 


\subsubsection{Ensaio de rotação}

O fêmur foi posicionado de forma análoga ao ensaio de encurvamento, onde sua extremidade distal fora presa ao dispositivo mecânico acoplado à base da máquina de ensaios, e sua extremidade proximal, presa à parte móvel do dispositivo (Figura 4.16-C). A parte móvel é composta pela garra cilíndrica para fixação ao fêmur, uma polia (Figuras 4.16-E e 4.17 ) presa à garra (Figura 4.16D) com diâmetro de 100 mm e um fio de aço (Figura 4.16-F) com diâmetro de 1 mm conectado a célula de carga e travessão móvel da máquina. O calibrador (Figura 4.18-C) e as câmeras (Figura 4.18-H) foram montados como descritos no ensaio de flexão (Figura 4.19).

Com o movimento de ascensão do travessão, a polia aplicou momento de torção de até 2,5 N.m, o ensaio foi descontínuo com paradas a cada 0,5 N.m de incremento. Foram tiradas, no mesmo instante, duas fotos antes do inicio do ensaio e duas fotos 5 segundos após cada parada da máquina, totalizando cinco paradas e 12 fotos (figura 4.20).

Esse tipo de ensaio permitiu adquirir o momento de torção em função da deformação angular sofrida pela estrutura ensaiada. O momento é calculado multiplicando-se a força medida pela célula de carga pelo raio da polia e a deformação angular calcula-se relacionando o deslocamento linear do travessão móvel com o perímetro da polia ou seja:

Deformação angular $=\underline{\text { Deslocamento linear } \times 360^{\circ}}$

Perímetro da polia 


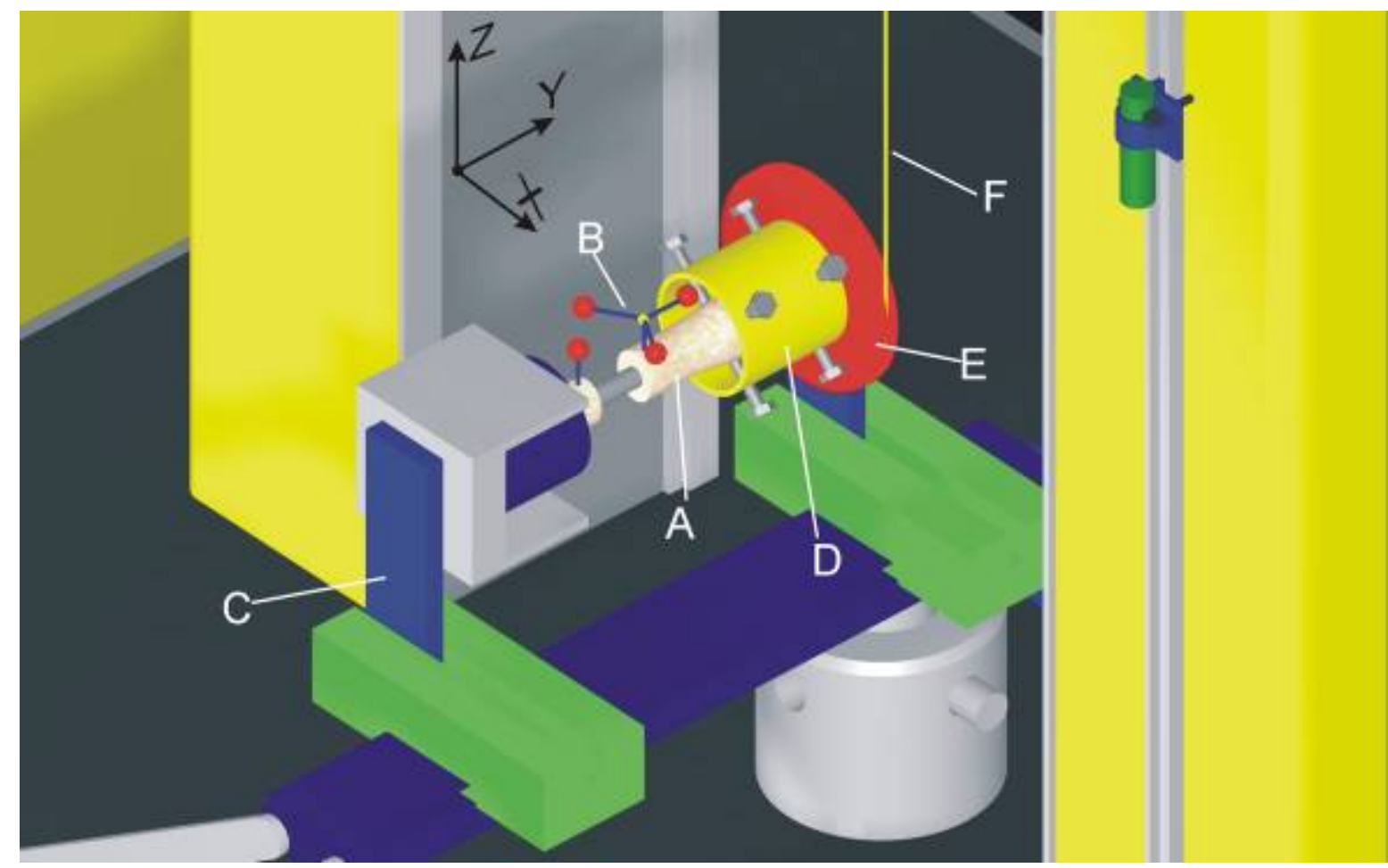
A - Fêmur
B - Marcadores esféricos
C - Dispositivo mecânico
D - Garra cilíndrica
E - Polia
F - Fio de aço

Figura 4.16- Desenho esquemático do ensaio de torção do fêmur sem o calibrador e as câmeras - São Paulo - 2007

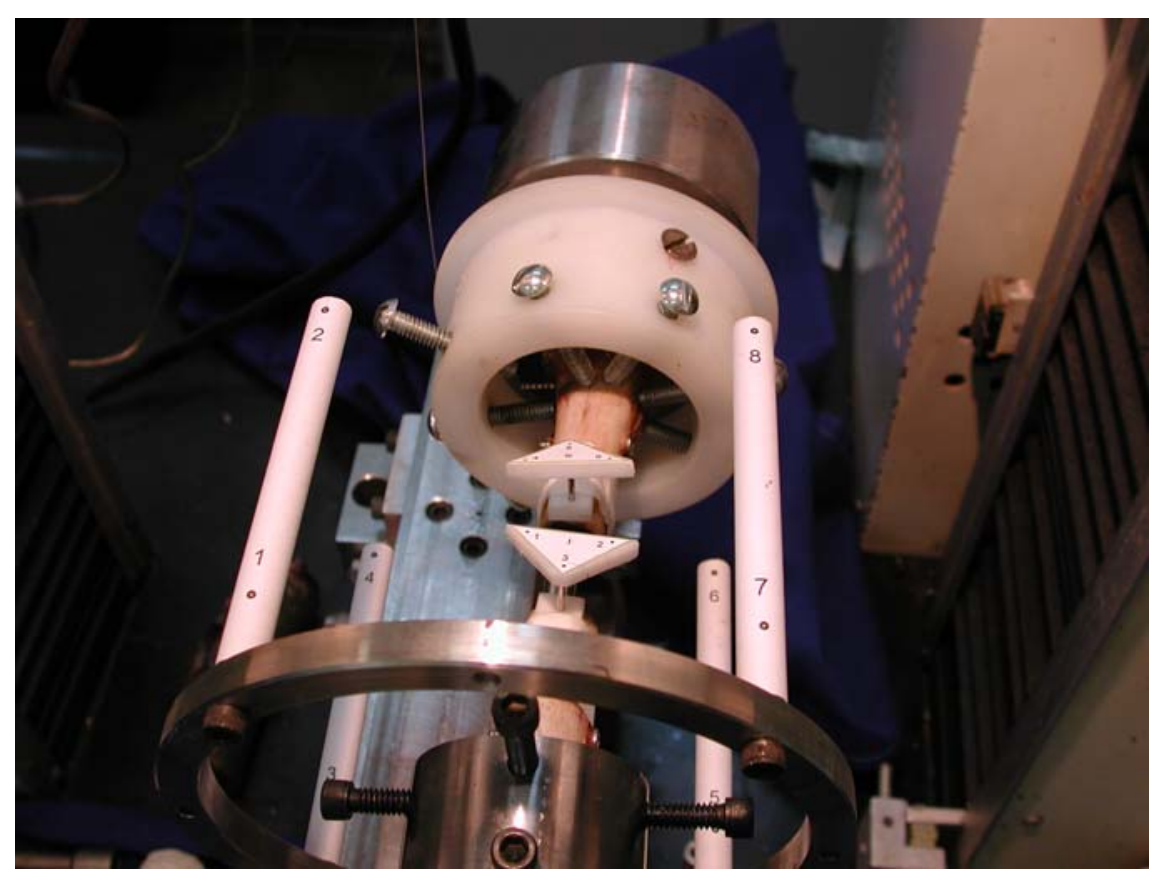

Figura 4.17- Imagem fotográfica ilustrando garra cilíndrica acoplada à epífise proximal para ensaio de rotação - São Paulo - 2007 


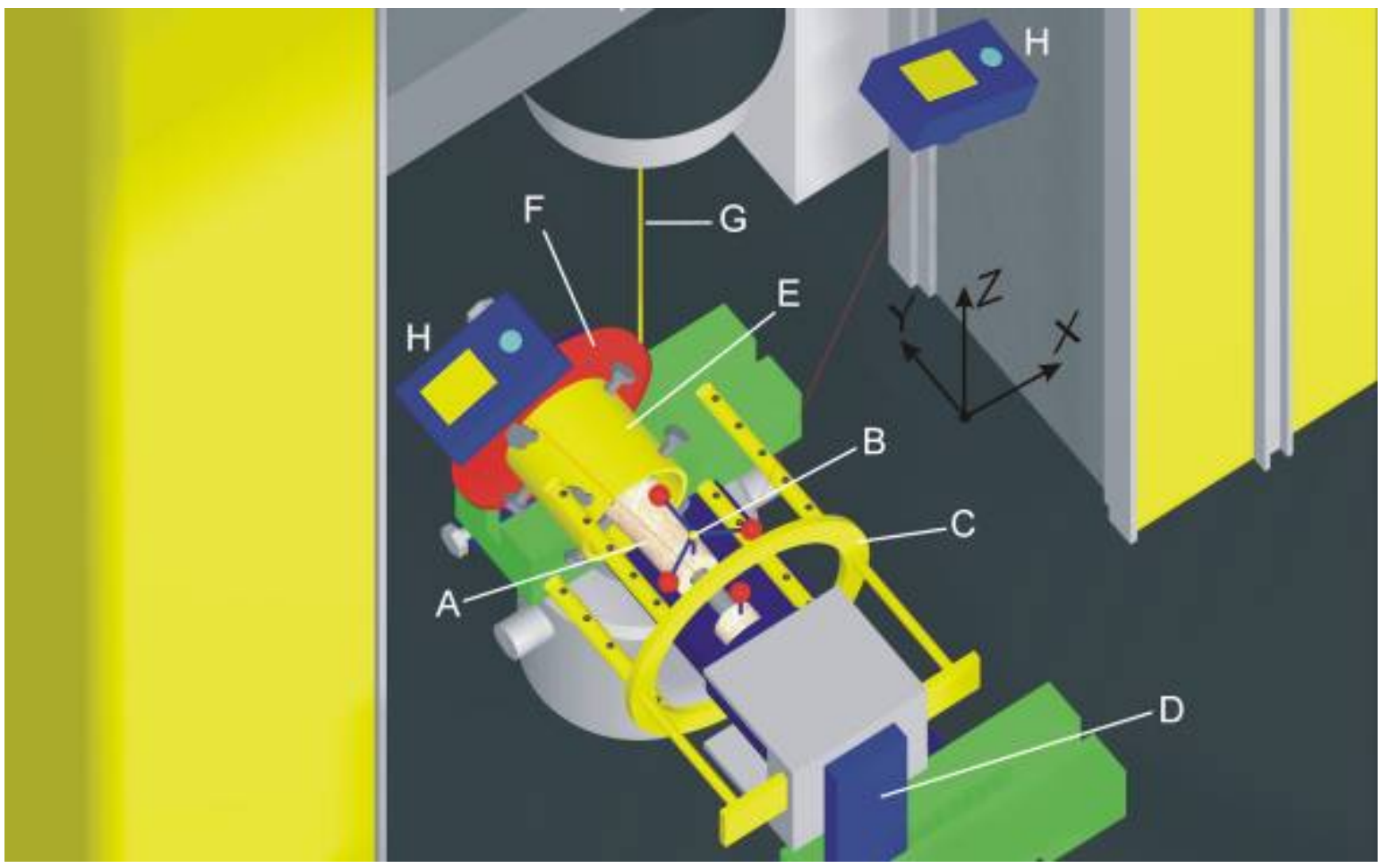
A - Fêmur
B - Marcadores esféricos
C - Calibrador
D - Dispositivo mecânico
E - Garra cilíndrica
F - Polia
G - Fio de aço
$\mathrm{H}$ - Câmeras fotográficas digitais

Figura 4.18- Desenho esquemático do ensaio de torção do fêmur com o calibrador e as câmeras - São Paulo - 2007 
Fig

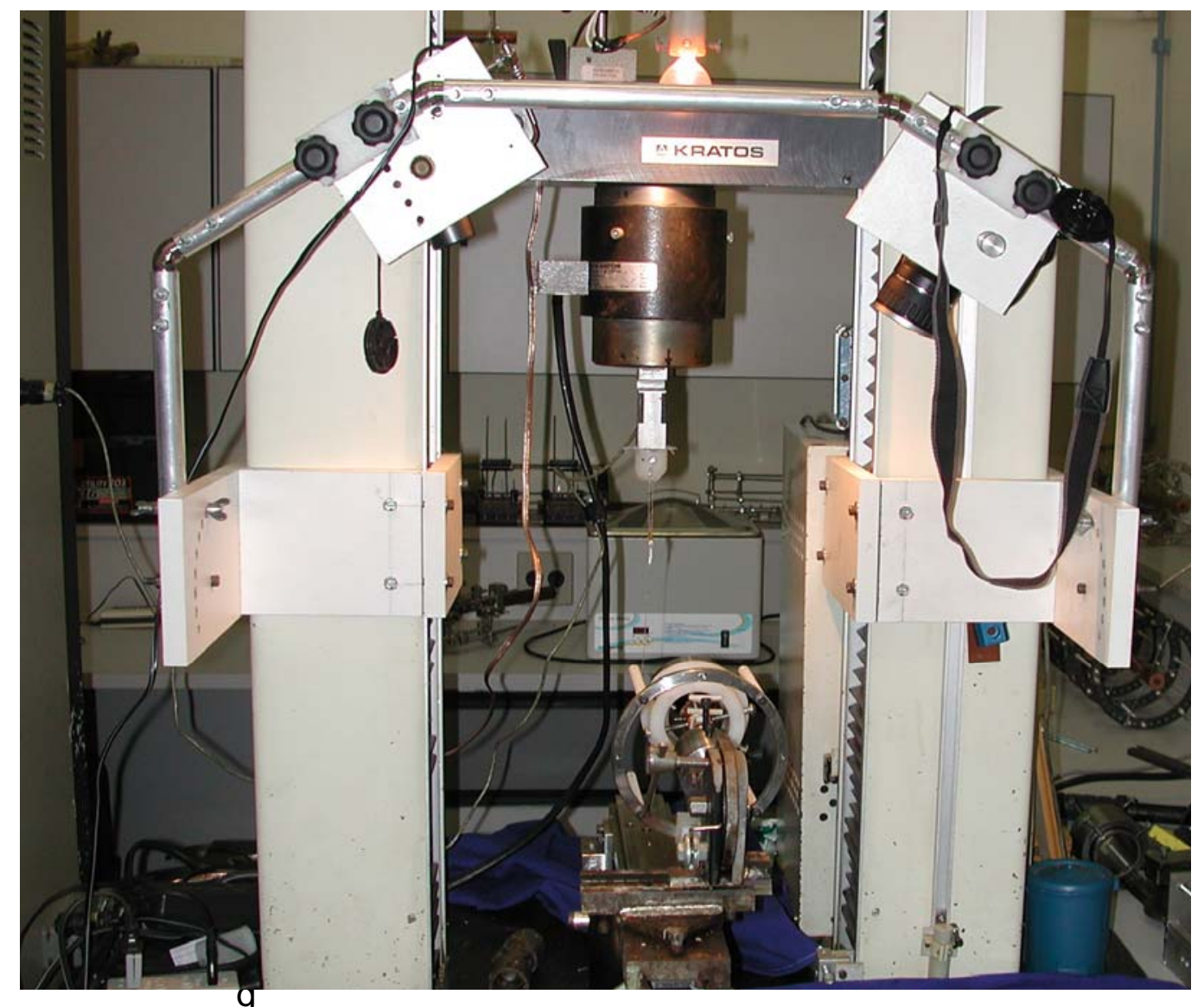

ráfica ilustrando disposição das câmeras fotográficas fixadas em travessão e anguladas a 45 graus entre si, nos ensaios de encurvamento e rotação- São Paulo - 2007 


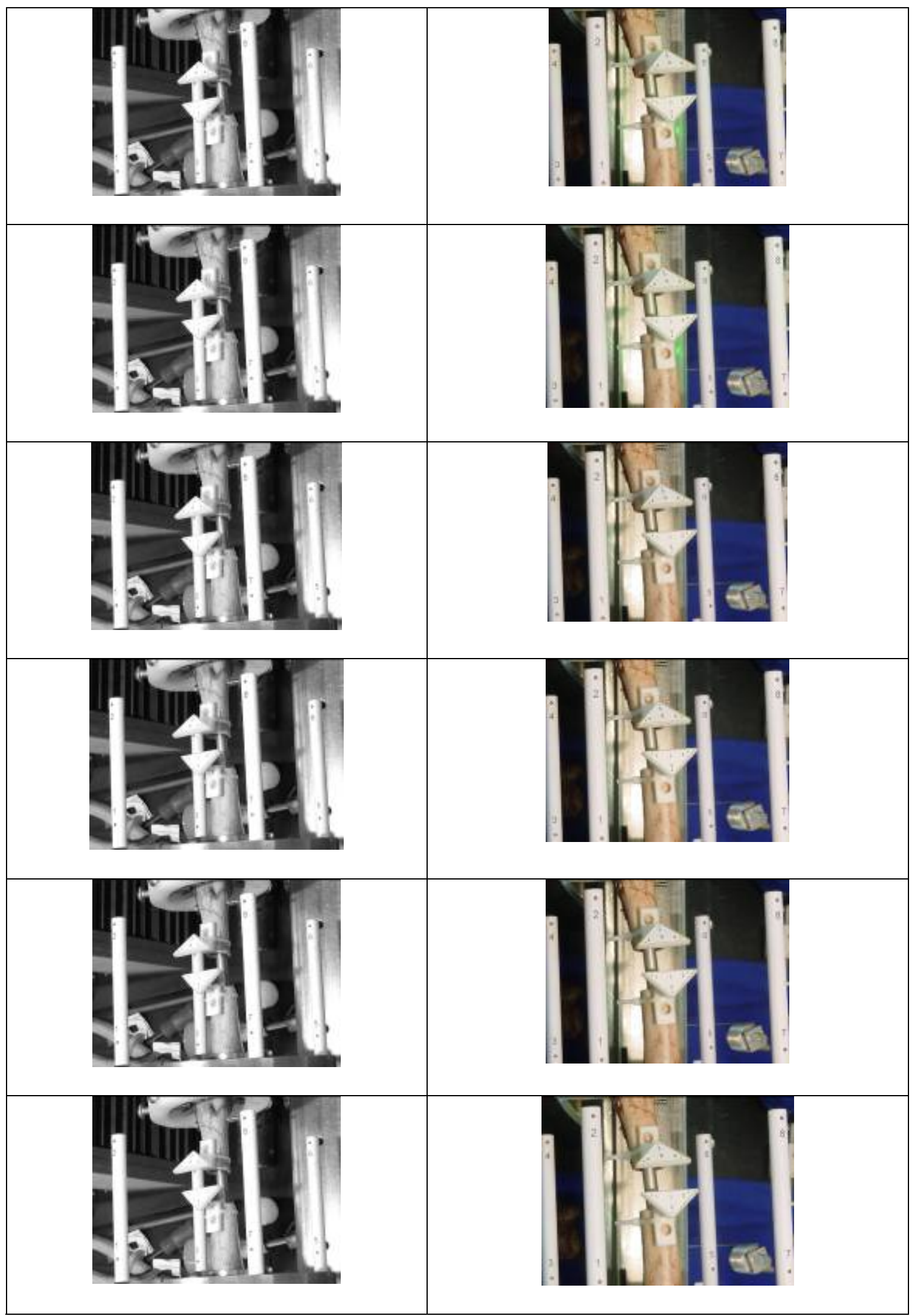

Figura 4.20 - Seqüência de imagens fotográficas demonstrando o ensaio de rotação - São Paulo - 2007 


\subsection{MÉTODO FOTOGRAMÉTRICO}

Programa desenvolvido no laboratório de biomecânica permite abrir as duas fotos tiradas em cada situação estudada. Primeiramente foi informado ao programa as coordenadas bidimensionais de cada ponto do calibrador nas duas fotos e as dimensões reais do calibrador em relação a um ponto de referência. Após o procedimento de calibração foram informadas as coordenadas bidimensionais dos marcadores nas duas fotos e o programa retornou as coordenadas espaciais $\mathrm{X}, \mathrm{Y}$ e $\mathrm{Z}$ referente aos marcadores.

O mesmo programa calcula os seis graus de liberdade (três translacionais e três rotacionais) do segmento proximal em relação ao segmento distal através das coordenadas espaciais dos seis marcadores envolvidos.

\subsubsection{Parâmetros analisados}

Foram analisados os deslocamentos (seis graus de liberdade) do segmento proximal em relação ao segmento distal segundo a variação da força para os ensaios de compressão e flexão e variações de momento de torção para o ensaio de torção.

\subsection{ANÁLISE ESTATÍSTICA}

As análises estatísticas foram processadas com auxílio de programa estatístico computadorizado (MINITAB RELEASE 13, 2000). 
Os dados finais obtidos Foram analisados quanto a sua distribuição paramétrica ou não pela prova de Kolmogorov-Smirnov. Os dados analisados, que apresentaram distribuição paramétrica, tiveram médias confrontadas pelo teste análise de variância de Tukey. As variáveis que não obedecerem à distribuição paramétrica, referentes à análise de deslocamento nos eixos $X, Y$ e Z em relação à $0 N$, foram analisadas pelo teste de Kruskall-Wallis (Anova nãoparamétrica) com pós-teste de Comparação Múltipla de Dunn's.

\subsubsection{Níveis de Significância}

Foram consideradas significativas as diferenças cujo valor de "p" apresentou valores iguais ou inferiores a 0,05. 
Restiditados 


\section{RESULTADOS}

Com o objetivo de facilitar a visualização e interpretação dos resultados obtidos na presente tese, optou-se por sua apresentação em tabelas e figuras, sendo os mesmos divididos em quatro partes.

Na primeira parte foram apresentados os resultados obtidos segundo a análise dos dados obtidos pelo sistema de aquisição analógica Lynx® modelo ADS2000.

$\mathrm{Na}$ segunda parte, os resultados foram apresentados segundo a análise fotogramétrica das imagens fotográficas digitais, de acordo com o deslocamento superior e inferior, quando comparados ao momento original (0 $\mathrm{N}$ de carga), nos ensaios de compressão, encurvamento e rotação.

$\mathrm{Na}$ terceira parte, foram apresentados os dados referentes ao deslocamento dos eixos $X, Y$ e $Z$, em relação ao momento original ( $0 \mathrm{~N}$ de carga), nos ensaios de compressão, encurvamento e rotação.

Na quarta parte, apresentados os gráficos de comparação das médias obtidas no deslocamento superior e superior em relação ao inferior. 
5.1 ANÁLISE DOS DADOS OBTIDOS PELO SISTEMA DE AQUISIÇÃO ANALÓGICA LYNX ${ }^{\circledR}$ MODELO ADS-2000

Tal análise permite observar a rigidez dos corpos de prova quando submetidos aos ensaios de compressão, encurvamento e rotação. Os dados, apresentados na tabela 5.1, obtiveram distribuição paramétrica e não apresentaram diferença significativa entre os grupos analisados. 
Tabela 5.1 - Valores obtidos, em N/mm, de rigidez dos corpos de prova, obtidos junto ao sistema lynx ${ }^{\circledR}$ modelo ads-2000, divididos nos grupos estudados, segundo os ensaios de compressão, encurvamento e rotação - São Paulo - 2007.

\begin{tabular}{|c|c|c|c|c|}
\hline & \multicolumn{4}{|c|}{ Rigidez } \\
\hline & & $\mathrm{N} / \mathrm{mm}$ & $\mathrm{N} / \mathrm{mm}$ & N.mm/grau \\
\hline Fêmur & Montagem & compressão & Encurvamento & Rotação \\
\hline 2 & G1 & 387 & 20,5 & 517 \\
\hline 5 & G1 & 690 & 21,5 & 558 \\
\hline 6 & G1 & 486 & 13,7 & 525 \\
\hline 15 & G1 & 327 & 8,8 & 379 \\
\hline 23 & G1 & 815 & 25,9 & 390 \\
\hline \multirow[t]{3}{*}{26} & G1 & 605 & 12,7 & 408 \\
\hline & M & 552 & 17,2 & 463 \\
\hline & DP & 186 & 6,5 & 79 \\
\hline 1 & G2 & 662 & 13,5 & 526 \\
\hline 8 & G2 & 718 & 15,7 & 531 \\
\hline 13 & G2 & 706 & 21,8 & 246 \\
\hline 14 & G2 & 665 & 16,6 & 576 \\
\hline 19 & G2 & 537 & 13,7 & 504 \\
\hline \multirow{3}{*}{25} & G2 & 549 & 10,5 & 296 \\
\hline & M & 640 & 15,3 & 447 \\
\hline & DP & 78 & 3,8 & 139 \\
\hline 9 & G3 & 466 & 12,9 & 406 \\
\hline 7 & G3 & 425 & 13,1 & 513 \\
\hline 17 & G3 & 445 & 9,1 & 517 \\
\hline 18 & G3 & 582 & 17,8 & 539 \\
\hline 20 & G3 & 771 & 13,1 & 428 \\
\hline \multirow[t]{3}{*}{24} & G3 & 532 & 9,2 & 271 \\
\hline & M & 537 & 12,5 & 446 \\
\hline & DP & 129 & 3,2 & 101 \\
\hline 4 & G4 & 570 & 14,9 & 431 \\
\hline 10 & G4 & 495 & 10,1 & 460 \\
\hline 11 & G4 & 334 & 9,4 & 577 \\
\hline 21 & G4 & 770 & 17,1 & 386 \\
\hline 27 & G4 & 657 & 12,3 & 263 \\
\hline \multirow[t]{3}{*}{29} & G4 & 592 & 11,4 & 246 \\
\hline & M & 570 & 12,5 & 394 \\
\hline & DP & 148 & 3,0 & 125 \\
\hline 3 & G5 & 468 & 9,0 & 589 \\
\hline 12 & G5 & 631 & 9,7 & 471 \\
\hline 16 & G5 & 617 & 15,2 & 505 \\
\hline 22 & G5 & 562 & 14,0 & 371 \\
\hline 28 & G5 & 543 & 14,3 & 676 \\
\hline \multirow[t]{3}{*}{30} & G5 & 503 & 13,3 & 386 \\
\hline & $M$ & 554 & 12,6 & 500 \\
\hline & DP & 63 & 2,6 & 118 \\
\hline
\end{tabular}




\subsection{ANÁLISE FOTOGRAMÉTRICA}

Esta análise permitiu compreender a dinâmica dos corpos de prova durante seus ensaios. Embora fixados à máquina por sua epífise distal, a forma de preensão e posicionamento da célula de carga na epífise proximal permitiu a movimentação tridimensional dos corpos de prova durante os ensaios, mensurada e disposta nas tabelas à seguir.

\subsubsection{Análise das distâncias em relação a 0 N}

Para cada ensaio, foram obtidos os dados da movimentação interfragmentária em cada parada, comparando os dados obtidos com aqueles apresentados no momento inicial (ON) do ensaio.

Os dados obtidos refletem a movimentação tridimensional dos corpos de prova, sendo analisados os comportamentos das porções superior e inferior, e o comportamento conjunto da porção superior em relação à inferior.

\subsubsection{Ensaio de compressão}

Os dados obtidos refletem a movimentação interfragmentária tridimensional dos corpos de prova durante o ensaio de compressão. Os dados, apresentados nas tabelas 5.2, 5.3 e 5.4, obtiveram distribuição paramétrica e não apresentaram diferença significativa entre os grupos analisados. 
Tabela 5.2 - Valores obtidos, em mm, de deslocamentos da porção superior dos corpos de prova em relação à situação inicial, em cada intervalo dos ensaios realizados, obtidos por análise fotogramétrica, divididos nos grupos estudados, segundo o ensaio de compressão- São Paulo - 2007.

\begin{tabular}{|c|c|c|c|c|c|c|c|c|}
\hline GRUPO & FEMUR & & 0 & 40 & 80 & 120 & 160 & 200 \\
\hline 1 & Femur2 & DISTANCIA_SUPERIOR & 0,0 & 0,1 & 0,2 & 0,3 & 0,3 & 0,3 \\
\hline 1 & Femur5 & DISTANCIA_SUPERIOR & 0,0 & 0,0 & 0,1 & 0,1 & 0,2 & 0,2 \\
\hline 1 & Femur6 & DISTANCIA_SUPERIOR & 0,0 & 0,1 & 0,3 & 0,3 & 0,3 & 0,4 \\
\hline 1 & Femur15 & DISTANCIA_SUPERIOR & 0,0 & 0,1 & 0,1 & 0,2 & 0,3 & 0,4 \\
\hline 1 & Femur23 & DISTANCIA_SUPERIOR & 0,0 & 0,1 & 0,1 & 0,1 & 0,1 & 0,2 \\
\hline \multirow[t]{3}{*}{1} & Femur26 & DISTANCIA_SUPERIOR & 0,0 & 0,1 & 0,2 & 0,2 & 0,3 & 0,3 \\
\hline & & M & 0,0 & 0,1 & 0,2 & 0,2 & 0,3 & 0,3 \\
\hline & & $\mathrm{DP}$ & 0,0 & 0,0 & 0,1 & 0,1 & 0,1 & 0,1 \\
\hline 2 & Femur1 & DISTANCIA_SUPERIOR & 0,0 & 0,2 & 0,2 & 0,2 & 0,2 & 0,2 \\
\hline 2 & Femur8 & DISTANCIA_SUPERIOR & 0,0 & 0,1 & 0,1 & 0,2 & 0,2 & 0,3 \\
\hline 2 & Femur13 & DISTANCIA_SUPERIOR & 0,0 & 0,2 & 0,2 & 0,2 & 0,3 & 0,5 \\
\hline 2 & Femur14 & DISTANCIA_SUPERIOR & 0,0 & 0,4 & 0,9 & 1,0 & 0,9 & 1,0 \\
\hline 2 & Femur19 & DISTANCIA_SUPERIOR & 0,0 & 0,1 & 0,1 & 0,2 & 0,3 & 0,3 \\
\hline \multirow[t]{3}{*}{2} & Femur25 & DISTANCIA_SUPERIOR & 0,0 & 0,4 & 0,4 & 0,3 & 0,3 & 0,3 \\
\hline & & M & 0,0 & 0,2 & 0,3 & 0,4 & 0,4 & 0,4 \\
\hline & & DP & 0,0 & 0,1 & 0,3 & 0,3 & 0,3 & 0,3 \\
\hline 3 & Femur7 & DISTANCIA_SUPERIOR & 0,0 & 0,2 & 0,4 & 0,6 & 0,8 & 0,9 \\
\hline 3 & Femur9 & DISTANCIA_SUPERIOR & 0,0 & 0,2 & 0,4 & 0,6 & 0,7 & 0,9 \\
\hline 3 & Femur17 & DISTANCIA_SUPERIOR & 0,0 & 0,2 & 0,1 & 0,1 & 0,2 & 0,2 \\
\hline 3 & Femur18 & DISTANCIA_SUPERIOR & 0,0 & 0,1 & 0,4 & 0,5 & 0,6 & 0,6 \\
\hline 3 & Femur20 & DISTANCIA_SUPERIOR & 0,0 & 0,1 & 0,1 & 0,1 & 0,1 & 0,1 \\
\hline \multirow[t]{3}{*}{3} & Femur24 & DISTANCIA_SUPERIOR & 0,0 & 0,1 & 0,5 & 0,6 & 0,8 & 0,8 \\
\hline & & M & 0,0 & 0,2 & 0,3 & 0,4 & 0,5 & 0,6 \\
\hline & & DP & 0,0 & 0,1 & 0,2 & 0,2 & 0,3 & 0,4 \\
\hline 4 & Femur4 & DISTANCIA_SUPERIOR & 0,0 & 0,1 & 0,2 & 0,2 & 0,2 & 0,2 \\
\hline 4 & Femur10 & DISTANCIA_SUPERIOR & 0,0 & 0,1 & 0,2 & 0,3 & 0,4 & 0,5 \\
\hline 4 & Femur11 & DISTANCIA_SUPERIOR & 0,0 & 0,2 & 0,4 & 0,6 & 0,8 & 0,9 \\
\hline 4 & Femur21 & DISTANCIA_SUPERIOR & 0,0 & 0,1 & 0,0 & 0,1 & 0,1 & 0,2 \\
\hline 4 & Femur27 & DISTANCIA_SUPERIOR & 0,0 & 0,0 & 0,0 & 0,1 & 0,2 & 0,3 \\
\hline \multirow[t]{3}{*}{4} & Femur29 & DISTANCIA_SUPERIOR & 0,0 & 0,1 & 0,1 & 0,2 & 0,2 & 0,3 \\
\hline & & M & 0,0 & 0,1 & 0,2 & 0,3 & 0,3 & 0,4 \\
\hline & & $\mathrm{DP}$ & 0,0 & 0,1 & 0,2 & 0,2 & 0,3 & 0,3 \\
\hline 5 & Femur3 & DISTANCIA_SUPERIOR & 0,0 & 0,8 & 1,4 & 1,6 & 1,7 & 1,8 \\
\hline 5 & Femur12 & DISTANCIA_SUPERIOR & 0,0 & 0,4 & 0,5 & 0,5 & 0,5 & 0,5 \\
\hline 5 & Femur16 & DISTANCIA_SUPERIOR & 0,0 & 0,2 & 0,4 & 0,5 & 0,6 & 0,7 \\
\hline 5 & Femur22 & DISTANCIA_SUPERIOR & 0,0 & 0,1 & 0,1 & 0,2 & 0,4 & 0,6 \\
\hline 5 & Femur28 & DISTANCIA_SUPERIOR & 0,0 & 1,0 & 1,1 & 1,0 & 1,1 & 1,7 \\
\hline \multirow[t]{3}{*}{5} & Femur30 & DISTANCIA_SUPERIOR & 0,0 & 0,3 & 0,3 & 0,3 & 0,4 & 0,5 \\
\hline & & M & 0,0 & 0,5 & 0,6 & 0,7 & 0,8 & 1,0 \\
\hline & & $\mathrm{DP}$ & 0,0 & 0,4 & 0,5 & 0,5 & 0,5 & 0,6 \\
\hline
\end{tabular}


Tabela 5.3 - Valores obtidos, em mm, de deslocamentos da porção inferior dos corpos de prova em relação à situação inicial, em cada intervalo dos ensaios realizados, obtidos por análise fotogramétrica, divididos nos grupos estudados, segundo o ensaio de compressão- São Paulo - 2007.

\begin{tabular}{|c|c|c|c|c|c|c|c|c|}
\hline GRUPO & FEMUR & & 0 & 40 & 80 & 120 & 160 & 200 \\
\hline 1 & Femur2 & DISTANCIA_INFERIOR & 0,0 & 0,1 & 0,1 & 0,1 & 0,1 & 0,1 \\
\hline 1 & Femur5 & DISTANCIA_INFERIOR & 0,0 & 0,1 & 0,1 & 0,1 & 0,1 & 0,1 \\
\hline 1 & Femur6 & DISTANCIA_INFERIOR & 0,0 & 0,1 & 0,1 & 0,1 & 0,1 & 0,1 \\
\hline 1 & Femur15 & DISTANCIA_INFERIOR & 0,0 & 0,0 & 0,0 & 0,0 & 0,1 & 0,2 \\
\hline 1 & Femur23 & DISTANCIA_INFERIOR & 0,0 & 0,1 & 0,1 & 0,1 & 0,1 & 0,2 \\
\hline \multirow[t]{3}{*}{1} & Femur26 & DISTANCIA_INFERIOR & 0,0 & 0,0 & 0,1 & 0,1 & 0,1 & 0,2 \\
\hline & & M & 0,0 & 0,1 & 0,1 & 0,1 & 0,1 & 0,2 \\
\hline & & DP & 0,0 & 0,1 & 0,0 & 0,0 & 0,0 & 0,1 \\
\hline 2 & Femur1 & DISTANCIA_INFERIOR & 0,0 & 0,1 & 0,1 & 0,1 & 0,0 & 0,1 \\
\hline 2 & Femur8 & DISTANCIA_INFERIOR & 0,0 & 0,1 & 0,1 & 0,1 & 0,2 & 0,2 \\
\hline 2 & Femur13 & DISTANCIA_INFERIOR & 0,0 & 0,1 & 0,2 & 0,2 & 0,2 & 0,4 \\
\hline 2 & Femur14 & DISTANCIA_INFERIOR & 0,0 & 0,3 & 0,9 & 0,9 & 0,9 & 0,9 \\
\hline 2 & Femur19 & DISTANCIA_INFERIOR & 0,0 & 0,1 & 0,1 & 0,1 & 0,1 & 0,2 \\
\hline \multirow[t]{3}{*}{2} & Femur25 & DISTANCIA_INFERIOR & 0,0 & 0,2 & 0,2 & 0,2 & 0,1 & 0,1 \\
\hline & & M & 0,0 & 0,2 & 0,3 & 0,3 & 0,3 & 0,3 \\
\hline & & DP & 0,0 & 0,1 & 0,3 & 0,3 & 0,3 & 0,3 \\
\hline 3 & Femur7 & DISTANCIA_INFERIOR & 0,0 & 0,1 & 0,2 & 0,2 & 0,3 & 0,3 \\
\hline 3 & Femur9 & DISTANCIA_INFERIOR & 0,0 & 0,1 & 0,1 & 0,1 & 0,2 & 0,2 \\
\hline 3 & Femur17 & DISTANCIA_INFERIOR & 0,0 & 0,1 & 0,1 & 0,2 & 0,2 & 0,2 \\
\hline 3 & Femur18 & DISTANCIA_INFERIOR & 0,0 & 0,1 & 0,1 & 0,2 & 0,1 & 0,2 \\
\hline 3 & Femur20 & DISTANCIA_INFERIOR & 0,0 & 0,1 & 0,1 & 0,1 & 0,1 & 0,1 \\
\hline \multirow[t]{3}{*}{3} & Femur24 & DISTANCIA_INFERIOR & 0,0 & 0,0 & 0,1 & 0,2 & 0,2 & 0,2 \\
\hline & & M & 0,0 & 0,1 & 0,1 & 0,2 & 0,2 & 0,2 \\
\hline & & DP & 0,0 & 0,0 & 0,0 & 0,1 & 0,1 & 0,1 \\
\hline 4 & Femur4 & DISTANCIA_INFERIOR & 0,0 & 0,1 & 0,1 & 0,1 & 0,1 & 0,1 \\
\hline 4 & Femur10 & DISTANCIA_INFERIOR & 0,0 & 0,1 & 0,1 & 0,1 & 0,1 & 0,1 \\
\hline 4 & Femur11 & DISTANCIA_INFERIOR & 0,0 & 0,1 & 0,1 & 0,1 & 0,2 & 0,2 \\
\hline 4 & Femur21 & DISTANCIA_INFERIOR & 0,0 & 0,1 & 0,0 & 0,1 & 0,1 & 0,2 \\
\hline 4 & Femur27 & DISTANCIA_INFERIOR & 0,0 & 0,1 & 0,1 & 0,1 & 0,1 & 0,1 \\
\hline \multirow[t]{3}{*}{4} & Femur29 & DISTANCIA_INFERIOR & 0,0 & 0,0 & 0,1 & 0,1 & 0,2 & 0,3 \\
\hline & & M & 0,0 & 0,1 & 0,1 & 0,1 & 0,1 & 0,2 \\
\hline & & DP & 0,0 & 0,0 & 0,0 & 0,0 & 0,1 & 0,1 \\
\hline 5 & Femur3 & DISTANCIA_INFERIOR & 0,0 & 0,2 & 0,3 & 0,3 & 0,3 & 0,3 \\
\hline 5 & Femur12 & DISTANCIA_INFERIOR & 0,0 & 0,5 & 0,5 & 0,5 & 0,6 & 0,6 \\
\hline 5 & Femur16 & DISTANCIA_INFERIOR & 0,0 & 0,1 & 0,2 & 0,2 & 0,3 & 0,4 \\
\hline 5 & Femur22 & DISTANCIA_INFERIOR & 0,0 & 0,0 & 0,0 & 0,1 & 0,2 & 0,2 \\
\hline 5 & Femur28 & DISTANCIA_INFERIOR & 0,0 & 0,9 & 0,9 & 0,8 & 0,8 & 1,3 \\
\hline \multirow[t]{3}{*}{5} & Femur30 & DISTANCIA_INFERIOR & 0,0 & 0,2 & 0,2 & 0,2 & 0,2 & 0,2 \\
\hline & & $M$ & 0,0 & 0,3 & 0,4 & 0,4 & 0,4 & 0,5 \\
\hline & & DP & 0,0 & 0,3 & 0,3 & 0,3 & 0,2 & 0,4 \\
\hline
\end{tabular}


Tabela 5.4 - Valores obtidos, em mm, de deslocamentos da porção superior dos corpos de prova em relação à porção inferior, em cada intervalo dos ensaios realizados, obtidos por análise fotogramétrica, divididos nos grupos estudados, segundo o ensaio de compressão- São Paulo - 2007.

\begin{tabular}{|c|c|c|c|c|c|c|c|c|c|}
\hline GRUPO & FEMUR & & & 0 & 40 & 80 & 120 & 160 & 200 \\
\hline 1 & Femur2 & DISTANCIA_INF-SUP & & 0,0 & 0,1 & 0,1 & 0,1 & 0,1 & 0,2 \\
\hline 1 & Femur5 & DISTANCIA_INF-SUP & & 0,0 & 0,1 & 0,0 & 0,1 & 0,2 & 0,1 \\
\hline 1 & Femur6 & DISTANCIA_INF-SUP & & 0,0 & 0,1 & 0,0 & 0,0 & 0,0 & 0,0 \\
\hline 1 & Femur15 & DISTANCIA_INF-SUP & & 0,0 & 0,0 & 0,0 & 0,0 & 0,1 & 0,1 \\
\hline 1 & Femur23 & DISTANCIA_INF-SUP & & 0,0 & 0,0 & 0,0 & 0,0 & 0,0 & 0,0 \\
\hline \multirow[t]{3}{*}{1} & Femur26 & DISTANCIA_INF-SUP & & 0,0 & 0,0 & 0,1 & 0,0 & 0,1 & 0,0 \\
\hline & & & M & 0,0 & 0,1 & 0,0 & 0,0 & 0,1 & 0,1 \\
\hline & & & DP & 0,0 & 0,1 & 0,1 & 0,1 & 0,1 & 0,1 \\
\hline 2 & Femur1 & DISTANCIA_INF-SUP & & 0,0 & 0,1 & 0,1 & 0,2 & 0,2 & 0,2 \\
\hline 2 & Femur8 & DISTANCIA_INF-SUP & & 0,0 & 0,0 & 0,0 & 0,0 & 0,0 & 0,1 \\
\hline 2 & Femur13 & DISTANCIA_INF-SUP & & 0,0 & 0,0 & 0,1 & 0,0 & 0,0 & 0,0 \\
\hline 2 & Femur14 & DISTANCIA_INF-SUP & & 0,0 & 0,1 & 0,1 & 0,0 & 0,0 & 0,0 \\
\hline 2 & Femur19 & DISTANCIA_INF-SUP & & 0,0 & 0,0 & 0,0 & 0,0 & 0,1 & 0,1 \\
\hline \multirow[t]{3}{*}{2} & Femur25 & DISTANCIA_INF-SUP & & 0,0 & 0,0 & 0,0 & 0,0 & 0,1 & 0,1 \\
\hline & & & M & 0,0 & 0,0 & 0,1 & 0,0 & 0,1 & 0,1 \\
\hline & & & DP & 0,0 & 0,1 & 0,1 & 0,1 & 0,1 & 0,1 \\
\hline 3 & Femur7 & DISTANCIA_INF-SUP & & 0,0 & 0,0 & 0,0 & 0,0 & 0,1 & 0,2 \\
\hline 3 & Femur9 & DISTANCIA_INF-SUP & & 0,0 & 0,0 & 0,1 & 0,1 & 0,2 & 0,2 \\
\hline 3 & Femur17 & DISTANCIA_INF-SUP & & 0,0 & 0,0 & 0,0 & 0,0 & 0,1 & 0,0 \\
\hline 3 & Femur18 & DISTANCIA_INF-SUP & & 0,0 & 0,0 & 0,1 & 0,1 & 0,2 & 0,1 \\
\hline 3 & Femur20 & DISTANCIA_INF-SUP & & 0,0 & 0,1 & 0,0 & 0,0 & 0,0 & 0,0 \\
\hline \multirow[t]{3}{*}{3} & Femur24 & DISTANCIA_INF-SUP & & 0,0 & 0,0 & 0,1 & 0,1 & 0,2 & 0,2 \\
\hline & & & M & 0,0 & 0,0 & 0,1 & 0,1 & 0,1 & 0,1 \\
\hline & & & $\mathrm{DP}$ & 0,0 & 0,0 & 0,1 & 0,1 & 0,1 & 0,1 \\
\hline 4 & Femur4 & DISTANCIA_INF-SUP & & 0,0 & 0,1 & 0,0 & 0,1 & 0,0 & 0,0 \\
\hline 4 & Femur10 & DISTANCIA_INF-SUP & & 0,0 & 0,1 & 0,0 & 0,1 & 0,1 & 0,2 \\
\hline 4 & Femur11 & DISTANCIA_INF-SUP & & 0,0 & 0,0 & 0,0 & 0,0 & 0,1 & 0,1 \\
\hline 4 & Femur21 & DISTANCIA_INF-SUP & & 0,0 & 0,0 & 0,0 & 0,0 & 0,0 & 0,0 \\
\hline 4 & Femur27 & DISTANCIA_INF-SUP & & 0,0 & 0,0 & 0,0 & 0,0 & 0,1 & 0,0 \\
\hline \multirow[t]{3}{*}{4} & Femur29 & DISTANCIA_INF-SUP & & 0,0 & 0,0 & 0,1 & 0,1 & 0,0 & 0,0 \\
\hline & & & M & 0,0 & 0,0 & 0,0 & 0,1 & 0,1 & 0,1 \\
\hline & & & $\mathrm{DP}$ & 0,0 & 0,1 & 0,0 & 0,1 & 0,1 & 0,1 \\
\hline 5 & Femur3 & DISTANCIA_INF-SUP & & 0,0 & 0,0 & 0,0 & 0,0 & 0,1 & 0,1 \\
\hline 5 & Femur12 & DISTANCIA_INF-SUP & & 0,0 & 0,0 & 0,0 & 0,1 & 0,1 & 0,1 \\
\hline 5 & Femur16 & DISTANCIA_INF-SUP & & 0,0 & 0,0 & 0,0 & 0,1 & 0,1 & 0,1 \\
\hline 5 & Femur22 & DISTANCIA_INF-SUP & & 0,0 & 0,1 & 0,0 & 0,1 & 0,0 & 0,0 \\
\hline 5 & Femur28 & DISTANCIA_INF-SUP & & 0,0 & 0,1 & 0,1 & 0,1 & 0,2 & 0,3 \\
\hline \multirow[t]{3}{*}{5} & Femur30 & DISTANCIA_INF-SUP & & 0,0 & 0,1 & 0,0 & 0,0 & 0,0 & 0,1 \\
\hline & & & M & 0,0 & 0,1 & 0,0 & 0,1 & 0,1 & 0,1 \\
\hline & & & DP & 0,0 & 0,1 & 0,0 & 0,1 & 0,1 & 0,1 \\
\hline
\end{tabular}


5.2.1.2 Ensaio de Encurvamento

Os dados obtidos refletem a movimentação interfragmentária tridimensional dos corpos de prova durante o ensaio de encurvamento. A análise dos dados, apresentados nas tabelas 5.5, 5.6 e 5.7, demonstrou distribuição paramétrica, não apresentando diferença significativa entre os grupos analisados. 
Tabela 5.5- Valores obtidos, em $\mathrm{mm}$, de deslocamentos da porção superior dos corpos de prova em relação à situação inicial, em cada intervalo dos ensaios realizados, obtidos por análise fotogramétrica, divididos nos grupos estudados, segundo o ensaio de encurvamento- São Paulo - 2007.

\begin{tabular}{|c|c|c|c|c|c|c|c|c|c|}
\hline GRUPO & FEMUR & & & 0 & 12 & 24 & 36 & 48 & 60 \\
\hline 1 & Femur2 & DISTANCIA_SUPERIOR & & 0,0 & 0,5 & 0,8 & 1,1 & 1,4 & 1,8 \\
\hline 1 & Femur5 & DISTANCIA_SUPERIOR & & 0,0 & 0,1 & 0,4 & 0,6 & 0,9 & 1,2 \\
\hline 1 & Femur6 & DISTANCIA_SUPERIOR & & 0,0 & 0,4 & 0,9 & 1,4 & 1,9 & 2,5 \\
\hline 1 & Femur15 & DISTANCIA_SUPERIOR & & 0,0 & 0,4 & 0,9 & 2,0 & 2,6 & 3,3 \\
\hline 1 & Femur23 & DISTANCIA_SUPERIOR & & 0,0 & 0,3 & 0,6 & 0,8 & 1,0 & 1,4 \\
\hline \multirow[t]{3}{*}{1} & Femur26 & DISTANCIA_SUPERIOR & & 0,0 & 1,0 & 1,9 & 2,4 & 2,9 & 3,5 \\
\hline & & & M & 0,0 & 0,5 & 0,9 & 1,4 & 1,8 & 2,3 \\
\hline & & & DP & 0,0 & 0,3 & 0,5 & 0,7 & 0,8 & 1,0 \\
\hline 2 & Femur1 & DISTANCIA_SUPERIOR & & 0,0 & 0,3 & 0,6 & 1,1 & 1,6 & 2,0 \\
\hline 2 & Femur8 & DISTANCIA_SUPERIOR & & 0,0 & 0,3 & 0,7 & 1,1 & 1,4 & 1,9 \\
\hline 2 & Femur13 & DISTANCIA_SUPERIOR & & 0,0 & 1,6 & 1,5 & 1,2 & 1,1 & 0,9 \\
\hline 2 & Femur14 & DISTANCIA_SUPERIOR & & 0,0 & 0,5 & 0,8 & 1,2 & 1,5 & 1,9 \\
\hline 2 & Femur19 & DISTANCIA_SUPERIOR & & 0,0 & 0,4 & 0,8 & 1,2 & 1,6 & 2,0 \\
\hline \multirow[t]{3}{*}{2} & Femur25 & DISTANCIA_SUPERIOR & & 0,0 & 0,5 & 1,1 & 1,6 & 2,0 & 2,7 \\
\hline & & & M & 0,0 & 0,6 & 0,9 & 1,2 & 1,5 & 1,9 \\
\hline & & & DP & 0,0 & 0,5 & 0,3 & 0,2 & 0,3 & 0,6 \\
\hline 3 & Femur7 & DISTANCIA_SUPERIOR & & 0,0 & 0,3 & 0,5 & 0,8 & 1,4 & 1,8 \\
\hline 3 & Femur9 & DISTANCIA_SUPERIOR & & 0,0 & 0,5 & 1,0 & 1,4 & 1,9 & 2,4 \\
\hline 3 & Femur17 & DISTANCIA SUPERIOR & & 0,0 & 0,7 & 1,4 & 1,8 & 2,6 & 3,3 \\
\hline 3 & Femur18 & DISTANCIA SUPERIOR & & 0,0 & 0,2 & 0,5 & 0,7 & 1,1 & 1,4 \\
\hline 3 & Femur20 & DISTANCIA SUPERIOR & & 0,0 & 0,2 & 0,6 & 0,9 & 1,3 & 1,7 \\
\hline \multirow[t]{3}{*}{3} & Femur24 & DISTANCIA SUPERIOR & & 0,0 & 0,6 & 1,3 & 1,9 & 2,4 & 3,1 \\
\hline & & & M & 0,0 & 0,4 & 0,9 & 1,3 & 1,8 & 2,3 \\
\hline & & & DP & 0,0 & 0,2 & 0,4 & 0,5 & 0,6 & 0,8 \\
\hline 4 & Femur4 & DISTANCIA_SUPERIOR & & 0,0 & 0,3 & 0,6 & 1,0 & 1,3 & 1,7 \\
\hline 4 & Femur10 & DISTANCIA_SUPERIOR & & 0,0 & 0,7 & 1,4 & 2,1 & 2,7 & 3,5 \\
\hline 4 & Femur11 & DISTANCIA_SUPERIOR & & 0,0 & 0,8 & 1,2 & 1,9 & 2,6 & 3,2 \\
\hline 4 & Femur21 & DISTANCIA_SUPERIOR & & 0,0 & 0,3 & 0,5 & 0,9 & 1,3 & 1,5 \\
\hline 4 & Femur27 & DISTANCIA_SUPERIOR & & 0,0 & 1,0 & 1,8 & 2,5 & 3,0 & 3,6 \\
\hline \multirow[t]{3}{*}{4} & Femur29 & DISTANCIA_SUPERIOR & & 0,0 & 0,7 & 1,2 & 1,6 & 2,1 & 2,7 \\
\hline & & & M & 0,0 & 0,6 & 1,1 & 1,7 & 2,2 & 2,7 \\
\hline & & & DP & 0,0 & 0,3 & 0,5 & 0,6 & 0,7 & 0,9 \\
\hline 5 & Femur3 & DISTANCIA_SUPERIOR & & 0,0 & 0,7 & 1,3 & 1,9 & 2,5 & 3,2 \\
\hline 5 & Femur12 & DISTANCIA SUPERIOR & & 0,0 & 0,3 & 0,8 & 1,5 & 2,0 & 2,7 \\
\hline 5 & Femur16 & DISTANCIA_SUPERIOR & & 0,0 & 0,3 & 0,4 & 0,8 & 1,1 & 2,3 \\
\hline 5 & Femur22 & DISTANCIA_SUPERIOR & & 0,0 & 0,1 & 0,4 & 0,8 & 1,2 & 1,5 \\
\hline 5 & Femur28 & DISTANCIA_SUPERIOR & & 0,0 & 0,3 & 0,7 & 1,1 & 1,4 & 1,8 \\
\hline \multirow[t]{3}{*}{5} & Femur30 & DISTANCIA_SUPERIOR & & 0,0 & 1,2 & 1,7 & 2,0 & 2,4 & 2,8 \\
\hline & & & M & 0,0 & 0,5 & 0,9 & 1,4 & 1,8 & 2,4 \\
\hline & & & $\mathrm{DP}$ & 0,0 & 0,4 & 0,5 & 0,5 & 0,6 & 0,6 \\
\hline
\end{tabular}


Tabela 5.6- Valores obtidos, em mm, de deslocamentos da porção inferior dos corpos de prova em relação à situação inicial, em cada intervalo dos ensaios realizados, obtidos por análise fotogramétrica, divididos nos grupos estudados, segundo o ensaio de encurvamento- São Paulo - 2007.

\begin{tabular}{|c|c|c|c|c|c|c|c|c|}
\hline GRUPO & FEMUR & & 0 & 12 & 24 & 36 & 48 & 60 \\
\hline 1 & Femur2 & DISTANCIA_INFERIOR & 0,0 & 0,2 & 0,4 & 0,5 & 0,5 & 0,8 \\
\hline 1 & Femur5 & DISTANCIA_INFERIOR & 0,0 & 0,1 & 0,1 & 0,1 & 0,2 & 0,3 \\
\hline 1 & Femur6 & DISTANCIA_INFERIOR & 0,0 & 0,0 & 0,2 & 0,4 & 0,5 & 0,6 \\
\hline 1 & Femur15 & DISTANCIA_INFERIOR & 0,0 & 0,5 & 0,4 & 1,0 & 1,2 & 1,5 \\
\hline 1 & Femur23 & DISTANCIA_INFERIOR & 0,0 & 0,1 & 0,1 & 0,3 & 0,4 & 0,5 \\
\hline \multirow[t]{3}{*}{1} & Femur26 & DISTANCIA_INFERIOR & 0,0 & 0,1 & 0,2 & 0,3 & 0,5 & 0,6 \\
\hline & & M & 0,0 & 0,2 & 0,2 & 0,4 & 0,6 & 0,7 \\
\hline & & DP & 0,0 & 0,2 & 0,1 & 0,3 & 0,3 & 0,4 \\
\hline 2 & Femur1 & DISTANCIA_INFERIOR & 0,0 & 0,0 & 0,1 & 0,1 & 0,2 & 0,3 \\
\hline 2 & Femur8 & DISTANCIA_INFERIOR & 0,0 & 0,2 & 0,3 & 0,6 & 0,7 & 0,8 \\
\hline 2 & Femur13 & DISTANCIA_INFERIOR & 0,0 & 1,8 & 1,7 & 1,6 & 1,5 & 1,5 \\
\hline 2 & Femur14 & DISTANCIA_INFERIOR & 0,0 & 0,1 & 0,1 & 0,2 & 0,3 & 0,3 \\
\hline 2 & Femur19 & DISTANCIA_INFERIOR & 0,0 & 0,1 & 0,0 & 0,2 & 0,3 & 0,3 \\
\hline \multirow[t]{3}{*}{2} & Femur25 & DISTANCIA_INFERIOR & 0,0 & 0,2 & 0,2 & 0,5 & 0,5 & 0,7 \\
\hline & & M & 0,0 & 0,4 & 0,4 & 0,5 & 0,6 & 0,7 \\
\hline & & DP & 0,0 & 0,7 & 0,6 & 0,6 & 0,5 & 0,5 \\
\hline 3 & Femur7 & DISTANCIA_INFERIOR & 0,0 & 0,1 & 0,2 & 0,3 & 0,5 & 0,6 \\
\hline 3 & Femur9 & DISTANCIA_INFERIOR & 0,0 & 0,1 & 0,2 & 0,3 & 0,5 & 0,6 \\
\hline 3 & Femur17 & DISTANCIA_INFERIOR & 0,0 & 0,3 & 0,5 & 0,7 & 0,9 & 1,1 \\
\hline 3 & Femur18 & DISTANCIA_INFERIOR & 0,0 & 0,1 & 0,3 & 0,4 & 0,5 & 0,5 \\
\hline 3 & Femur20 & DISTANCIA_INFERIOR & 0,0 & 0,2 & 0,2 & 0,3 & 0,4 & 0,5 \\
\hline \multirow[t]{3}{*}{3} & Femur24 & DISTANCIA_INFERIOR & 0,0 & 0,1 & 0,2 & 0,5 & 0,7 & 0,9 \\
\hline & & $\mathrm{M}$ & 0,0 & 0,2 & 0,3 & 0,4 & 0,6 & 0,7 \\
\hline & & DP & 0,0 & 0,1 & 0,1 & 0,2 & 0,2 & 0,2 \\
\hline 4 & Femur4 & DISTANCIA_INFERIOR & 0,0 & 0,1 & 0,2 & 0,3 & 0,4 & 0,5 \\
\hline 4 & Femur10 & DISTANCIA_INFERIOR & 0,0 & 0,1 & 0,2 & 0,3 & 0,4 & 0,5 \\
\hline 4 & Femur11 & DISTANCIA_INFERIOR & 0,0 & 0,2 & 0,4 & 0,4 & 0,3 & 0,3 \\
\hline 4 & Femur21 & DISTANCIA_INFERIOR & 0,0 & 0,1 & 0,2 & 0,4 & 0,4 & 0,6 \\
\hline 4 & Femur27 & DISTANCIA_INFERIOR & 0,0 & 0,1 & 0,1 & 0,4 & 0,4 & 0,6 \\
\hline \multirow[t]{3}{*}{4} & Femur29 & DISTANCIA_INFERIOR & 0,0 & 0,2 & 0,4 & 0,6 & 1,0 & 1,1 \\
\hline & & $\mathrm{M}$ & 0,0 & 0,1 & 0,3 & 0,4 & 0,5 & 0,6 \\
\hline & & DP & 0,0 & 0,1 & 0,1 & 0,1 & 0,3 & 0,3 \\
\hline 5 & Femur3 & DISTANCIA_INFERIOR & 0,0 & 0,1 & 0,3 & 0,3 & 0,6 & 0,7 \\
\hline 5 & Femur12 & DISTANCIA_INFERIOR & 0,0 & 0,1 & 0,1 & 0,3 & 0,4 & 0,6 \\
\hline 5 & Femur16 & DISTANCIA_INFERIOR & 0,0 & 0,7 & 0,6 & 0,6 & 0,5 & 0,6 \\
\hline 5 & Femur22 & DISTANCIA_INFERIOR & 0,0 & 0,1 & 0,2 & 0,3 & 0,4 & 0,6 \\
\hline 5 & Femur28 & DISTANCIA_INFERIOR & 0,0 & 0,1 & 0,1 & 0,2 & 0,2 & 0,3 \\
\hline \multirow[t]{3}{*}{5} & Femur30 & DISTANCIA_INFERIOR & 0,0 & 0,2 & 0,4 & 0,6 & 0,7 & 0,9 \\
\hline & & M & 0,0 & 0,2 & 0,3 & 0,4 & 0,5 & 0,6 \\
\hline & & DP & 0,0 & 0,2 & 0,2 & 0,2 & 0,2 & 0,2 \\
\hline
\end{tabular}


Tabela 5.7- Valores obtidos, em $\mathrm{mm}$, de deslocamentos da porção superior dos corpos de prova em relação à porção inferior, em cada intervalo dos ensaios realizados, obtidos por análise fotogramétrica, divididos nos grupos estudados, segundo o ensaio de encurvamento- São Paulo - 2007.

\begin{tabular}{|c|c|c|c|c|c|c|c|c|c|}
\hline GRUPO & FEMUR & & & 0 & 12 & 24 & 36 & 48 & 60 \\
\hline 1 & Femur2 & DISTANCIA_INF-SUP & & 0,0 & 0,0 & 0,2 & 0,3 & 0,4 & 0,4 \\
\hline 1 & Femur5 & DISTANCIA_INF-SUP & & 0,0 & 0,1 & 0,2 & 0,3 & 0,5 & 0,5 \\
\hline 1 & Femur6 & DISTANCIA_INF-SUP & & 0,0 & 0,3 & 0,4 & 0,5 & 0,6 & 0,6 \\
\hline 1 & Femur15 & DISTANCIA_INF-SUP & & 0,0 & 0,1 & 0,1 & 0,3 & 0,3 & 0,4 \\
\hline 1 & Femur23 & DISTANCIA_INF-SUP & & 0,0 & 0,1 & 0,1 & 0,3 & 0,3 & 0,4 \\
\hline \multirow[t]{3}{*}{1} & Femur26 & DISTANCIA_INF-SUP & & 0,0 & 0,3 & 0,5 & 0,6 & 0,7 & 0,8 \\
\hline & & & M & 0,0 & 0,2 & 0,3 & 0,4 & 0,5 & 0,5 \\
\hline & & & DP & 0,0 & 0,1 & 0,2 & 0,1 & 0,2 & 0,2 \\
\hline 2 & Femur1 & DISTANCIA_INF-SUP & & 0,0 & 0,2 & 0,3 & 0,5 & 0,7 & 0,8 \\
\hline 2 & Femur8 & DISTANCIA_INF-SUP & & 0,0 & 0,1 & 0,1 & 0,2 & 0,2 & 0,4 \\
\hline 2 & Femur13 & DISTANCIA_INF-SUP & & 0,0 & 0,0 & 0,1 & 0,0 & 0,2 & 0,2 \\
\hline 2 & Femur14 & DISTANCIA_INF-SUP & & 0,0 & 0,2 & 0,3 & 0,4 & 0,5 & 0,6 \\
\hline 2 & Femur19 & DISTANCIA_INF-SUP & & 0,0 & 0,1 & 0,3 & 0,4 & 0,5 & 0,7 \\
\hline \multirow[t]{3}{*}{2} & Femur25 & DISTANCIA_INF-SUP & & 0,0 & 0,1 & 0,2 & 0,3 & 0,4 & 0,6 \\
\hline & & & M & 0,0 & 0,1 & 0,2 & 0,3 & 0,4 & 0,6 \\
\hline & & & DP & 0,0 & 0,1 & 0,1 & 0,2 & 0,2 & 0,2 \\
\hline 3 & Femur7 & DISTANCIA_INF-SUP & & 0,0 & 0,0 & 0,1 & 0,3 & 0,4 & 0,4 \\
\hline 3 & Femur9 & DISTANCIA_INF-SUP & & 0,0 & 0,1 & 0,3 & 0,3 & 0,5 & 0,7 \\
\hline 3 & Femur17 & DISTANCIA_INF-SUP & & 0,0 & 0,2 & 0,3 & 0,3 & 0,6 & 0,6 \\
\hline 3 & Femur18 & DISTANCIA_INF-SUP & & 0,0 & 0,1 & 0,1 & 0,1 & 0,2 & 0,3 \\
\hline 3 & Femur20 & DISTANCIA_INF-SUP & & 0,0 & 0,0 & 0,2 & 0,2 & 0,3 & 0,4 \\
\hline \multirow[t]{3}{*}{3} & Femur24 & DISTANCIA_INF-SUP & & 0,0 & 0,2 & 0,3 & 0,5 & 0,5 & 0,7 \\
\hline & & & M & 0,0 & 0,1 & 0,2 & 0,3 & 0,4 & 0,5 \\
\hline & & & $\mathrm{DP}$ & 0,0 & 0,1 & 0,1 & 0,1 & 0,1 & 0,2 \\
\hline 4 & Femur4 & DISTANCIA_INF-SUP & & 0,0 & 0,2 & 0,3 & 0,4 & 0,5 & 0,6 \\
\hline 4 & Femur10 & DISTANCIA_INF-SUP & & 0,0 & 0,2 & 0,3 & 0,5 & 0,6 & 0,8 \\
\hline 4 & Femur11 & DISTANCIA_INF-SUP & & 0,0 & 0,3 & 0,6 & 0,8 & 1,0 & 1,2 \\
\hline 4 & Femur21 & DISTANCIA_INF-SUP & & 0,0 & 0,1 & 0,2 & 0,1 & 0,3 & 0,3 \\
\hline 4 & Femur27 & DISTANCIA INF-SUP & & 0,0 & 0,1 & 0,4 & 0,5 & 0,6 & 0,7 \\
\hline \multirow[t]{3}{*}{4} & Femur29 & DISTANCIA_INF-SUP & & 0,0 & 0,2 & 0,3 & 0,4 & 0,4 & 0,5 \\
\hline & & & M & 0,0 & 0,2 & 0,4 & 0,5 & 0,6 & 0,7 \\
\hline & & & DP & 0,0 & 0,1 & 0,1 & 0,2 & 0,2 & 0,3 \\
\hline 5 & Femur3 & DISTANCIA_INF-SUP & & 0,0 & 0,3 & 0,5 & 0,8 & 1,0 & 1,3 \\
\hline 5 & Femur12 & DISTANCIA_INF-SUP & & 0,0 & 0,0 & 0,2 & 0,3 & 0,4 & 0,6 \\
\hline 5 & Femur16 & DISTANCIA_INF-SUP & & 0,0 & 0,1 & 0,2 & 0,3 & 0,3 & 0,6 \\
\hline 5 & Femur22 & DISTANCIA_INF-SUP & & 0,0 & 0,0 & 0,1 & 0,3 & 0,4 & 0,4 \\
\hline 5 & Femur28 & DISTANCIA_INF-SUP & & 0,0 & 0,0 & 0,2 & 0,3 & 0,4 & 0,5 \\
\hline \multirow[t]{3}{*}{5} & Femur30 & DISTANCIA_INF-SUP & & 0,0 & 0,4 & 0,6 & 0,7 & 0,8 & 0,9 \\
\hline & & & M & 0,0 & 0,1 & 0,3 & 0,5 & 0,6 & 0,7 \\
\hline & & & $\mathrm{DP}$ & 0,0 & 0,2 & 0,2 & 0,2 & 0,3 & 0,3 \\
\hline
\end{tabular}


5.2.1.3 Ensaio de Rotação

Os dados obtidos refletem a movimentação interfragmentária tridimensional dos corpos de prova durante o ensaio de rotação. Os dados, apresentados nas tabelas 5.8, 5.9 e 5.10, obtiveram distribuição paramétrica e não apresentaram diferença significativa entre os grupos analisados. 
Tabela 5.8- Valores obtidos, em $\mathrm{mm}$, de deslocamentos da porção superior dos corpos de prova em relação à situação inicial, em cada intervalo dos ensaios realizados, obtidos por análise fotogramétrica, divididos nos grupos estudados, segundo o ensaio de rotação- São Paulo - 2007.

\begin{tabular}{|c|c|c|c|c|c|c|c|c|c|}
\hline GRUPO & FEMUR & & & 0,0 & 0,5 & 1,0 & 1,5 & 2,0 & 2,5 \\
\hline 1 & Femur2 & DISTANCIA_SUPERIOR & & 0,0 & 1,6 & 2,7 & 4,3 & 4,6 & 4,9 \\
\hline 1 & Femur5 & DISTANCIA_SUPERIOR & & 0,0 & 0,3 & 0,7 & 1,0 & 1,2 & 1,5 \\
\hline 1 & Femur6 & DISTANCIA_SUPERIOR & & 0,0 & 3,5 & 4,6 & 5,0 & 5,2 & 5,4 \\
\hline 1 & Femur15 & DISTANCIA_SUPERIOR & & 0,0 & 1,7 & 2,5 & 3,1 & 3,4 & 3,7 \\
\hline 1 & Femur23 & DISTANCIA_SUPERIOR & & 0,0 & 0,3 & 0,4 & 0,6 & 0,7 & 1,0 \\
\hline \multirow[t]{3}{*}{1} & Femur26 & DISTANCIA_SUPERIOR & & 0,0 & 0,2 & 0,5 & 2,1 & 2,6 & 2,9 \\
\hline & & & M & 0,0 & 1,3 & 1,9 & 2,7 & 3,0 & 3,2 \\
\hline & & & DP & 0,0 & 1,3 & 1,7 & 1,8 & 1,8 & 1,8 \\
\hline 2 & Femur1 & DISTANCIA_SUPERIOR & & 0,0 & 4,9 & 5,5 & 5,9 & 6,2 & 6,4 \\
\hline 2 & Femur8 & DISTANCIA_SUPERIOR & & 0,0 & 0,1 & 0,3 & 2,1 & 2,2 & 2,4 \\
\hline 2 & Femur13 & DISTANCIA_SUPERIOR & & 0,0 & 0,2 & 0,8 & 1,5 & 2,1 & 2,9 \\
\hline 2 & Femur14 & DISTANCIA_SUPERIOR & & 0,0 & 3,5 & 3,8 & 3,9 & 4,1 & 4,2 \\
\hline 2 & Femur19 & DISTANCIA_SUPERIOR & & 0,0 & 1,8 & 3,3 & 3,8 & 4,0 & 4,2 \\
\hline \multirow[t]{3}{*}{2} & Femur25 & DISTANCIA_SUPERIOR & & 0,0 & 0,3 & 0,8 & 1,1 & 1,7 & 1,9 \\
\hline & & & M & 0,0 & 1,8 & 2,4 & 3,1 & 3,4 & 3,7 \\
\hline & & & DP & 0,0 & 2,0 & 2,1 & 1,8 & 1,7 & 1,6 \\
\hline 3 & Femur7 & DISTANCIA_SUPERIOR & & 0,0 & 2,2 & 3,4 & 3,9 & 4,1 & 4,3 \\
\hline 3 & Femur9 & DISTANCIA_SUPERIOR & & 0,0 & 3,9 & 5,3 & 5,7 & 5,9 & 6,2 \\
\hline 3 & Femur17 & DISTANCIA_SUPERIOR & & 0,0 & 3,9 & 5,1 & 5,5 & 5,8 & 6,1 \\
\hline 3 & Femur18 & DISTANCIA_SUPERIOR & & 0,0 & 2,5 & 3,1 & 3,5 & 3,6 & 3,9 \\
\hline 3 & Femur20 & DISTANCIA_SUPERIOR & & 0,0 & 0,0 & 0,5 & 2,1 & 2,3 & 2,6 \\
\hline \multirow[t]{3}{*}{3} & Femur24 & DISTANCIA_SUPERIOR & & 0,0 & 0,2 & 1,1 & 2,0 & 2,6 & 3,5 \\
\hline & & & M & 0,0 & 2,1 & 3,1 & 3,8 & 4,1 & 4,4 \\
\hline & & & DP & 0,0 & 1,7 & 2,0 & 1,6 & 1,5 & 1,4 \\
\hline 4 & Femur4 & DISTANCIA_SUPERIOR & & 0,0 & 1,6 & 2,7 & 3,3 & 3,7 & 4,1 \\
\hline 4 & Femur10 & DISTANCIA_SUPERIOR & & 0,0 & 4,3 & 4,8 & 5,1 & 5,3 & 5,6 \\
\hline 4 & Femur11 & DISTANCIA_SUPERIOR & & 0,0 & 0,2 & 3,8 & 4,2 & 4,4 & 4,5 \\
\hline 4 & Femur21 & DISTANCIA_SUPERIOR & & 0,0 & 0,3 & 0,9 & 1,1 & 1,4 & 1,7 \\
\hline 4 & Femur27 & DISTANCIA_SUPERIOR & & 0,0 & 2,4 & 3,4 & 3,9 & 4,9 & 5,4 \\
\hline \multirow[t]{3}{*}{4} & Femur29 & DISTANCIA_SUPERIOR & & 0,0 & 0,3 & 0,9 & 1,4 & 2,1 & 2,4 \\
\hline & & & M & 0,0 & 1,5 & 2,8 & 3,2 & 3,6 & 4,0 \\
\hline & & & DP & 0,0 & 1,6 & 1,6 & 1,6 & 1,6 & 1,6 \\
\hline 5 & Femur3 & DISTANCIA_SUPERIOR & & 0,0 & 6,1 & 6,5 & 6,7 & 6,9 & 7,1 \\
\hline 5 & Femur12 & DISTANCIA_SUPERIOR & & 0,0 & 2,8 & 3,5 & 3,9 & 4,1 & 4,5 \\
\hline 5 & Femur16 & DISTANCIA_SUPERIOR & & 0,0 & 1,0 & 1,8 & 2,1 & 2,2 & 2,3 \\
\hline 5 & Femur22 & DISTANCIA_SUPERIOR & & 0,0 & 0,2 & 1,1 & 1,9 & 2,3 & 2,8 \\
\hline 5 & Femur28 & DISTANCIA_SUPERIOR & & 0,0 & 0,1 & 1,2 & 2,2 & 2,3 & 2,4 \\
\hline \multirow[t]{3}{*}{5} & Femur30 & DISTANCIA_SUPERIOR & & 0,0 & 0,5 & 2,4 & 3,1 & 3,4 & 3,7 \\
\hline & & & M & 0,0 & 1,8 & 2,8 & 3,3 & 3,5 & 3,8 \\
\hline & & & $\mathrm{DP}$ & 0,0 & 2,3 & 2,0 & 1,8 & 1,8 & 1,8 \\
\hline
\end{tabular}


Tabela 5.9- Valores obtidos, em mm, de deslocamentos da porção inferior dos corpos de prova em relação à situação inicial, em cada intervalo dos ensaios realizados, obtidos por análise fotogramétrica, divididos nos grupos estudados, segundo o ensaio de rotaçãoSão Paulo - 2007.

\begin{tabular}{|c|c|c|c|c|c|c|c|c|}
\hline GRUPO & FEMUR & & 0,0 & 0,5 & 1,0 & 1,5 & 2,0 & 2,5 \\
\hline 1 & Femur2 & DISTANCIA_INFERIOR & 0,0 & 0,1 & 0,1 & 0,1 & 0,0 & 0,1 \\
\hline 1 & Femur5 & DISTANCIA_INFERIOR & 0,0 & 0,0 & 0,0 & 0,0 & 0,1 & 0,1 \\
\hline 1 & Femur6 & DISTANCIA_INFERIOR & 0,0 & 0,1 & 0,1 & 0,1 & 0,1 & 0,1 \\
\hline 1 & Femur15 & DISTANCIA_INFERIOR & 0,0 & 0,1 & 0,2 & 0,3 & 0,4 & 0,4 \\
\hline 1 & Femur23 & DISTANCIA_INFERIOR & 0,0 & 0,0 & 0,1 & 0,1 & 0,1 & 0,2 \\
\hline \multirow[t]{3}{*}{1} & Femur26 & DISTANCIA_INFERIOR & 0,0 & 0,1 & 0,1 & 0,1 & 0,2 & 0,1 \\
\hline & & M & 0,0 & 0,1 & 0,1 & 0,1 & 0,2 & 0,2 \\
\hline & & DP & 0,0 & 0,1 & 0,1 & 0,1 & 0,1 & 0,1 \\
\hline 2 & Femur1 & DISTANCIA_INFERIOR & 0,0 & 0,1 & 0,2 & 0,2 & 0,2 & 0,2 \\
\hline 2 & Femur8 & DISTANCIA_INFERIOR & 0,0 & 0,1 & 0,0 & 0,1 & 0,0 & 0,1 \\
\hline 2 & Femur13 & DISTANCIA_INFERIOR & 0,0 & 0,0 & 0,0 & 0,1 & 0,1 & 0,1 \\
\hline 2 & Femur14 & DISTANCIA_INFERIOR & 0,0 & 0,3 & 0,4 & 0,3 & 0,4 & 0,4 \\
\hline 2 & Femur19 & DISTANCIA_INFERIOR & 0,0 & 0,1 & 0,1 & 0,2 & 0,1 & 0,2 \\
\hline \multirow[t]{3}{*}{2} & Femur25 & DISTANCIA_INFERIOR & 0,0 & 0,1 & 0,1 & 0,2 & 0,2 & 0,2 \\
\hline & & M & 0,0 & 0,1 & 0,1 & 0,2 & 0,2 & 0,2 \\
\hline & & DP & 0,0 & 0,1 & 0,2 & 0,1 & 0,1 & 0,1 \\
\hline 3 & Femur7 & DISTANCIA_INFERIOR & 0,0 & 0,2 & 0,3 & 0,3 & 0,4 & 0,3 \\
\hline 3 & Femur9 & DISTANCIA_INFERIOR & 0,0 & 0,1 & 0,1 & 0,1 & 0,1 & 0,1 \\
\hline 3 & Femur17 & DISTANCIA_INFERIOR & 0,0 & 0,1 & 0,2 & 0,1 & 0,1 & 0,1 \\
\hline 3 & Femur18 & DISTANCIA_INFERIOR & 0,0 & 0,1 & 0,1 & 0,1 & 0,1 & 0,1 \\
\hline 3 & Femur20 & DISTANCIA_INFERIOR & 0,0 & 0,1 & 0,1 & 0,1 & 0,1 & 0,1 \\
\hline \multirow[t]{3}{*}{3} & Femur24 & DISTANCIA_INFERIOR & 0,0 & 0,1 & 0,1 & 0,1 & 0,2 & 0,2 \\
\hline & & M & 0,0 & 0,1 & 0,2 & 0,1 & 0,2 & 0,2 \\
\hline & & DP & 0,0 & 0,0 & 0,1 & 0,1 & 0,1 & 0,1 \\
\hline 4 & Femur4 & DISTANCIA_INFERIOR & 0,0 & 0,1 & 0,1 & 0,1 & 0,1 & 0,2 \\
\hline 4 & Femur10 & DISTANCIA_INFERIOR & 0,0 & 0,1 & 0,1 & 0,1 & 0,2 & 0,2 \\
\hline 4 & Femur11 & DISTANCIA_INFERIOR & 0,0 & 0,1 & 0,1 & 0,1 & 0,1 & 0,2 \\
\hline 4 & Femur21 & DISTANCIA_INFERIOR & 0,0 & 0,1 & 0,2 & 0,1 & 0,2 & 0,3 \\
\hline 4 & Femur27 & DISTANCIA_INFERIOR & 0,0 & 0,2 & 0,2 & 0,2 & 0,5 & 0,5 \\
\hline \multirow[t]{3}{*}{4} & Femur29 & DISTANCIA_INFERIOR & 0,0 & 0,1 & 0,1 & 0,1 & 0,1 & 0,1 \\
\hline & & M & 0,0 & 0,1 & 0,1 & 0,1 & 0,2 & 0,3 \\
\hline & & DP & 0,0 & 0,0 & 0,1 & 0,0 & 0,2 & 0,1 \\
\hline 5 & Femur3 & DISTANCIA_INFERIOR & 0,0 & 0,1 & 0,1 & 0,2 & 0,2 & 0,2 \\
\hline 5 & Femur12 & DISTANCIA_INFERIOR & 0,0 & 0,0 & 0,0 & 0,1 & 0,1 & 0,1 \\
\hline 5 & Femur16 & DISTANCIA_INFERIOR & 0,0 & 0,1 & 0,1 & 0,2 & 0,2 & 0,2 \\
\hline 5 & Femur22 & DISTANCIA_INFERIOR & 0,0 & 0,0 & 0,1 & 0,1 & 0,1 & 0,1 \\
\hline 5 & Femur28 & DISTANCIA_INFERIOR & 0,0 & 0,0 & 0,0 & 0,1 & 0,1 & 0,2 \\
\hline \multirow[t]{3}{*}{5} & Femur30 & DISTANCIA_INFERIOR & 0,0 & 0,0 & 0,1 & 0,1 & 0,1 & 0,1 \\
\hline & & M & 0,0 & 0,0 & 0,1 & 0,1 & 0,1 & 0,2 \\
\hline & & $\mathrm{DP}$ & 0,0 & 0,1 & 0,1 & 0,1 & 0,1 & 0,1 \\
\hline
\end{tabular}


Tabela 5.10- Valores obtidos, em mm, de deslocamentos da porção superior dos corpos de prova em relação à porção inferior, em cada intervalo dos ensaios realizados, obtidos por análise fotogramétrica, divididos nos grupos estudados, segundo o ensaio de rotação- São Paulo - 2007.

\begin{tabular}{|c|c|c|c|c|c|c|c|c|c|}
\hline GRUPO & FEMUR & & & 0,0 & 0,5 & 1,0 & 1,5 & 2,0 & 2,5 \\
\hline 1 & Femur2 & DISTANCIA_INF-SUP & & 0,0 & 0,1 & 0,0 & 0,1 & 0,0 & 0,1 \\
\hline 1 & Femur5 & DISTANCIA_INF-SUP & & 0,0 & 0,1 & 0,2 & 0,2 & 0,2 & 0,3 \\
\hline 1 & Femur6 & DISTANCIA_INF-SUP & & 0,0 & 0,4 & 0,5 & 0,5 & 0,5 & 0,5 \\
\hline 1 & Femur15 & DISTANCIA_INF-SUP & & 0,0 & 0,2 & 0,3 & 0,3 & 0,4 & 0,5 \\
\hline 1 & Femur23 & DISTANCIA_INF-SUP & & 0,0 & 0,1 & 0,0 & 0,1 & 0,1 & 0,2 \\
\hline \multirow[t]{3}{*}{1} & Femur26 & DISTANCIA_INF-SUP & & 0,0 & 0,0 & 0,1 & 0,1 & 0,1 & 0,0 \\
\hline & & & M & 0,0 & 0,2 & 0,2 & 0,2 & 0,2 & 0,3 \\
\hline & & & DP & 0,0 & 0,1 & 0,2 & 0,2 & 0,2 & 0,2 \\
\hline 2 & Femur1 & DISTANCIA_INF-SUP & & 0,0 & 0,2 & 0,2 & 0,2 & 0,2 & 0,2 \\
\hline 2 & Femur8 & DISTANCIA_INF-SUP & & 0,0 & 0,1 & 0,0 & 0,1 & 0,1 & 0,1 \\
\hline 2 & Femur13 & DISTANCIA_INF-SUP & & 0,0 & 0,0 & 0,1 & 0,2 & 0,2 & 0,3 \\
\hline 2 & Femur14 & DISTANCIA_INF-SUP & & 0,0 & 0,4 & 0,5 & 0,5 & 0,5 & 0,5 \\
\hline 2 & Femur19 & DISTANCIA_INF-SUP & & 0,0 & 0,1 & 0,2 & 0,2 & 0,2 & 0,2 \\
\hline \multirow[t]{3}{*}{2} & Femur25 & DISTANCIA_INF-SUP & & 0,0 & 0,0 & 0,0 & 0,1 & 0,1 & 0,0 \\
\hline & & & M & 0,0 & 0,1 & 0,2 & 0,2 & 0,2 & 0,2 \\
\hline & & & $\mathrm{DP}$ & 0,0 & 0,2 & 0,2 & 0,1 & 0,1 & 0,2 \\
\hline 3 & Femur7 & DISTANCIA_INF-SUP & & 0,0 & 0,1 & 0,0 & 0,1 & 0,1 & 0,1 \\
\hline 3 & Femur9 & DISTANCIA_INF-SUP & & 0,0 & 0,5 & 0,7 & 0,8 & 0,8 & 1,0 \\
\hline 3 & Femur17 & DISTANCIA INF-SUP & & 0,0 & 0,4 & 0,6 & 0,7 & 0,7 & 0,7 \\
\hline 3 & Femur18 & DISTANCIA INF-SUP & & 0,0 & 0,1 & 0,2 & 0,3 & 0,3 & 0,3 \\
\hline 3 & Femur20 & DISTANCIA INF-SUP & & 0,0 & 0,1 & 0,0 & 0,3 & 0,4 & 0,4 \\
\hline \multirow[t]{3}{*}{3} & Femur24 & DISTANCIA_INF-SUP & & 0,0 & 0,1 & 0,0 & 0,1 & 0,0 & 0,1 \\
\hline & & & M & 0,0 & 0,2 & 0,3 & 0,4 & 0,4 & 0,4 \\
\hline & & & $\mathrm{DP}$ & 0,0 & 0,2 & 0,3 & 0,3 & 0,3 & 0,4 \\
\hline 4 & Femur4 & DISTANCIA_INF-SUP & & 0,0 & 0,1 & 0,3 & 0,4 & 0,4 & 0,5 \\
\hline 4 & Femur10 & DISTANCIA INF-SUP & & 0,0 & 0,1 & 0,1 & 0,0 & 0,1 & 0,0 \\
\hline 4 & Femur11 & DISTANCIA INF-SUP & & 0,0 & 0,0 & 0,3 & 0,4 & 0,4 & 0,4 \\
\hline 4 & Femur21 & DISTANCIA INF-SUP & & 0,0 & 0,1 & 0,1 & 0,2 & 0,2 & 0,3 \\
\hline 4 & Femur27 & DISTANCIA_INF-SUP & & 0,0 & 0,1 & 0,0 & 0,1 & 0,1 & 0,1 \\
\hline \multirow[t]{3}{*}{4} & Femur29 & DISTANCIA_INF-SUP & & 0,0 & 0,1 & 0,2 & 0,2 & 0,3 & 0,3 \\
\hline & & & M & 0,0 & 0,1 & 0,2 & 0,2 & 0,3 & 0,3 \\
\hline & & & DP & 0,0 & 0,0 & 0,1 & 0,2 & 0,1 & 0,2 \\
\hline 5 & Femur3 & DISTANCIA_INF-SUP & & 0,0 & 0,3 & 0,3 & 0,2 & 0,2 & 0,1 \\
\hline 5 & Femur12 & DISTANCIA_INF-SUP & & 0,0 & 0,0 & 0,0 & 0,0 & 0,0 & 0,1 \\
\hline 5 & Femur16 & DISTANCIA_INF-SUP & & 0,0 & 0,1 & 0,1 & 0,1 & 0,2 & 0,1 \\
\hline 5 & Femur22 & DISTANCIA_INF-SUP & & 0,0 & 0,1 & 0,3 & 0,4 & 0,4 & 0,5 \\
\hline 5 & Femur28 & DISTANCIA_INF-SUP & & 0,0 & 0,0 & 0,1 & 0,1 & 0,1 & 0,2 \\
\hline \multirow[t]{3}{*}{5} & Femur30 & DISTANCIA_INF-SUP & & 0,0 & 0,0 & 0,0 & 0,0 & 0,1 & 0,1 \\
\hline & & & M & 0,0 & 0,1 & 0,1 & 0,1 & 0,2 & 0,2 \\
\hline & & & $\mathrm{DP}$ & 0,0 & 0,1 & 0,1 & 0,2 & 0,1 & 0,2 \\
\hline
\end{tabular}




\subsubsection{Análise de deslocamento nos eixos $X, Y$ e $Z$ em relação a $0 \mathrm{~N}$}

Tal análise permite demonstrar o desmembramento da movimentação dos corpos de prova em relação a cada eixo. Estes resultados demonstram que as forças utilizadas para os ensaios de compressão, encurvamento e rotação não estão sendo dissipadas em outro sentido, produzindo ensaios mistos. No entanto, são apontados deslocamentos menores, com diferença estatística significativa, nos eixos secundários em cada ensaio, que comprovam os seis graus de liberdade permitidos em cada análise.

\subsubsection{Ensaio de compressão}

Os dados obtidos refletem a movimentação interfragmentária das porções superior e inferior dos corpos de prova em cada eixo espacial, durante o ensaio de compressão. A análise dos dados, apresentados nas tabelas 5.11, 5.12, 5.13, 5.14, 5.15 e 5.16, demonstrou distribuição não paramétrica, não apresentando diferença significativa entre os grupos analisados. 
Tabela 5.11- Valores obtidos, em mm, de deslocamentos da porção superior dos corpos de prova em relação à situação inicial, em cada intervalo dos ensaios realizados, obtidos por análise fotogramétrica, segundo a coordenada espacial $X$, nos ensaios de compressão- São Paulo - 2007.

\begin{tabular}{|c|c|c|c|c|c|c|c|c|}
\hline GRUPO & FEMUR & & 0 & 40 & 80 & 120 & 160 & 200 \\
\hline 1 & Femur2 & X_DESLOCAMENTO_SUPERIOR & 0,0 & 0,1 & 0,1 & 0,2 & 0,2 & 0,3 \\
\hline 1 & Femur5 & X_DESLOCAMENTO_SUPERIOR & 0,0 & 0,0 & 0,0 & 0,1 & 0,1 & 0,1 \\
\hline 1 & Femur6 & X_DESLOCAMENTO_SUPERIOR & 0,0 & 0,1 & 0,2 & 0,2 & 0,2 & 0,3 \\
\hline 1 & Femur15 & X_DESLOCAMENTO_SUPERIOR & 0,0 & 0,1 & 0,1 & 0,2 & 0,3 & 0,3 \\
\hline 1 & Femur23 & X_DESLOCAMENTO_SUPERIOR & 0,0 & 0,1 & 0,1 & 0,0 & 0,0 & 0,1 \\
\hline \multirow[t]{3}{*}{1} & Femur26 & X_DESLOCAMENTO_SUPERIOR & 0,0 & 0,1 & 0,2 & 0,1 & 0,2 & 0,2 \\
\hline & & M & 0,0 & 0,1 & 0,1 & 0,1 & 0,2 & 0,2 \\
\hline & & DP & 0,0 & 0,0 & 0,1 & 0,1 & 0,1 & 0,1 \\
\hline 2 & Femur1 & X_DESLOCAMENTO_SUPERIOR & 0,0 & 0,1 & 0,1 & 0,1 & 0,1 & 0,1 \\
\hline 2 & Femur8 & X_DESLOCAMENTO_SUPERIOR & 0,0 & 0,0 & 0,0 & 0,1 & 0,1 & 0,1 \\
\hline 2 & Femur13 & X_DESLOCAMENTO_SUPERIOR & 0,0 & 0,1 & 0,0 & 0,1 & 0,0 & 0,2 \\
\hline 2 & Femur14 & X_DESLOCAMENTO_SUPERIOR & 0,0 & 0,0 & 0,9 & 1,0 & 0,9 & 1,0 \\
\hline 2 & Femur19 & X_DESLOCAMENTO_SUPERIOR & 0,0 & 0,0 & 0,0 & 0,1 & 0,1 & 0,1 \\
\hline \multirow[t]{3}{*}{2} & Femur25 & X_DESLOCAMENTO_SUPERIOR & 0,0 & 0,2 & 0,1 & 0,1 & 0,0 & 0,1 \\
\hline & & M & 0,0 & 0,1 & 0,2 & 0,3 & 0,2 & 0,3 \\
\hline & & DP & 0,0 & 0,1 & 0,4 & 0,4 & 0,3 & 0,4 \\
\hline 3 & Femur7 & X_DESLOCAMENTO_SUPERIOR & 0,0 & 0,1 & 0,1 & 0,0 & 0,1 & 0,1 \\
\hline 3 & Femur9 & X_DESLOCAMENTO_SUPERIOR & 0,0 & 0,0 & 0,1 & 0,3 & 0,4 & 0,5 \\
\hline 3 & Femur17 & X_DESLOCAMENTO_SUPERIOR & 0,0 & 0,1 & 0,1 & 0,1 & 0,2 & 0,1 \\
\hline 3 & Femur18 & X_DESLOCAMENTO_SUPERIOR & 0,0 & 0,0 & 0,2 & 0,3 & 0,4 & 0,4 \\
\hline 3 & Femur20 & X_DESLOCAMENTO_SUPERIOR & 0,0 & 0,0 & 0,1 & 0,0 & 0,1 & 0,0 \\
\hline \multirow[t]{3}{*}{3} & Femur24 & X_DESLOCAMENTO_SUPERIOR & 0,0 & 0,1 & 0,3 & 0,4 & 0,5 & 0,4 \\
\hline & & M & 0,0 & 0,1 & 0,2 & 0,2 & 0,3 & 0,3 \\
\hline & & DP & 0,0 & 0,1 & 0,1 & 0,2 & 0,2 & 0,2 \\
\hline 4 & Femur4 & X_DESLOCAMENTO_SUPERIOR & 0,0 & 0,0 & 0,0 & 0,2 & 0,1 & 0,1 \\
\hline 4 & Femur10 & X_DESLOCAMENTO_SUPERIOR & 0,0 & 0,0 & 0,1 & 0,2 & 0,3 & 0,4 \\
\hline 4 & Femur11 & X_DESLOCAMENTO_SUPERIOR & 0,0 & 0,1 & 0,2 & 0,2 & 0,3 & 0,2 \\
\hline 4 & Femur21 & X_DESLOCAMENTO_SUPERIOR & 0,0 & 0,0 & 0,0 & 0,1 & 0,0 & 0,0 \\
\hline 4 & Femur27 & X_DESLOCAMENTO_SUPERIOR & 0,0 & 0,0 & 0,0 & 0,0 & 0,1 & 0,2 \\
\hline \multirow[t]{3}{*}{4} & Femur29 & X_DESLOCAMENTO_SUPERIOR & 0,0 & 0,0 & 0,1 & 0,2 & 0,1 & 0,2 \\
\hline & & M & 0,0 & 0,0 & 0,1 & 0,2 & 0,2 & 0,2 \\
\hline & & DP & 0,0 & 0,0 & 0,1 & 0,1 & 0,1 & 0,1 \\
\hline 5 & Femur3 & X_DESLOCAMENTO_SUPERIOR & 0,0 & 0,5 & 0,7 & 0,8 & 0,9 & 0,8 \\
\hline 5 & Femur12 & X_DESLOCAMENTO_SUPERIOR & 0,0 & 0,3 & 0,3 & 0,4 & 0,4 & 0,4 \\
\hline 5 & Femur16 & X_DESLOCAMENTO_SUPERIOR & 0,0 & 0,1 & 0,1 & 0,1 & 0,2 & 0,3 \\
\hline 5 & Femur22 & X_DESLOCAMENTO_SUPERIOR & 0,0 & 0,1 & 0,0 & 0,1 & 0,0 & 0,0 \\
\hline 5 & Femur28 & X_DESLOCAMENTO_SUPERIOR & 0,0 & 0,8 & 0,9 & 0,8 & 0,9 & 1,3 \\
\hline \multirow[t]{3}{*}{5} & Femur30 & X_DESLOCAMENTO_SUPERIOR & 0,0 & 0,3 & 0,3 & 0,3 & 0,3 & 0,4 \\
\hline & & M & 0,0 & 0,4 & 0,4 & 0,4 & 0,5 & 0,5 \\
\hline & & DP & 0,0 & 0,3 & 0,3 & 0,3 & 0,4 & 0,5 \\
\hline
\end{tabular}


Tabela 5.12- Valores obtidos, em mm, de deslocamentos da porção inferior dos corpos de prova em relação à situação inicial, em cada intervalo dos ensaios realizados, obtidos por análise fotogramétrica, segundo a coordenada espacial $X$, nos ensaios de compressãoSão Paulo - 2007.

\begin{tabular}{|c|c|c|c|c|c|c|c|c|}
\hline GRUPO & FEMUR & & 0 & 40 & 80 & 120 & 160 & 200 \\
\hline 1 & Femur2 & X_DESLOCAMENTO_INFERIOR & 0,0 & 0,1 & 0,1 & 0,1 & 0,1 & 0,1 \\
\hline 1 & Femur5 & X_DESLOCAMENTO_INFERIOR & 0,0 & 0,0 & 0,0 & 0,0 & 0,0 & 0,0 \\
\hline 1 & Femur6 & X_DESLOCAMENTO_INFERIOR & 0,0 & 0,1 & 0,1 & 0,1 & 0,1 & 0,1 \\
\hline 1 & Femur15 & X_DESLOCAMENTO_INFERIOR & 0,0 & 0,0 & 0,0 & 0,0 & 0,1 & 0,2 \\
\hline 1 & Femur23 & X_DESLOCAMENTO_INFERIOR & 0,0 & 0,0 & 0,0 & 0,0 & 0,0 & 0,1 \\
\hline \multirow[t]{3}{*}{1} & Femur26 & X_DESLOCAMENTO_INFERIOR & 0,0 & 0,0 & 0,1 & 0,1 & 0,1 & 0,1 \\
\hline & & M & 0,0 & 0,0 & 0,1 & 0,1 & 0,1 & 0,1 \\
\hline & & DP & 0,0 & 0,1 & 0,1 & 0,1 & 0,1 & 0,1 \\
\hline 2 & Femur1 & X_DESLOCAMENTO_INFERIOR & 0,0 & 0,1 & 0,0 & 0,0 & 0,0 & 0,1 \\
\hline 2 & Femur8 & X_DESLOCAMENTO_INFERIOR & 0,0 & 0,0 & 0,0 & 0,0 & 0,0 & 0,1 \\
\hline 2 & Femur13 & X_DESLOCAMENTO_INFERIOR & 0,0 & 0,1 & 0,1 & 0,1 & 0,1 & 0,1 \\
\hline 2 & Femur14 & X_DESLOCAMENTO_INFERIOR & 0,0 & 0,0 & 0,9 & 0,9 & 0,9 & 0,9 \\
\hline 2 & Femur19 & X_DESLOCAMENTO_INFERIOR & 0,0 & 0,1 & 0,0 & 0,1 & 0,1 & 0,0 \\
\hline \multirow[t]{3}{*}{2} & Femur25 & X_DESLOCAMENTO_INFERIOR & 0,0 & 0,0 & 0,1 & 0,1 & 0,0 & 0,0 \\
\hline & & M & 0,0 & 0,1 & 0,2 & 0,2 & 0,2 & 0,2 \\
\hline & & DP & 0,0 & 0,1 & 0,4 & 0,3 & 0,4 & 0,3 \\
\hline 3 & Femur7 & X_DESLOCAMENTO_INFERIOR & 0,0 & 0,0 & 0,1 & 0,1 & 0,0 & 0,0 \\
\hline 3 & Femur9 & X_DESLOCAMENTO_INFERIOR & 0,0 & 0,1 & 0,1 & 0,1 & 0,1 & 0,1 \\
\hline 3 & Femur17 & X_DESLOCAMENTO_INFERIOR & 0,0 & 0,0 & 0,0 & 0,0 & 0,0 & 0,1 \\
\hline 3 & Femur18 & X_DESLOCAMENTO_INFERIOR & 0,0 & 0,1 & 0,1 & 0,2 & 0,0 & 0,2 \\
\hline 3 & Femur20 & X_DESLOCAMENTO_INFERIOR & 0,0 & 0,0 & 0,0 & 0,0 & 0,1 & 0,0 \\
\hline \multirow[t]{3}{*}{3} & Femur24 & X_DESLOCAMENTO_INFERIOR & 0,0 & 0,0 & 0,1 & 0,1 & 0,1 & 0,1 \\
\hline & & M & 0,0 & 0,0 & 0,1 & 0,1 & 0,1 & 0,1 \\
\hline & & DP & 0,0 & 0,1 & 0,1 & 0,1 & 0,1 & 0,1 \\
\hline 4 & Femur4 & X_DESLOCAMENTO_INFERIOR & 0,0 & 0,1 & 0,1 & 0,0 & 0,0 & 0,0 \\
\hline 4 & Femur10 & X_DESLOCAMENTO_INFERIOR & 0,0 & 0,1 & 0,0 & 0,0 & 0,1 & 0,1 \\
\hline 4 & Femur11 & X_DESLOCAMENTO_INFERIOR & 0,0 & 0,0 & 0,1 & 0,1 & 0,2 & 0,1 \\
\hline 4 & Femur21 & X_DESLOCAMENTO_INFERIOR & 0,0 & 0,1 & 0,0 & 0,0 & 0,0 & 0,1 \\
\hline 4 & Femur27 & X_DESLOCAMENTO_INFERIOR & 0,0 & 0,1 & 0,1 & 0,1 & 0,1 & 0,1 \\
\hline \multirow[t]{3}{*}{4} & Femur29 & X_DESLOCAMENTO_INFERIOR & 0,0 & 0,0 & 0,0 & 0,0 & 0,1 & 0,2 \\
\hline & & M & 0,0 & 0,1 & 0,1 & 0,0 & 0,1 & 0,1 \\
\hline & & DP & 0,0 & 0,1 & 0,1 & 0,1 & 0,1 & 0,1 \\
\hline 5 & Femur3 & X_DESLOCAMENTO_INFERIOR & 0,0 & 0,1 & 0,2 & 0,3 & 0,2 & 0,2 \\
\hline 5 & Femur12 & X_DESLOCAMENTO_INFERIOR & 0,0 & 0,4 & 0,4 & 0,4 & 0,5 & 0,5 \\
\hline 5 & Femur16 & X_DESLOCAMENTO_INFERIOR & 0,0 & 0,1 & 0,1 & 0,1 & 0,2 & 0,2 \\
\hline 5 & Femur22 & X_DESLOCAMENTO_INFERIOR & 0,0 & 0,0 & 0,0 & 0,0 & 0,1 & 0,0 \\
\hline 5 & Femur28 & X_DESLOCAMENTO_INFERIOR & 0,0 & 0,8 & 0,8 & 0,7 & 0,7 & 1,2 \\
\hline \multirow[t]{3}{*}{5} & Femur30 & X_DESLOCAMENTO_INFERIOR & 0,0 & 0,2 & 0,1 & 0,2 & 0,2 & 0,2 \\
\hline & & $M$ & 0,0 & 0,3 & 0,3 & 0,3 & 0,3 & 0,4 \\
\hline & & DP & 0,0 & 0,3 & 0,3 & 0,2 & 0,2 & 0,4 \\
\hline
\end{tabular}


Tabela 5.13- Valores obtidos, em $\mathrm{mm}$, de deslocamentos da porção superior dos corpos de prova em relação à situação inicial, em cada intervalo dos ensaios realizados, obtidos por análise fotogramétrica, segundo a coordenada espacial $\mathrm{Y}$, nos ensaios de compressão- São Paulo - 2007.

\begin{tabular}{|c|c|c|c|c|c|c|c|c|}
\hline GRUPO & FEMUR & & 0 & 40 & 80 & 120 & 160 & 200 \\
\hline 1 & Femur2 & Y_DESLOCAMENTO_SUPERIOR & 0,0 & 0,0 & 0,1 & 0,1 & 0,2 & 0,1 \\
\hline 1 & Femur5 & Y_DESLOCAMENTO_SUPERIOR & 0,0 & 0,0 & 0,0 & 0,1 & 0,1 & 0,1 \\
\hline 1 & Femur6 & Y_DESLOCAMENTO_SUPERIOR & 0,0 & 0,1 & 0,2 & 0,2 & 0,3 & 0,3 \\
\hline 1 & Femur15 & Y_DESLOCAMENTO_SUPERIOR & 0,0 & 0,0 & 0,0 & 0,1 & 0,1 & 0,2 \\
\hline 1 & Femur23 & Y_DESLOCAMENTO_SUPERIOR & 0,0 & 0,0 & 0,0 & 0,1 & 0,1 & 0,1 \\
\hline \multirow[t]{3}{*}{1} & Femur26 & Y_DESLOCAMENTO_SUPERIOR & 0,0 & 0,0 & 0,1 & 0,1 & 0,2 & 0,2 \\
\hline & & M & 0,0 & 0,0 & 0,1 & 0,1 & 0,2 & 0,2 \\
\hline & & DP & 0,0 & 0,0 & 0,1 & 0,0 & 0,1 & 0,1 \\
\hline 2 & Femur1 & Y_DESLOCAMENTO_SUPERIOR & 0,0 & 0,1 & 0,1 & 0,0 & 0,0 & 0,0 \\
\hline 2 & Femur8 & Y_DESLOCAMENTO_SUPERIOR & 0,0 & 0,1 & 0,1 & 0,1 & 0,2 & 0,2 \\
\hline 2 & Femur13 & Y_DESLOCAMENTO_SUPERIOR & 0,0 & 0,2 & 0,2 & 0,2 & 0,3 & 0,4 \\
\hline 2 & Femur14 & Y_DESLOCAMENTO_SUPERIOR & 0,0 & 0,4 & 0,0 & 0,0 & 0,0 & 0,0 \\
\hline 2 & Femur19 & Y_DESLOCAMENTO_SUPERIOR & 0,0 & 0,1 & 0,1 & 0,1 & 0,1 & 0,2 \\
\hline \multirow[t]{3}{*}{2} & Femur25 & Y_DESLOCAMENTO_SUPERIOR & 0,0 & 0,3 & 0,4 & 0,3 & 0,2 & 0,2 \\
\hline & & M & 0,0 & 0,2 & 0,2 & 0,1 & 0,1 & 0,2 \\
\hline & & DP & 0,0 & 0,1 & 0,1 & 0,1 & 0,1 & 0,2 \\
\hline 3 & Femur7 & Y_DESLOCAMENTO_SUPERIOR & 0,0 & 0,2 & 0,4 & 0,6 & 0,7 & 0,9 \\
\hline 3 & Femur9 & Y_DESLOCAMENTO_SUPERIOR & 0,0 & 0,2 & 0,3 & 0,5 & 0,5 & 0,7 \\
\hline 3 & Femur17 & Y_DESLOCAMENTO_SUPERIOR & 0,0 & 0,1 & 0,1 & 0,1 & 0,0 & 0,0 \\
\hline 3 & Femur18 & Y_DESLOCAMENTO_SUPERIOR & 0,0 & 0,1 & 0,2 & 0,3 & 0,3 & 0,3 \\
\hline 3 & Femur20 & Y_DESLOCAMENTO_SUPERIOR & 0,0 & 0,1 & 0,1 & 0,1 & 0,0 & 0,0 \\
\hline \multirow[t]{3}{*}{3} & Femur24 & Y_DESLOCAMENTO_SUPERIOR & 0,0 & 0,1 & 0,3 & 0,4 & 0,6 & 0,6 \\
\hline & & M & 0,0 & 0,1 & 0,2 & 0,3 & 0,4 & 0,4 \\
\hline & & DP & 0,0 & 0,1 & 0,1 & 0,2 & 0,3 & 0,4 \\
\hline 4 & Femur4 & Y_DESLOCAMENTO_SUPERIOR & 0,0 & 0,1 & 0,2 & 0,2 & 0,2 & 0,2 \\
\hline 4 & Femur10 & Y_DESLOCAMENTO_SUPERIOR & 0,0 & 0,1 & 0,1 & 0,1 & 0,1 & 0,2 \\
\hline 4 & Femur11 & Y_DESLOCAMENTO_SUPERIOR & 0,0 & 0,2 & 0,3 & 0,5 & 0,7 & 0,9 \\
\hline 4 & Femur21 & Y_DESLOCAMENTO_SUPERIOR & 0,0 & 0,0 & 0,0 & 0,1 & 0,1 & 0,2 \\
\hline 4 & Femur27 & Y_DESLOCAMENTO_SUPERIOR & 0,0 & 0,0 & 0,0 & 0,0 & 0,1 & 0,1 \\
\hline \multirow[t]{3}{*}{4} & Femur29 & Y_DESLOCAMENTO_SUPERIOR & 0,0 & 0,0 & 0,0 & 0,1 & 0,1 & 0,1 \\
\hline & & M & 0,0 & 0,1 & 0,1 & 0,2 & 0,2 & 0,3 \\
\hline & & DP & 0,0 & 0,1 & 0,1 & 0,2 & 0,2 & 0,3 \\
\hline 5 & Femur3 & Y_DESLOCAMENTO_SUPERIOR & 0,0 & 0,5 & 1,2 & 1,4 & 1,5 & 1,6 \\
\hline 5 & Femur12 & Y_DESLOCAMENTO_SUPERIOR & 0,0 & 0,3 & 0,4 & 0,3 & 0,4 & 0,4 \\
\hline 5 & Femur16 & Y_DESLOCAMENTO_SUPERIOR & 0,0 & 0,2 & 0,4 & 0,4 & 0,6 & 0,6 \\
\hline 5 & Femur22 & Y_DESLOCAMENTO_SUPERIOR & 0,0 & 0,0 & 0,1 & 0,2 & 0,4 & 0,6 \\
\hline 5 & Femur28 & Y_DESLOCAMENTO_SUPERIOR & 0,0 & 0,5 & 0,6 & 0,6 & 0,7 & 0,9 \\
\hline \multirow[t]{3}{*}{5} & Femur30 & Y_DESLOCAMENTO_SUPERIOR & 0,0 & 0,0 & 0,0 & 0,0 & 0,2 & 0,3 \\
\hline & & M & 0,0 & 0,3 & 0,5 & 0,5 & 0,6 & 0,7 \\
\hline & & DP & 0,0 & 0,2 & 0,4 & 0,5 & 0,5 & 0,5 \\
\hline
\end{tabular}


Tabela 5.14- Valores obtidos, em mm, de deslocamentos da porção inferior dos corpos de prova em relação à situação inicial, em cada intervalo dos ensaios realizados, obtidos por análise fotogramétrica, segundo a coordenada espacial $Y$, nos ensaios de compressãoSão Paulo - 2007.

\begin{tabular}{|c|c|c|c|c|c|c|c|c|}
\hline GRUPO & FEMUR & & 0 & 40 & 80 & 120 & 160 & 200 \\
\hline 1 & Femur2 & Y_DESLOCAMENTO_INFERIOR & 0,0 & 0,0 & 0,1 & 0,0 & 0,0 & 0,1 \\
\hline 1 & Femur5 & Y_DESLOCAMENTO_INFERIOR & 0,0 & 0,0 & 0,0 & 0,0 & 0,1 & 0,1 \\
\hline 1 & Femur6 & Y_DESLOCAMENTO_INFERIOR & 0,0 & 0,0 & 0,0 & 0,0 & 0,0 & 0,0 \\
\hline 1 & Femur15 & Y_DESLOCAMENTO_INFERIOR & 0,0 & 0,0 & 0,0 & 0,0 & 0,0 & 0,0 \\
\hline 1 & Femur23 & Y_DESLOCAMENTO_INFERIOR & 0,0 & 0,0 & 0,1 & 0,1 & 0,1 & 0,1 \\
\hline \multirow[t]{3}{*}{1} & Femur26 & Y_DESLOCAMENTO_INFERIOR & 0,0 & 0,0 & 0,0 & 0,1 & 0,1 & 0,1 \\
\hline & & M & 0,0 & 0,0 & 0,0 & 0,0 & 0,1 & 0,1 \\
\hline & & DP & 0,0 & 0,0 & 0,1 & 0,1 & 0,1 & 0,1 \\
\hline 2 & Femur1 & Y_DESLOCAMENTO_INFERIOR & 0,0 & 0,0 & 0,0 & 0,0 & 0,0 & 0,0 \\
\hline 2 & Femur8 & Y_DESLOCAMENTO_INFERIOR & 0,0 & 0,0 & 0,1 & 0,1 & 0,1 & 0,1 \\
\hline 2 & Femur13 & Y_DESLOCAMENTO_INFERIOR & 0,0 & 0,1 & 0,1 & 0,2 & 0,2 & 0,3 \\
\hline 2 & Femur14 & Y_DESLOCAMENTO_INFERIOR & 0,0 & 0,2 & 0,2 & 0,1 & 0,2 & 0,2 \\
\hline 2 & Femur19 & Y_DESLOCAMENTO_INFERIOR & 0,0 & 0,0 & 0,0 & 0,0 & 0,1 & 0,1 \\
\hline \multirow[t]{3}{*}{2} & Femur25 & Y_DESLOCAMENTO_INFERIOR & 0,0 & 0,2 & 0,2 & 0,2 & 0,1 & 0,0 \\
\hline & & M & 0,0 & 0,1 & 0,1 & 0,1 & 0,1 & 0,1 \\
\hline & & DP & 0,0 & 0,1 & 0,1 & 0,1 & 0,1 & 0,1 \\
\hline 3 & Femur7 & Y_DESLOCAMENTO_INFERIOR & 0,0 & 0,1 & 0,2 & 0,2 & 0,3 & 0,3 \\
\hline 3 & Femur9 & Y_DESLOCAMENTO_INFERIOR & 0,0 & 0,0 & 0,0 & 0,1 & 0,1 & 0,2 \\
\hline 3 & Femur17 & Y_DESLOCAMENTO_INFERIOR & 0,0 & 0,1 & 0,1 & 0,1 & 0,1 & 0,1 \\
\hline 3 & Femur18 & Y_DESLOCAMENTO_INFERIOR & 0,0 & 0,0 & 0,1 & 0,1 & 0,1 & 0,1 \\
\hline 3 & Femur20 & Y_DESLOCAMENTO_INFERIOR & 0,0 & 0,0 & 0,0 & 0,1 & 0,0 & 0,0 \\
\hline \multirow[t]{3}{*}{3} & Femur24 & Y_DESLOCAMENTO_INFERIOR & 0,0 & 0,0 & 0,1 & 0,1 & 0,2 & 0,2 \\
\hline & & M & 0,0 & 0,0 & 0,1 & 0,1 & 0,1 & 0,2 \\
\hline & & DP & 0,0 & 0,1 & 0,1 & 0,0 & 0,1 & 0,1 \\
\hline 4 & Femur4 & Y_DESLOCAMENTO_INFERIOR & 0,0 & 0,0 & 0,0 & 0,0 & 0,1 & 0,1 \\
\hline 4 & Femur10 & Y_DESLOCAMENTO_INFERIOR & 0,0 & 0,0 & 0,0 & 0,0 & 0,0 & 0,0 \\
\hline 4 & Femur11 & Y_DESLOCAMENTO_INFERIOR & 0,0 & 0,0 & 0,0 & 0,0 & 0,1 & 0,2 \\
\hline 4 & Femur21 & Y_DESLOCAMENTO_INFERIOR & 0,0 & 0,0 & 0,0 & 0,1 & 0,1 & 0,1 \\
\hline 4 & Femur27 & Y_DESLOCAMENTO_INFERIOR & 0,0 & 0,0 & 0,0 & 0,1 & 0,1 & 0,1 \\
\hline \multirow[t]{3}{*}{4} & Femur29 & Y_DESLOCAMENTO_INFERIOR & 0,0 & 0,0 & 0,1 & 0,1 & 0,2 & 0,2 \\
\hline & & M & 0,0 & 0,0 & 0,0 & 0,1 & 0,1 & 0,1 \\
\hline & & DP & 0,0 & 0,0 & 0,0 & 0,1 & 0,1 & 0,1 \\
\hline 5 & Femur3 & Y_DESLOCAMENTO_INFERIOR & 0,0 & 0,2 & 0,2 & 0,2 & 0,2 & 0,2 \\
\hline 5 & Femur12 & Y_DESLOCAMENTO_INFERIOR & 0,0 & 0,3 & 0,3 & 0,3 & 0,3 & 0,3 \\
\hline 5 & Femur16 & Y_DESLOCAMENTO_INFERIOR & 0,0 & 0,0 & 0,2 & 0,2 & 0,3 & 0,3 \\
\hline 5 & Femur22 & Y_DESLOCAMENTO_INFERIOR & 0,0 & 0,0 & 0,0 & 0,1 & 0,1 & 0,2 \\
\hline 5 & Femur28 & Y_DESLOCAMENTO_INFERIOR & 0,0 & 0,3 & 0,4 & 0,3 & 0,3 & 0,5 \\
\hline \multirow[t]{3}{*}{5} & Femur30 & Y_DESLOCAMENTO_INFERIOR & 0,0 & 0,0 & 0,1 & 0,1 & 0,1 & 0,1 \\
\hline & & M & 0,0 & 0,1 & 0,2 & 0,2 & 0,2 & 0,3 \\
\hline & & DP & 0,0 & 0,2 & 0,1 & 0,1 & 0,1 & 0,1 \\
\hline
\end{tabular}


Tabela 5.15- Valores obtidos, em $\mathrm{mm}$, de deslocamentos da porção superior dos corpos de prova em relação à situação inicial, em cada intervalo dos ensaios realizados, obtidos por análise fotogramétrica, segundo a coordenada espacial Z, nos ensaios de compressão- São Paulo - 2007.

\begin{tabular}{|c|c|c|c|c|c|c|c|c|}
\hline GRUPO & FEMUR & & 0 & 40 & 80 & 120 & 160 & 200 \\
\hline 1 & Femur2 & Z_DESLOCAMENTO_SUPERIOR & 0,0 & 0,0 & 0,1 & 0,1 & 0,1 & 0,1 \\
\hline 1 & Femur5 & Z_DESLOCAMENTO_SUPERIOR & 0,0 & 0,0 & 0,0 & 0,0 & 0,1 & 0,0 \\
\hline 1 & Femur6 & Z_DESLOCAMENTO_SUPERIOR & 0,0 & 0,1 & 0,1 & 0,1 & 0,0 & 0,0 \\
\hline 1 & Femur15 & Z_DESLOCAMENTO_SUPERIOR & 0,0 & 0,0 & 0,0 & 0,1 & 0,1 & 0,1 \\
\hline 1 & Femur23 & Z_DESLOCAMENTO_SUPERIOR & 0,0 & 0,0 & 0,0 & 0,0 & 0,0 & 0,0 \\
\hline \multirow[t]{3}{*}{1} & Femur26 & Z_DESLOCAMENTO_SUPERIOR & 0,0 & 0,0 & 0,0 & 0,0 & 0,0 & 0,1 \\
\hline & & M & 0,0 & 0,0 & 0,0 & 0,1 & 0,1 & 0,1 \\
\hline & & DP & 0,0 & 0,0 & 0,1 & 0,1 & 0,1 & 0,1 \\
\hline 2 & Femur1 & Z_DESLOCAMENTO_SUPERIOR & 0,0 & 0,1 & 0,1 & 0,1 & 0,2 & 0,2 \\
\hline 2 & Femur8 & Z_DESLOCAMENTO_SUPERIOR & 0,0 & 0,0 & 0,0 & 0,0 & 0,0 & 0,0 \\
\hline 2 & Femur13 & Z_DESLOCAMENTO_SUPERIOR & 0,0 & 0,1 & 0,1 & 0,1 & 0,1 & 0,1 \\
\hline 2 & Femur14 & Z_DESLOCAMENTO_SUPERIOR & 0,0 & 0,1 & 0,0 & 0,1 & 0,1 & 0,0 \\
\hline 2 & Femur19 & Z_DESLOCAMENTO_SUPERIOR & 0,0 & 0,0 & 0,1 & 0,2 & 0,2 & 0,3 \\
\hline \multirow[t]{3}{*}{2} & Femur25 & Z_DESLOCAMENTO_SUPERIOR & 0,0 & 0,1 & 0,1 & 0,1 & 0,2 & 0,2 \\
\hline & & M & 0,0 & 0,1 & 0,1 & 0,1 & 0,1 & 0,1 \\
\hline & & DP & 0,0 & 0,1 & 0,1 & 0,1 & 0,1 & 0,1 \\
\hline 3 & Femur7 & Z_DESLOCAMENTO_SUPERIOR & 0,0 & 0,0 & 0,1 & 0,1 & 0,2 & 0,3 \\
\hline 3 & Femur9 & Z_DESLOCAMENTO_SUPERIOR & 0,0 & 0,0 & 0,1 & 0,2 & 0,3 & 0,3 \\
\hline 3 & Femur17 & Z_DESLOCAMENTO_SUPERIOR & 0,0 & 0,0 & 0,0 & 0,1 & 0,1 & 0,2 \\
\hline 3 & Femur18 & Z_DESLOCAMENTO_SUPERIOR & 0,0 & 0,0 & 0,2 & 0,2 & 0,3 & 0,3 \\
\hline 3 & Femur20 & Z_DESLOCAMENTO_SUPERIOR & 0,0 & 0,0 & 0,0 & 0,1 & 0,1 & 0,1 \\
\hline \multirow[t]{3}{*}{3} & Femur24 & Z_DESLOCAMENTO_SUPERIOR & 0,0 & 0,0 & 0,2 & 0,2 & 0,2 & 0,3 \\
\hline & & M & 0,0 & 0,0 & 0,1 & 0,2 & 0,2 & 0,3 \\
\hline & & DP & 0,0 & 0,0 & 0,1 & 0,1 & 0,1 & 0,1 \\
\hline 4 & Femur4 & Z_DESLOCAMENTO_SUPERIOR & 0,0 & 0,0 & 0,0 & 0,0 & 0,1 & 0,0 \\
\hline 4 & Femur10 & Z_DESLOCAMENTO_SUPERIOR & 0,0 & 0,0 & 0,1 & 0,1 & 0,2 & 0,3 \\
\hline 4 & Femur11 & Z_DESLOCAMENTO_SUPERIOR & 0,0 & 0,0 & 0,0 & 0,1 & 0,2 & 0,3 \\
\hline 4 & Femur21 & Z_DESLOCAMENTO_SUPERIOR & 0,0 & 0,0 & 0,0 & 0,0 & 0,0 & 0,0 \\
\hline 4 & Femur27 & Z_DESLOCAMENTO_SUPERIOR & 0,0 & 0,0 & 0,0 & 0,1 & 0,1 & 0,1 \\
\hline \multirow[t]{3}{*}{4} & Femur29 & Z_DESLOCAMENTO_SUPERIOR & 0,0 & 0,0 & 0,1 & 0,1 & 0,1 & 0,1 \\
\hline & & M & 0,0 & 0,0 & 0,0 & 0,1 & 0,1 & 0,1 \\
\hline & & DP & 0,0 & 0,0 & 0,1 & 0,1 & 0,1 & 0,1 \\
\hline 5 & Femur3 & Z_DESLOCAMENTO_SUPERIOR & 0,0 & 0,1 & 0,1 & 0,1 & 0,0 & 0,0 \\
\hline 5 & Femur12 & Z_DESLOCAMENTO_SUPERIOR & 0,0 & 0,1 & 0,0 & 0,0 & 0,0 & 0,0 \\
\hline 5 & Femur16 & Z_DESLOCAMENTO_SUPERIOR & 0,0 & 0,0 & 0,1 & 0,1 & 0,2 & 0,2 \\
\hline 5 & Femur22 & Z_DESLOCAMENTO_SUPERIOR & 0,0 & 0,0 & 0,0 & 0,0 & 0,1 & 0,1 \\
\hline 5 & Femur28 & Z_DESLOCAMENTO_SUPERIOR & 0,0 & 0,2 & 0,2 & 0,2 & 0,3 & 0,4 \\
\hline \multirow[t]{3}{*}{5} & Femur30 & Z_DESLOCAMENTO_SUPERIOR & 0,0 & 0,0 & 0,1 & 0,1 & 0,1 & 0,2 \\
\hline & & M & 0,0 & 0,1 & 0,1 & 0,1 & 0,1 & 0,2 \\
\hline & & DP & 0,0 & 0,1 & 0,1 & 0,1 & 0,1 & 0,2 \\
\hline
\end{tabular}


Tabela 5.16- Valores obtidos, em $\mathrm{mm}$, de deslocamentos da porção inferior dos corpos de prova em relação à situação inicial, em cada intervalo dos ensaios realizados, obtidos por análise fotogramétrica, segundo a coordenada espacial Z, nos ensaios de compressãoSão Paulo - 2007.

\begin{tabular}{|c|c|c|c|c|c|c|c|c|}
\hline GRUPO & FEMUR & & 0 & 40 & 80 & 120 & 160 & 200 \\
\hline 1 & Femur2 & Z_DESLOCAMENTO_INFERIOR & 0,0 & 0,0 & 0,1 & 0,0 & 0,0 & 0,0 \\
\hline 1 & Femur5 & Z_DESLOCAMENTO_INFERIOR & 0,0 & 0,1 & 0,0 & 0,0 & 0,1 & 0,0 \\
\hline 1 & Femur6 & Z_DESLOCAMENTO_INFERIOR & 0,0 & 0,0 & 0,0 & 0,0 & 0,0 & 0,0 \\
\hline 1 & Femur15 & Z_DESLOCAMENTO_INFERIOR & 0,0 & 0,0 & 0,0 & 0,0 & 0,0 & 0,0 \\
\hline 1 & Femur23 & Z_DESLOCAMENTO_INFERIOR & 0,0 & 0,0 & 0,0 & 0,0 & 0,0 & 0,0 \\
\hline \multirow[t]{3}{*}{1} & Femur26 & Z_DESLOCAMENTO_INFERIOR & 0,0 & 0,0 & 0,0 & 0,0 & 0,1 & 0,1 \\
\hline & & M & 0,0 & 0,0 & 0,0 & 0,0 & 0,0 & 0,0 \\
\hline & & DP & 0,0 & 0,0 & 0,0 & 0,0 & 0,1 & 0,0 \\
\hline 2 & Femur1 & Z_DESLOCAMENTO_INFERIOR & 0,0 & 0,0 & 0,1 & 0,0 & 0,0 & 0,0 \\
\hline 2 & Femur8 & Z_DESLOCAMENTO_INFERIOR & 0,0 & 0,0 & 0,1 & 0,1 & 0,1 & 0,1 \\
\hline 2 & Femur13 & Z_DESLOCAMENTO_INFERIOR & 0,0 & 0,0 & 0,0 & 0,1 & 0,1 & 0,1 \\
\hline 2 & Femur14 & Z_DESLOCAMENTO_INFERIOR & 0,0 & 0,1 & 0,1 & 0,0 & 0,0 & 0,0 \\
\hline 2 & Femur19 & Z_DESLOCAMENTO_INFERIOR & 0,0 & 0,0 & 0,1 & 0,1 & 0,1 & 0,1 \\
\hline \multirow[t]{3}{*}{2} & Femur25 & Z_DESLOCAMENTO_INFERIOR & 0,0 & 0,1 & 0,1 & 0,1 & 0,1 & 0,1 \\
\hline & & M & 0,0 & 0,0 & 0,1 & 0,1 & 0,1 & 0,1 \\
\hline & & DP & 0,0 & 0,1 & 0,0 & 0,1 & 0,1 & 0,1 \\
\hline 3 & Femur7 & Z_DESLOCAMENTO_INFERIOR & 0,0 & 0,0 & 0,1 & 0,1 & 0,1 & 0,1 \\
\hline 3 & Femur9 & Z_DESLOCAMENTO_INFERIOR & 0,0 & 0,0 & 0,0 & 0,0 & 0,0 & 0,0 \\
\hline 3 & Femur17 & Z_DESLOCAMENTO_INFERIOR & 0,0 & 0,0 & 0,1 & 0,1 & 0,2 & 0,2 \\
\hline 3 & Femur18 & Z_DESLOCAMENTO_INFERIOR & 0,0 & 0,1 & 0,0 & 0,1 & 0,0 & 0,1 \\
\hline 3 & Femur20 & Z_DESLOCAMENTO_INFERIOR & 0,0 & 0,1 & 0,0 & 0,1 & 0,1 & 0,1 \\
\hline \multirow[t]{3}{*}{3} & Femur24 & Z_DESLOCAMENTO_INFERIOR & 0,0 & 0,0 & 0,0 & 0,1 & 0,0 & 0,1 \\
\hline & & M & 0,0 & 0,0 & 0,0 & 0,1 & 0,1 & 0,1 \\
\hline & & DP & 0,0 & 0,1 & 0,1 & 0,0 & 0,1 & 0,1 \\
\hline 4 & Femur4 & Z_DESLOCAMENTO_INFERIOR & 0,0 & 0,1 & 0,0 & 0,1 & 0,0 & 0,0 \\
\hline 4 & Femur10 & Z_DESLOCAMENTO_INFERIOR & 0,0 & 0,1 & 0,1 & 0,0 & 0,1 & 0,1 \\
\hline 4 & Femur11 & Z_DESLOCAMENTO_INFERIOR & 0,0 & 0,0 & 0,0 & 0,0 & 0,0 & 0,0 \\
\hline 4 & Femur21 & Z_DESLOCAMENTO_INFERIOR & 0,0 & 0,0 & 0,0 & 0,0 & 0,1 & 0,0 \\
\hline 4 & Femur27 & Z_DESLOCAMENTO_INFERIOR & 0,0 & 0,0 & 0,0 & 0,0 & 0,0 & 0,1 \\
\hline \multirow[t]{3}{*}{4} & Femur29 & Z_DESLOCAMENTO_INFERIOR & 0,0 & 0,0 & 0,0 & 0,0 & 0,1 & 0,1 \\
\hline & & M & 0,0 & 0,0 & 0,0 & 0,0 & 0,1 & 0,1 \\
\hline & & DP & 0,0 & 0,1 & 0,0 & 0,0 & 0,1 & 0,1 \\
\hline 5 & Femur3 & Z_DESLOCAMENTO_INFERIOR & 0,0 & 0,1 & 0,0 & 0,1 & 0,1 & 0,0 \\
\hline 5 & Femur12 & Z_DESLOCAMENTO_INFERIOR & 0,0 & 0,1 & 0,1 & 0,1 & 0,1 & 0,1 \\
\hline 5 & Femur16 & Z_DESLOCAMENTO_INFERIOR & 0,0 & 0,0 & 0,0 & 0,0 & 0,0 & 0,0 \\
\hline 5 & Femur22 & Z_DESLOCAMENTO_INFERIOR & 0,0 & 0,0 & 0,0 & 0,1 & 0,1 & 0,0 \\
\hline 5 & Femur28 & Z_DESLOCAMENTO_INFERIOR & 0,0 & 0,1 & 0,1 & 0,1 & 0,1 & 0,1 \\
\hline \multirow[t]{3}{*}{5} & Femur30 & Z_DESLOCAMENTO_INFERIOR & 0,0 & 0,0 & 0,1 & 0,0 & 0,1 & 0,1 \\
\hline & & M & 0,0 & 0,1 & 0,1 & 0,1 & 0,1 & 0,1 \\
\hline & & DP & 0,0 & 0,1 & 0,1 & 0,1 & 0,0 & 0,1 \\
\hline
\end{tabular}


5.2.2.2 Ensaio de encurvamento

Os dados obtidos refletem a movimentação interfragmentária das porções superior e inferior dos corpos de prova em cada eixo espacial, durante o ensaio de encurvamento. A análise dos dados, apresentados nas tabelas 5.17, 5.18, 5.19, 5.20, 5.21 e 5.22, demonstrou distribuição não paramétrica, não apresentando diferença significativa entre os grupos analisados. 
Tabela 5.17- Valores obtidos, em mm, de deslocamentos da porção superior dos corpos de prova em relação à situação inicial, em cada intervalo dos ensaios realizados, obtidos por análise fotogramétrica, segundo a coordenada espacial X, nos ensaios de encurvamento- São Paulo - 2007.

\begin{tabular}{|c|c|c|c|c|c|c|c|c|}
\hline GRUPO & FEMUR & & 0 & 12 & 24 & 36 & 48 & 60 \\
\hline 1 & Femur2 & X_DESLOCAMENTO_SUPERIOR & 0,0 & 0,5 & 0,7 & 1,0 & 1,2 & 1,5 \\
\hline 1 & Femur5 & X_DESLOCAMENTO_SUPERIOR & 0,0 & 0,1 & 0,2 & 0,5 & 0,6 & 0,9 \\
\hline 1 & Femur6 & X_DESLOCAMENTO_SUPERIOR & 0,0 & 0,3 & 0,8 & 1,2 & 1,7 & 2,3 \\
\hline 1 & Femur15 & X_DESLOCAMENTO_SUPERIOR & 0,0 & 0,1 & 0,7 & 2,0 & 2,5 & 3,1 \\
\hline 1 & Femur23 & X_DESLOCAMENTO_SUPERIOR & 0,0 & 0,2 & 0,5 & 0,7 & 0,9 & 1,3 \\
\hline \multirow[t]{3}{*}{1} & Femur26 & X_DESLOCAMENTO_SUPERIOR & 0,0 & 1,0 & 1,8 & 2,4 & 2,8 & 3,3 \\
\hline & & M & 0,0 & 0,4 & 0,8 & 1,3 & 1,6 & 2,1 \\
\hline & & DP & 0,0 & 0,3 & 0,5 & 0,7 & 0,9 & 1,0 \\
\hline 2 & Femur1 & X_DESLOCAMENTO_SUPERIOR & 0,0 & 0,2 & 0,5 & 0,8 & 1,2 & 1,5 \\
\hline 2 & Femur8 & X_DESLOCAMENTO_SUPERIOR & 0,0 & 0,3 & 0,6 & 1,0 & 1,3 & 1,7 \\
\hline 2 & Femur13 & X_DESLOCAMENTO_SUPERIOR & 0,0 & 1,4 & 1,3 & 1,0 & 0,7 & 0,4 \\
\hline 2 & Femur14 & X_DESLOCAMENTO_SUPERIOR & 0,0 & 0,4 & 0,7 & 1,0 & 1,4 & 1,7 \\
\hline 2 & Femur19 & X_DESLOCAMENTO_SUPERIOR & 0,0 & 0,4 & 0,7 & 1,1 & 1,4 & 1,8 \\
\hline \multirow[t]{3}{*}{2} & Femur25 & X_DESLOCAMENTO_SUPERIOR & 0,0 & 0,4 & 0,9 & 1,4 & 1,8 & 2,5 \\
\hline & & M & 0,0 & 0,5 & 0,8 & 1,1 & 1,3 & 1,6 \\
\hline & & DP & 0,0 & 0,4 & 0,3 & 0,2 & 0,4 & 0,7 \\
\hline 3 & Femur7 & X_DESLOCAMENTO_SUPERIOR & 0,0 & 0,2 & 0,5 & 0,7 & 1,2 & 1,5 \\
\hline 3 & Femur9 & X_DESLOCAMENTO_SUPERIOR & 0,0 & 0,5 & 0,9 & 1,3 & 1,7 & 2,0 \\
\hline 3 & Femur17 & X_DESLOCAMENTO_SUPERIOR & 0,0 & 0,7 & 1,3 & 1,7 & 2,3 & 3,0 \\
\hline 3 & Femur18 & X_DESLOCAMENTO_SUPERIOR & 0,0 & 0,2 & 0,4 & 0,6 & 1,0 & 1,3 \\
\hline 3 & Femur20 & X_DESLOCAMENTO_SUPERIOR & 0,0 & 0,1 & 0,5 & 0,8 & 1,2 & 1,6 \\
\hline \multirow[t]{3}{*}{3} & Femur24 & X_DESLOCAMENTO_SUPERIOR & 0,0 & 0,5 & 1,2 & 1,8 & 2,2 & 2,9 \\
\hline & & M & 0,0 & 0,4 & 0,8 & 1,2 & 1,6 & 2,1 \\
\hline & & DP & 0,0 & 0,2 & 0,4 & 0,5 & 0,6 & 0,7 \\
\hline 4 & Femur4 & X_DESLOCAMENTO_SUPERIOR & 0,0 & 0,2 & 0,3 & 0,6 & 0,9 & 1,3 \\
\hline 4 & Femur10 & X_DESLOCAMENTO_SUPERIOR & 0,0 & 0,6 & 1,3 & 2,0 & 2,6 & 3,4 \\
\hline 4 & Femur11 & X_DESLOCAMENTO_SUPERIOR & 0,0 & 0,6 & 1,0 & 1,6 & 2,2 & 2,8 \\
\hline 4 & Femur21 & X_DESLOCAMENTO_SUPERIOR & 0,0 & 0,3 & 0,5 & 0,8 & 1,2 & 1,4 \\
\hline 4 & Femur27 & X_DESLOCAMENTO_SUPERIOR & 0,0 & 0,9 & 1,7 & 2,4 & 2,9 & 3,4 \\
\hline \multirow[t]{3}{*}{4} & Femur29 & X_DESLOCAMENTO_SUPERIOR & 0,0 & 0,7 & 1,1 & 1,5 & 2,0 & 2,5 \\
\hline & & M & 0,0 & 0,6 & 1,0 & 1,5 & 2,0 & 2,5 \\
\hline & & DP & 0,0 & 0,3 & 0,5 & 0,7 & 0,8 & 0,9 \\
\hline 5 & Femur3 & X_DESLOCAMENTO_SUPERIOR & 0,0 & 0,2 & 0,8 & 1,4 & 1,9 & 2,5 \\
\hline 5 & Femur12 & X_DESLOCAMENTO_SUPERIOR & 0,0 & 0,2 & 0,7 & 1,4 & 1,9 & 2,5 \\
\hline 5 & Femur16 & X_DESLOCAMENTO_SUPERIOR & 0,0 & 0,2 & 0,2 & 0,6 & 1,0 & 2,1 \\
\hline 5 & Femur22 & X_DESLOCAMENTO_SUPERIOR & 0,0 & 0,0 & 0,3 & 0,5 & 0,9 & 1,1 \\
\hline 5 & Femur28 & X_DESLOCAMENTO_SUPERIOR & 0,0 & 0,3 & 0,7 & 0,9 & 1,2 & 1,6 \\
\hline \multirow[t]{3}{*}{5} & Femur30 & X_DESLOCAMENTO_SUPERIOR & 0,0 & 1,1 & 1,6 & 1,9 & 2,2 & 2,7 \\
\hline & & $\mathrm{M}$ & 0,0 & 0,3 & 0,7 & 1,1 & 1,5 & 2,1 \\
\hline & & DP & 0,0 & 0,4 & 0,5 & 0,5 & 0,5 & 0,6 \\
\hline
\end{tabular}


Tabela 5.18- Valores obtidos, em mm, de deslocamentos da porção inferior dos corpos de prova em relação à situação inicial, em cada intervalo dos ensaios realizados, obtidos por análise fotogramétrica, segundo a coordenada espacial X, nos ensaios de encurvamentoSão Paulo - 2007.

\begin{tabular}{|c|c|c|c|c|c|c|c|c|}
\hline GRUPO & FEMUR & & 0 & 12 & 24 & 36 & 48 & 60 \\
\hline 1 & Femur2 & X_DESLOCAMENTO_INFERIOR & 0,0 & 0,2 & 0,4 & 0,5 & 0,5 & 0,8 \\
\hline 1 & Femur5 & X_DESLOCAMENTO_INFERIOR & 0,0 & 0,0 & 0,0 & 0,1 & 0,2 & 0,2 \\
\hline 1 & Femur6 & X_DESLOCAMENTO_INFERIOR & 0,0 & 0,0 & 0,2 & 0,3 & 0,5 & 0,6 \\
\hline 1 & Femur15 & X_DESLOCAMENTO_INFERIOR & 0,0 & 0,4 & 0,1 & 0,9 & 1,1 & 1,4 \\
\hline 1 & Femur23 & X_DESLOCAMENTO_INFERIOR & 0,0 & 0,1 & 0,1 & 0,3 & 0,3 & 0,5 \\
\hline \multirow[t]{3}{*}{1} & Femur26 & X_DESLOCAMENTO_INFERIOR & 0,0 & 0,0 & 0,2 & 0,3 & 0,5 & 0,6 \\
\hline & & $\mathrm{M}$ & 0,0 & 0,1 & 0,2 & 0,4 & 0,5 & 0,7 \\
\hline & & DP & 0,0 & 0,2 & 0,1 & 0,3 & 0,3 & 0,4 \\
\hline 2 & Femur1 & X_DESLOCAMENTO_INFERIOR & 0,0 & 0,0 & 0,1 & 0,1 & 0,2 & 0,2 \\
\hline 2 & Femur8 & X_DESLOCAMENTO_INFERIOR & 0,0 & 0,1 & 0,3 & 0,5 & 0,7 & 0,8 \\
\hline 2 & Femur13 & X_DESLOCAMENTO_INFERIOR & 0,0 & 1,6 & 1,5 & 1,4 & 1,3 & 1,2 \\
\hline 2 & Femur14 & X_DESLOCAMENTO_INFERIOR & 0,0 & 0,1 & 0,1 & 0,2 & 0,3 & 0,3 \\
\hline 2 & Femur19 & X_DESLOCAMENTO_INFERIOR & 0,0 & 0,0 & 0,0 & 0,2 & 0,2 & 0,3 \\
\hline \multirow[t]{3}{*}{2} & Femur25 & X_DESLOCAMENTO_INFERIOR & 0,0 & 0,2 & 0,2 & 0,5 & 0,5 & 0,7 \\
\hline & & $M$ & 0,0 & 0,3 & 0,4 & 0,5 & 0,5 & 0,6 \\
\hline & & DP & 0,0 & 0,6 & 0,6 & 0,5 & 0,4 & 0,4 \\
\hline 3 & Femur7 & X_DESLOCAMENTO_INFERIOR & 0,0 & 0,1 & 0,2 & 0,3 & 0,5 & 0,5 \\
\hline 3 & Femur9 & X_DESLOCAMENTO_INFERIOR & 0,0 & 0,1 & 0,2 & 0,3 & 0,4 & 0,6 \\
\hline 3 & Femur17 & X_DESLOCAMENTO_INFERIOR & 0,0 & 0,3 & 0,4 & 0,7 & 0,8 & 1,1 \\
\hline 3 & Femur18 & X_DESLOCAMENTO_INFERIOR & 0,0 & 0,1 & 0,2 & 0,3 & 0,4 & 0,5 \\
\hline 3 & Femur20 & X_DESLOCAMENTO_INFERIOR & 0,0 & 0,2 & 0,2 & 0,3 & 0,4 & 0,5 \\
\hline \multirow[t]{3}{*}{3} & Femur24 & X_DESLOCAMENTO_INFERIOR & 0,0 & 0,1 & 0,2 & 0,4 & 0,6 & 0,8 \\
\hline & & M & 0,0 & 0,2 & 0,2 & 0,4 & 0,5 & 0,7 \\
\hline & & DP & 0,0 & 0,1 & 0,1 & 0,2 & 0,2 & 0,2 \\
\hline 4 & Femur4 & X_DESLOCAMENTO_INFERIOR & 0,0 & 0,1 & 0,2 & 0,3 & 0,4 & 0,5 \\
\hline 4 & Femur10 & X_DESLOCAMENTO_INFERIOR & 0,0 & 0,1 & 0,2 & 0,3 & 0,4 & 0,5 \\
\hline 4 & Femur11 & X_DESLOCAMENTO_INFERIOR & 0,0 & 0,2 & 0,2 & 0,2 & 0,1 & 0,0 \\
\hline 4 & Femur21 & X_DESLOCAMENTO_INFERIOR & 0,0 & 0,1 & 0,2 & 0,4 & 0,4 & 0,5 \\
\hline 4 & Femur27 & X_DESLOCAMENTO_INFERIOR & 0,0 & 0,1 & 0,1 & 0,3 & 0,4 & 0,5 \\
\hline \multirow[t]{3}{*}{4} & Femur29 & X_DESLOCAMENTO_INFERIOR & 0,0 & 0,2 & 0,4 & 0,6 & 0,9 & 1,1 \\
\hline & & M & 0,0 & 0,1 & 0,2 & 0,4 & 0,4 & 0,5 \\
\hline & & DP & 0,0 & 0,1 & 0,1 & 0,1 & 0,3 & 0,3 \\
\hline 5 & Femur3 & X_DESLOCAMENTO_INFERIOR & 0,0 & 0,1 & 0,3 & 0,3 & 0,5 & 0,7 \\
\hline 5 & Femur12 & X_DESLOCAMENTO_INFERIOR & 0,0 & 0,0 & 0,1 & 0,3 & 0,4 & 0,5 \\
\hline 5 & Femur16 & X_DESLOCAMENTO_INFERIOR & 0,0 & 0,6 & 0,4 & 0,4 & 0,2 & 0,6 \\
\hline 5 & Femur22 & X_DESLOCAMENTO_INFERIOR & 0,0 & 0,1 & 0,1 & 0,3 & 0,4 & 0,6 \\
\hline 5 & Femur28 & X_DESLOCAMENTO_INFERIOR & 0,0 & 0,0 & 0,0 & 0,1 & 0,2 & 0,3 \\
\hline \multirow[t]{3}{*}{5} & Femur30 & X_DESLOCAMENTO_INFERIOR & 0,0 & 0,2 & 0,4 & 0,5 & 0,7 & 0,8 \\
\hline & & M & 0,0 & 0,2 & 0,2 & 0,3 & 0,4 & 0,6 \\
\hline & & DP & 0,0 & 0,2 & 0,2 & 0,1 & 0,2 & 0,2 \\
\hline
\end{tabular}


Tabela 5.19- Valores obtidos, em $\mathrm{mm}$, de deslocamentos da porção superior dos corpos de prova em relação à situação inicial, em cada intervalo dos ensaios realizados, obtidos por análise fotogramétrica, segundo a coordenada espacial $\mathrm{Y}$, nos ensaios de encurvamento- São Paulo - 2007.

\begin{tabular}{|c|c|c|c|c|c|c|c|c|}
\hline GRUPO & FEMUR & & 0 & 12 & 24 & 36 & 48 & 60 \\
\hline 1 & Femur2 & Y_DESLOCAMENTO_SUPERIOR & 0,0 & 0,2 & 0,3 & 0,4 & 0,5 & 0,6 \\
\hline 1 & Femur5 & Y_DESLOCAMENTO_SUPERIOR & 0,0 & 0,0 & 0,0 & 0,1 & 0,1 & 0,2 \\
\hline 1 & Femur6 & Y_DESLOCAMENTO_SUPERIOR & 0,0 & 0,0 & 0,1 & 0,0 & 0,0 & 0,1 \\
\hline 1 & Femur15 & Y_DESLOCAMENTO_SUPERIOR & 0,0 & 0,4 & 0,4 & 0,1 & 0,2 & 0,4 \\
\hline 1 & Femur23 & Y_DESLOCAMENTO_SUPERIOR & 0,0 & 0,0 & 0,0 & 0,0 & 0,0 & 0,0 \\
\hline \multirow[t]{3}{*}{1} & Femur26 & Y_DESLOCAMENTO_SUPERIOR & 0,0 & 0,1 & 0,0 & 0,0 & 0,1 & 0,2 \\
\hline & & M & 0,0 & 0,1 & 0,1 & 0,1 & 0,2 & 0,3 \\
\hline & & DP & 0,0 & 0,2 & 0,2 & 0,2 & 0,2 & 0,2 \\
\hline 2 & Femur1 & Y_DESLOCAMENTO_SUPERIOR & 0,0 & 0,1 & 0,2 & 0,3 & 0,4 & 0,5 \\
\hline 2 & Femur8 & Y_DESLOCAMENTO_SUPERIOR & 0,0 & 0,0 & 0,0 & 0,0 & 0,1 & 0,1 \\
\hline 2 & Femur13 & Y_DESLOCAMENTO_SUPERIOR & 0,0 & 0,8 & 0,8 & 0,8 & 0,7 & 0,7 \\
\hline 2 & Femur14 & Y_DESLOCAMENTO_SUPERIOR & 0,0 & 0,0 & 0,1 & 0,2 & 0,2 & 0,3 \\
\hline 2 & Femur19 & Y_DESLOCAMENTO_SUPERIOR & 0,0 & 0,0 & 0,2 & 0,3 & 0,4 & 0,5 \\
\hline \multirow[t]{3}{*}{2} & Femur25 & Y_DESLOCAMENTO_SUPERIOR & 0,0 & 0,2 & 0,4 & 0,5 & 0,5 & 0,5 \\
\hline & & $M$ & 0,0 & 0,2 & 0,3 & 0,4 & 0,4 & 0,4 \\
\hline & & DP & 0,0 & 0,3 & 0,3 & 0,3 & 0,2 & 0,2 \\
\hline 3 & Femur7 & Y_DESLOCAMENTO_SUPERIOR & 0,0 & 0,1 & 0,1 & 0,2 & 0,4 & 0,6 \\
\hline 3 & Femur9 & Y_DESLOCAMENTO_SUPERIOR & 0,0 & 0,0 & 0,1 & 0,2 & 0,5 & 0,9 \\
\hline 3 & Femur17 & Y_DESLOCAMENTO_SUPERIOR & 0,0 & 0,1 & 0,3 & 0,5 & 0,8 & 1,1 \\
\hline 3 & Femur18 & Y_DESLOCAMENTO_SUPERIOR & 0,0 & 0,0 & 0,1 & 0,1 & 0,1 & 0,1 \\
\hline 3 & Femur20 & Y_DESLOCAMENTO_SUPERIOR & 0,0 & 0,1 & 0,1 & 0,2 & 0,2 & 0,3 \\
\hline \multirow[t]{3}{*}{3} & Femur24 & Y_DESLOCAMENTO_SUPERIOR & 0,0 & 0,0 & 0,1 & 0,2 & 0,3 & 0,5 \\
\hline & & M & 0,0 & 0,1 & 0,1 & 0,2 & 0,4 & 0,6 \\
\hline & & DP & 0,0 & 0,1 & 0,1 & 0,1 & 0,2 & 0,4 \\
\hline 4 & Femur4 & Y_DESLOCAMENTO_SUPERIOR & 0,0 & 0,1 & 0,3 & 0,5 & 0,6 & 0,7 \\
\hline 4 & Femur10 & Y_DESLOCAMENTO_SUPERIOR & 0,0 & 0,0 & 0,0 & 0,0 & 0,2 & 0,3 \\
\hline 4 & Femur11 & Y_DESLOCAMENTO_SUPERIOR & 0,0 & 0,2 & 0,1 & 0,1 & 0,1 & 0,0 \\
\hline 4 & Femur21 & Y_DESLOCAMENTO_SUPERIOR & 0,0 & 0,0 & 0,0 & 0,0 & 0,0 & 0,0 \\
\hline 4 & Femur27 & Y_DESLOCAMENTO_SUPERIOR & 0,0 & 0,0 & 0,1 & 0,1 & 0,2 & 0,2 \\
\hline \multirow[t]{3}{*}{4} & Femur29 & Y_DESLOCAMENTO_SUPERIOR & 0,0 & 0,0 & 0,0 & 0,0 & 0,1 & 0,1 \\
\hline & & M & 0,0 & 0,1 & 0,1 & 0,1 & 0,2 & 0,2 \\
\hline & & DP & 0,0 & 0,1 & 0,1 & 0,2 & 0,2 & 0,3 \\
\hline 5 & Femur3 & Y_DESLOCAMENTO_SUPERIOR & 0,0 & 0,6 & 0,8 & 0,9 & 0,8 & 0,8 \\
\hline 5 & Femur12 & Y_DESLOCAMENTO_SUPERIOR & 0,0 & 0,1 & 0,1 & 0,0 & 0,0 & 0,1 \\
\hline 5 & Femur16 & Y_DESLOCAMENTO_SUPERIOR & 0,0 & 0,3 & 0,2 & 0,2 & 0,2 & 0,3 \\
\hline 5 & Femur22 & Y_DESLOCAMENTO_SUPERIOR & 0,0 & 0,0 & 0,2 & 0,4 & 0,5 & 0,5 \\
\hline 5 & Femur28 & Y_DESLOCAMENTO_SUPERIOR & 0,0 & 0,1 & 0,1 & 0,2 & 0,3 & 0,4 \\
\hline \multirow[t]{3}{*}{5} & Femur30 & Y_DESLOCAMENTO_SUPERIOR & 0,0 & 0,0 & 0,1 & 0,1 & 0,2 & 0,3 \\
\hline & & $\mathrm{M}$ & 0,0 & 0,2 & 0,3 & 0,3 & 0,3 & 0,4 \\
\hline & & DP & 0,0 & 0,2 & 0,3 & 0,3 & 0,3 & 0,2 \\
\hline
\end{tabular}


Tabela 5.20- Valores obtidos, em mm, de deslocamentos da porção inferior dos corpos de prova em relação à situação inicial, em cada intervalo dos ensaios realizados, obtidos por análise fotogramétrica, segundo a coordenada espacial $Y$, nos ensaios de encurvamentoSão Paulo - 2007.

\begin{tabular}{|c|c|c|c|c|c|c|c|c|}
\hline GRUPO & FEMUR & & 0 & 12 & 24 & 36 & 48 & 60 \\
\hline 1 & Femur2 & Y_DESLOCAMENTO_INFERIOR & 0,0 & 0,1 & 0,0 & 0,0 & 0,0 & 0,0 \\
\hline 1 & Femur5 & Y_DESLOCAMENTO_INFERIOR & 0,0 & 0,0 & 0,0 & 0,0 & 0,0 & 0,0 \\
\hline 1 & Femur6 & Y_DESLOCAMENTO_INFERIOR & 0,0 & 0,0 & 0,0 & 0,0 & 0,0 & 0,1 \\
\hline 1 & Femur15 & Y_DESLOCAMENTO_INFERIOR & 0,0 & 0,3 & 0,3 & 0,1 & 0,1 & 0,1 \\
\hline 1 & Femur23 & Y_DESLOCAMENTO_INFERIOR & 0,0 & 0,0 & 0,1 & 0,1 & 0,0 & 0,0 \\
\hline \multirow[t]{3}{*}{1} & Femur26 & Y_DESLOCAMENTO_INFERIOR & 0,0 & 0,0 & 0,0 & 0,0 & 0,0 & 0,0 \\
\hline & & M & 0,0 & 0,1 & 0,1 & 0,0 & 0,0 & 0,0 \\
\hline & & DP & 0,0 & 0,1 & 0,1 & 0,1 & 0,0 & 0,1 \\
\hline 2 & Femur1 & Y_DESLOCAMENTO_INFERIOR & 0,0 & 0,0 & 0,0 & 0,0 & 0,0 & 0,0 \\
\hline 2 & Femur8 & Y_DESLOCAMENTO_INFERIOR & 0,0 & 0,0 & 0,0 & 0,0 & 0,0 & 0,0 \\
\hline 2 & Femur13 & Y_DESLOCAMENTO_INFERIOR & 0,0 & 0,8 & 0,8 & 0,8 & 0,8 & 0,8 \\
\hline 2 & Femur14 & Y_DESLOCAMENTO_INFERIOR & 0,0 & 0,1 & 0,1 & 0,1 & 0,1 & 0,1 \\
\hline 2 & Femur19 & Y_DESLOCAMENTO_INFERIOR & 0,0 & 0,0 & 0,0 & 0,0 & 0,0 & 0,1 \\
\hline \multirow[t]{3}{*}{2} & Femur25 & Y_DESLOCAMENTO_INFERIOR & 0,0 & 0,0 & 0,0 & 0,0 & 0,0 & 0,0 \\
\hline & & M & 0,0 & 0,2 & 0,2 & 0,2 & 0,2 & 0,2 \\
\hline & & DP & 0,0 & 0,3 & 0,3 & 0,3 & 0,3 & 0,3 \\
\hline 3 & Femur7 & Y_DESLOCAMENTO_INFERIOR & 0,0 & 0,0 & 0,1 & 0,1 & 0,1 & 0,2 \\
\hline 3 & Femur9 & Y_DESLOCAMENTO_INFERIOR & 0,0 & 0,0 & 0,0 & 0,1 & 0,0 & 0,1 \\
\hline 3 & Femur17 & Y_DESLOCAMENTO_INFERIOR & 0,0 & 0,0 & 0,0 & 0,0 & 0,0 & 0,0 \\
\hline 3 & Femur18 & Y_DESLOCAMENTO_INFERIOR & 0,0 & 0,0 & 0,1 & 0,1 & 0,1 & 0,1 \\
\hline 3 & Femur20 & Y_DESLOCAMENTO_INFERIOR & 0,0 & 0,0 & 0,0 & 0,0 & 0,0 & 0,0 \\
\hline \multirow[t]{3}{*}{3} & Femur24 & Y_DESLOCAMENTO_INFERIOR & 0,0 & 0,0 & 0,0 & 0,0 & 0,0 & 0,0 \\
\hline & & M & 0,0 & 0,0 & 0,0 & 0,1 & 0,0 & 0,1 \\
\hline & & DP & 0,0 & 0,0 & 0,1 & 0,1 & 0,1 & 0,1 \\
\hline 4 & Femur4 & Y_DESLOCAMENTO_INFERIOR & 0,0 & 0,0 & 0,0 & 0,0 & 0,0 & 0,1 \\
\hline 4 & Femur10 & Y_DESLOCAMENTO_INFERIOR & 0,0 & 0,0 & 0,0 & 0,0 & 0,0 & 0,0 \\
\hline 4 & Femur11 & Y_DESLOCAMENTO_INFERIOR & 0,0 & 0,0 & 0,2 & 0,3 & 0,2 & 0,2 \\
\hline 4 & Femur21 & Y_DESLOCAMENTO_INFERIOR & 0,0 & 0,0 & 0,0 & 0,0 & 0,0 & 0,0 \\
\hline 4 & Femur27 & Y_DESLOCAMENTO_INFERIOR & 0,0 & 0,0 & 0,0 & 0,0 & 0,0 & 0,0 \\
\hline \multirow[t]{3}{*}{4} & Femur29 & Y_DESLOCAMENTO_INFERIOR & 0,0 & 0,0 & 0,0 & 0,0 & 0,0 & 0,1 \\
\hline & & $\mathrm{M}$ & 0,0 & 0,0 & 0,0 & 0,1 & 0,0 & 0,1 \\
\hline & & DP & 0,0 & 0,0 & 0,1 & 0,1 & 0,1 & 0,1 \\
\hline 5 & Femur3 & Y_DESLOCAMENTO_INFERIOR & 0,0 & 0,0 & 0,0 & 0,0 & 0,0 & 0,0 \\
\hline 5 & Femur12 & Y_DESLOCAMENTO_INFERIOR & 0,0 & 0,0 & 0,1 & 0,1 & 0,0 & 0,0 \\
\hline 5 & Femur16 & Y_DESLOCAMENTO_INFERIOR & 0,0 & 0,3 & 0,4 & 0,4 & 0,4 & 0,1 \\
\hline 5 & Femur22 & Y_DESLOCAMENTO_INFERIOR & 0,0 & 0,0 & 0,0 & 0,1 & 0,1 & 0,1 \\
\hline 5 & Femur28 & Y_DESLOCAMENTO_INFERIOR & 0,0 & 0,1 & 0,0 & 0,1 & 0,1 & 0,0 \\
\hline \multirow[t]{3}{*}{5} & Femur30 & Y_DESLOCAMENTO_INFERIOR & 0,0 & 0,0 & 0,0 & 0,0 & 0,0 & 0,0 \\
\hline & & $\mathrm{M}$ & 0,0 & 0,1 & 0,1 & 0,1 & 0,1 & 0,0 \\
\hline & & DP & 0,0 & 0,1 & 0,2 & 0,1 & 0,2 & 0,1 \\
\hline
\end{tabular}


Tabela 5.21- Valores obtidos, em $\mathrm{mm}$, de deslocamentos da porção superior dos corpos de prova em relação à situação inicial, em cada intervalo dos ensaios realizados, obtidos por análise fotogramétrica, segundo a coordenada espacial Z, nos ensaios de encurvamento- São Paulo - 2007.

\begin{tabular}{|c|c|c|c|c|c|c|c|c|}
\hline GRUPO & FEMUR & & 0 & 12 & 24 & 36 & 48 & 60 \\
\hline 1 & Femur2 & Z_DESLOCAMENTO_SUPERIOR & 0,0 & 0,1 & 0,3 & 0,3 & 0,5 & 0,6 \\
\hline 1 & Femur5 & Z_DESLOCAMENTO_SUPERIOR & 0,0 & 0,1 & 0,3 & 0,4 & 0,6 & 0,7 \\
\hline 1 & Femur6 & Z_DESLOCAMENTO_SUPERIOR & 0,0 & 0,3 & 0,5 & 0,6 & 0,8 & 0,9 \\
\hline 1 & Femur15 & Z_DESLOCAMENTO_SUPERIOR & 0,0 & 0,1 & 0,3 & 0,6 & 0,7 & 0,9 \\
\hline 1 & Femur23 & Z_DESLOCAMENTO_SUPERIOR & 0,0 & 0,1 & 0,2 & 0,3 & 0,4 & 0,5 \\
\hline \multirow[t]{3}{*}{1} & Femur26 & Z_DESLOCAMENTO_SUPERIOR & 0,0 & 0,2 & 0,4 & 0,6 & 0,8 & 0,9 \\
\hline & & M & 0,0 & 0,2 & 0,3 & 0,5 & 0,6 & 0,8 \\
\hline & & DP & 0,0 & 0,1 & 0,1 & 0,2 & 0,2 & 0,2 \\
\hline 2 & Femur1 & Z_DESLOCAMENTO_SUPERIOR & 0,0 & 0,3 & 0,4 & 0,7 & 1,0 & 1,2 \\
\hline 2 & Femur8 & Z_DESLOCAMENTO_SUPERIOR & 0,0 & 0,1 & 0,2 & 0,4 & 0,5 & 0,6 \\
\hline 2 & Femur13 & Z_DESLOCAMENTO_SUPERIOR & 0,0 & 0,1 & 0,0 & 0,1 & 0,3 & 0,3 \\
\hline 2 & Femur14 & Z_DESLOCAMENTO_SUPERIOR & 0,0 & 0,2 & 0,3 & 0,5 & 0,6 & 0,7 \\
\hline 2 & Femur19 & Z_DESLOCAMENTO_SUPERIOR & 0,0 & 0,1 & 0,3 & 0,4 & 0,6 & 0,7 \\
\hline \multirow[t]{3}{*}{2} & Femur25 & Z_DESLOCAMENTO_SUPERIOR & 0,0 & 0,2 & 0,4 & 0,5 & 0,7 & 0,9 \\
\hline & & $M$ & 0,0 & 0,2 & 0,3 & 0,4 & 0,6 & 0,7 \\
\hline & & DP & 0,0 & 0,1 & 0,2 & 0,2 & 0,2 & 0,3 \\
\hline 3 & Femur7 & Z_DESLOCAMENTO_SUPERIOR & 0,0 & 0,1 & 0,3 & 0,4 & 0,6 & 0,8 \\
\hline 3 & Femur9 & Z_DESLOCAMENTO_SUPERIOR & 0,0 & 0,2 & 0,4 & 0,6 & 0,8 & 1,1 \\
\hline 3 & Femur17 & Z_DESLOCAMENTO_SUPERIOR & 0,0 & 0,2 & 0,5 & 0,6 & 0,9 & 1,1 \\
\hline 3 & Femur18 & Z_DESLOCAMENTO_SUPERIOR & 0,0 & 0,1 & 0,2 & 0,3 & 0,4 & 0,5 \\
\hline 3 & Femur20 & Z_DESLOCAMENTO_SUPERIOR & 0,0 & 0,0 & 0,2 & 0,3 & 0,5 & 0,5 \\
\hline \multirow[t]{3}{*}{3} & Femur24 & Z_DESLOCAMENTO_SUPERIOR & 0,0 & 0,2 & 0,4 & 0,7 & 0,8 & 1,1 \\
\hline & & M & 0,0 & 0,1 & 0,3 & 0,5 & 0,7 & 0,9 \\
\hline & & DP & 0,0 & 0,1 & 0,1 & 0,2 & 0,2 & 0,3 \\
\hline 4 & Femur4 & Z_DESLOCAMENTO_SUPERIOR & 0,0 & 0,2 & 0,3 & 0,5 & 0,7 & 0,9 \\
\hline 4 & Femur10 & Z_DESLOCAMENTO_SUPERIOR & 0,0 & 0,2 & 0,4 & 0,5 & 0,7 & 0,9 \\
\hline 4 & Femur11 & Z_DESLOCAMENTO_SUPERIOR & 0,0 & 0,4 & 0,7 & 1,0 & 1,2 & 1,5 \\
\hline 4 & Femur21 & Z_DESLOCAMENTO_SUPERIOR & 0,0 & 0,1 & 0,2 & 0,3 & 0,5 & 0,6 \\
\hline 4 & Femur27 & Z_DESLOCAMENTO_SUPERIOR & 0,0 & 0,3 & 0,5 & 0,8 & 0,9 & 1,1 \\
\hline \multirow[t]{3}{*}{4} & Femur29 & Z_DESLOCAMENTO_SUPERIOR & 0,0 & 0,3 & 0,4 & 0,6 & 0,7 & 1,0 \\
\hline & & M & 0,0 & 0,3 & 0,4 & 0,6 & 0,8 & 1,0 \\
\hline & & DP & 0,0 & 0,1 & 0,2 & 0,2 & 0,2 & 0,3 \\
\hline 5 & Femur3 & Z_DESLOCAMENTO_SUPERIOR & 0,0 & 0,3 & 0,7 & 1,0 & 1,4 & 1,8 \\
\hline 5 & Femur12 & Z_DESLOCAMENTO_SUPERIOR & 0,0 & 0,1 & 0,3 & 0,5 & 0,6 & 0,9 \\
\hline 5 & Femur16 & Z_DESLOCAMENTO_SUPERIOR & 0,0 & 0,1 & 0,2 & 0,4 & 0,5 & 0,7 \\
\hline 5 & Femur22 & Z_DESLOCAMENTO_SUPERIOR & 0,0 & 0,1 & 0,2 & 0,5 & 0,7 & 0,8 \\
\hline 5 & Femur28 & Z_DESLOCAMENTO_SUPERIOR & 0,0 & 0,1 & 0,3 & 0,4 & 0,5 & 0,7 \\
\hline \multirow[t]{3}{*}{5} & Femur30 & Z_DESLOCAMENTO_SUPERIOR & 0,0 & 0,4 & 0,5 & 0,7 & 0,8 & 0,9 \\
\hline & & M & 0,0 & 0,2 & 0,4 & 0,6 & 0,8 & 1,0 \\
\hline & & DP & 0,0 & 0,1 & 0,2 & 0,2 & 0,3 & 0,4 \\
\hline
\end{tabular}


Tabela 5.22- Valores obtidos, em mm, de deslocamentos da porção inferior dos corpos de prova em relação à situação inicial, em cada intervalo dos ensaios realizados, obtidos por análise fotogramétrica, segundo a coordenada espacial Z, nos ensaios de encurvamentoSão Paulo - 2007.

\begin{tabular}{|c|c|c|c|c|c|c|c|c|}
\hline GRUPO & FEMUR & & 0 & 12 & 24 & 36 & 48 & 60 \\
\hline 1 & Femur2 & Z_DESLOCAMENTO_INFERIOR & 0,0 & 0,1 & 0,1 & 0,0 & 0,0 & 0,1 \\
\hline 1 & Femur5 & Z_DESLOCAMENTO_INFERIOR & 0,0 & 0,0 & 0,1 & 0,1 & 0,1 & 0,1 \\
\hline 1 & Femur6 & Z_DESLOCAMENTO_INFERIOR & 0,0 & 0,0 & 0,0 & 0,1 & 0,1 & 0,2 \\
\hline 1 & Femur15 & Z_DESLOCAMENTO_INFERIOR & 0,0 & 0,0 & 0,3 & 0,4 & 0,5 & 0,6 \\
\hline 1 & Femur23 & Z_DESLOCAMENTO_INFERIOR & 0,0 & 0,0 & 0,1 & 0,1 & 0,1 & 0,2 \\
\hline \multirow[t]{3}{*}{1} & Femur26 & Z_DESLOCAMENTO_INFERIOR & 0,0 & 0,0 & 0,0 & 0,1 & 0,1 & 0,2 \\
\hline & & M & 0,0 & 0,0 & 0,1 & 0,1 & 0,2 & 0,2 \\
\hline & & DP & 0,0 & 0,0 & 0,1 & 0,1 & 0,2 & 0,2 \\
\hline 2 & Femur1 & Z_DESLOCAMENTO_INFERIOR & 0,0 & 0,0 & 0,1 & 0,1 & 0,1 & 0,1 \\
\hline 2 & Femur8 & Z_DESLOCAMENTO_INFERIOR & 0,0 & 0,0 & 0,1 & 0,2 & 0,2 & 0,2 \\
\hline 2 & Femur13 & Z_DESLOCAMENTO_INFERIOR & 0,0 & 0,0 & 0,0 & 0,1 & 0,0 & 0,1 \\
\hline 2 & Femur14 & Z_DESLOCAMENTO_INFERIOR & 0,0 & 0,0 & 0,0 & 0,1 & 0,1 & 0,1 \\
\hline 2 & Femur19 & Z_DESLOCAMENTO_INFERIOR & 0,0 & 0,1 & 0,0 & 0,1 & 0,1 & 0,1 \\
\hline \multirow[t]{3}{*}{2} & Femur25 & Z_DESLOCAMENTO_INFERIOR & 0,0 & 0,0 & 0,1 & 0,2 & 0,2 & 0,2 \\
\hline & & M & 0,0 & 0,0 & 0,1 & 0,1 & 0,1 & 0,1 \\
\hline & & DP & 0,0 & 0,0 & 0,1 & 0,1 & 0,1 & 0,1 \\
\hline 3 & Femur7 & Z_DESLOCAMENTO_INFERIOR & 0,0 & 0,0 & 0,1 & 0,1 & 0,1 & 0,2 \\
\hline 3 & Femur9 & Z_DESLOCAMENTO_INFERIOR & 0,0 & 0,1 & 0,1 & 0,2 & 0,2 & 0,3 \\
\hline 3 & Femur17 & Z_DESLOCAMENTO_INFERIOR & 0,0 & 0,0 & 0,1 & 0,2 & 0,3 & 0,4 \\
\hline 3 & Femur18 & Z_DESLOCAMENTO_INFERIOR & 0,0 & 0,0 & 0,1 & 0,2 & 0,2 & 0,2 \\
\hline 3 & Femur20 & Z_DESLOCAMENTO_INFERIOR & 0,0 & 0,0 & 0,0 & 0,1 & 0,1 & 0,1 \\
\hline \multirow[t]{3}{*}{3} & Femur24 & Z_DESLOCAMENTO_INFERIOR & 0,0 & 0,0 & 0,1 & 0,2 & 0,3 & 0,4 \\
\hline & & M & 0,0 & 0,0 & 0,1 & 0,2 & 0,2 & 0,3 \\
\hline & & DP & 0,0 & 0,0 & 0,0 & 0,1 & 0,1 & 0,1 \\
\hline 4 & Femur4 & Z_DESLOCAMENTO_INFERIOR & 0,0 & 0,0 & 0,0 & 0,0 & 0,2 & 0,2 \\
\hline 4 & Femur10 & Z_DESLOCAMENTO_INFERIOR & 0,0 & 0,0 & 0,0 & 0,0 & 0,1 & 0,2 \\
\hline 4 & Femur11 & Z_DESLOCAMENTO_INFERIOR & 0,0 & 0,1 & 0,1 & 0,1 & 0,2 & 0,2 \\
\hline 4 & Femur21 & Z_DESLOCAMENTO_INFERIOR & 0,0 & 0,0 & 0,0 & 0,1 & 0,2 & 0,2 \\
\hline 4 & Femur27 & Z_DESLOCAMENTO_INFERIOR & 0,0 & 0,1 & 0,1 & 0,2 & 0,2 & 0,3 \\
\hline \multirow[t]{3}{*}{4} & Femur29 & Z_DESLOCAMENTO_INFERIOR & 0,0 & 0,0 & 0,1 & 0,2 & 0,3 & 0,4 \\
\hline & & M & 0,0 & 0,0 & 0,1 & 0,1 & 0,2 & 0,3 \\
\hline & & DP & 0,0 & 0,1 & 0,1 & 0,1 & 0,1 & 0,1 \\
\hline 5 & Femur3 & Z_DESLOCAMENTO_INFERIOR & 0,0 & 0,0 & 0,1 & 0,1 & 0,2 & 0,2 \\
\hline 5 & Femur12 & Z_DESLOCAMENTO_INFERIOR & 0,0 & 0,1 & 0,0 & 0,1 & 0,1 & 0,2 \\
\hline 5 & Femur16 & Z_DESLOCAMENTO_INFERIOR & 0,0 & 0,0 & 0,0 & 0,1 & 0,1 & 0,1 \\
\hline 5 & Femur22 & Z_DESLOCAMENTO_INFERIOR & 0,0 & 0,1 & 0,1 & 0,1 & 0,1 & 0,2 \\
\hline 5 & Femur28 & Z_DESLOCAMENTO_INFERIOR & 0,0 & 0,0 & 0,0 & 0,1 & 0,1 & 0,1 \\
\hline \multirow[t]{3}{*}{5} & Femur30 & Z_DESLOCAMENTO_INFERIOR & 0,0 & 0,1 & 0,1 & 0,2 & 0,3 & 0,4 \\
\hline & & M & 0,0 & 0,1 & 0,1 & 0,1 & 0,2 & 0,2 \\
\hline & & DP & 0,0 & 0,1 & 0,1 & 0,0 & 0,1 & 0,1 \\
\hline
\end{tabular}




\subsubsection{Ensaio de Rotação}

Os dados obtidos refletem a movimentação interfragmentária das porções superior e inferior dos corpos de prova em cada eixo espacial, durante o ensaio de rotação. A análise dos dados, apresentados nas tabelas 5.23, 5.24, 5.25, 5.26, 5.27 e 5.28, demonstrou distribuição não paramétrica, não apresentando diferença significativa entre os grupos analisados. 
Tabela 5.23- Valores obtidos, em $\mathrm{mm}$, de deslocamentos da porção superior dos corpos de prova em relação à situação inicial, em cada intervalo dos ensaios realizados, obtidos por análise fotogramétrica, segundo a coordenada espacial X, nos ensaios de rotação- São Paulo - 2007.

\begin{tabular}{|c|c|c|c|c|c|c|c|}
\hline$\overline{\text { GRUPO FEMUR }}$ & & $\overline{0,0}$ & 0,5 & 1,0 & 1,5 & 2,0 & 2,5 \\
\hline 1 Femur2 & X_DESLOCAMENTO_SUPERIOR & 0,0 & 0,1 & 0,2 & 0,1 & 0,2 & 0,1 \\
\hline 1 Femur5 & X_DESLOCAMENTO_SUPERIOR & 0,0 & 0,1 & 0,1 & 0,2 & 0,3 & 0,3 \\
\hline 1 Femur6 & X_DESLOCAMENTO_SUPERIOR & 0,0 & 0,1 & 0,0 & 0,1 & 0,0 & 0,0 \\
\hline 1 Femur15 & X_DESLOCAMENTO_SUPERIOR & 0,0 & 0,0 & 0,2 & 0,1 & 0,2 & 0,0 \\
\hline 1 Femur23 & X_DESLOCAMENTO_SUPERIOR & 0,0 & 0,2 & 0,2 & 0,2 & 0,1 & 0,0 \\
\hline \multirow[t]{3}{*}{1 Femur26 } & X_DESLOCAMENTO_SUPERIOR & 0,0 & 0,1 & 0,1 & 0,5 & 0,7 & 0,7 \\
\hline & M & 0,0 & 0,1 & 0,1 & 0,2 & 0,3 & 0,2 \\
\hline & DP & 0,0 & 0,1 & 0,1 & 0,2 & 0,2 & 0,3 \\
\hline 2 Femur1 & X_DESLOCAMENTO_SUPERIOR & 0,0 & 0,0 & 0,0 & 0,0 & 0,1 & 0,1 \\
\hline 2 Femur8 & X_DESLOCAMENTO_SUPERIOR & 0,0 & 0,0 & 0,1 & 0,3 & 0,3 & 0,4 \\
\hline 2 Femur13 & X_DESLOCAMENTO_SUPERIOR & 0,0 & 0,0 & 0,2 & 0,2 & 0,3 & 0,4 \\
\hline 2 Femur14 & X_DESLOCAMENTO_SUPERIOR & 0,0 & 0,1 & 0,3 & 0,2 & 0,3 & 0,3 \\
\hline 2 Femur19 & X_DESLOCAMENTO_SUPERIOR & 0,0 & 0,4 & 0,3 & 0,5 & 0,4 & 0,5 \\
\hline \multirow[t]{3}{*}{2 Femur25 } & X_DESLOCAMENTO_SUPERIOR & 0,0 & 0,0 & 0,1 & 0,1 & 0,2 & 0,3 \\
\hline & M & 0,0 & 0,1 & 0,2 & 0,2 & 0,3 & 0,3 \\
\hline & DP & 0,0 & 0,2 & 0,1 & 0,2 & 0,1 & 0,1 \\
\hline 3 Femur7 & X_DESLOCAMENTO_SUPERIOR & 0,0 & 0,2 & 0,3 & 0,3 & 0,4 & 0,3 \\
\hline 3 Femur9 & X_DESLOCAMENTO_SUPERIOR & 0,0 & 0,4 & 0,5 & 0,6 & 0,6 & 0,6 \\
\hline 3 Femur17 & X_DESLOCAMENTO_SUPERIOR & 0,0 & 0,1 & 0,3 & 0,4 & 0,4 & 0,5 \\
\hline 3 Femur18 & X_DESLOCAMENTO_SUPERIOR & 0,0 & 0,5 & 0,6 & 0,8 & 0,8 & 0,9 \\
\hline 3 Femur20 & X_DESLOCAMENTO_SUPERIOR & 0,0 & 0,0 & 0,2 & 0,6 & 0,6 & 0,8 \\
\hline \multirow[t]{3}{*}{3 Femur24 } & X_DESLOCAMENTO_SUPERIOR & 0,0 & 0,0 & 0,1 & 0,1 & 0,2 & 0,1 \\
\hline & M & 0,0 & 0,2 & 0,3 & 0,5 & 0,5 & 0,5 \\
\hline & DP & 0,0 & 0,2 & 0,2 & 0,3 & 0,2 & 0,3 \\
\hline 4 Femur4 & X_DESLOCAMENTO_SUPERIOR & 0,0 & 0,3 & 0,5 & 0,7 & 0,7 & 0,7 \\
\hline 4 Femur10 & X_DESLOCAMENTO_SUPERIOR & 0,0 & 0,0 & 0,1 & 0,2 & 0,2 & 0,2 \\
\hline 4 Femur11 & X_DESLOCAMENTO_SUPERIOR & 0,0 & 0,1 & 0,4 & 0,5 & 0,5 & 0,6 \\
\hline 4 Femur21 & X_DESLOCAMENTO_SUPERIOR & 0,0 & 0,0 & 0,1 & 0,0 & 0,0 & 0,0 \\
\hline 4 Femur27 & X_DESLOCAMENTO_SUPERIOR & 0,0 & 0,4 & 0,6 & 0,7 & 1,5 & 1,5 \\
\hline \multirow[t]{3}{*}{4 Femur29 } & X_DESLOCAMENTO_SUPERIOR & 0,0 & 0,0 & 0,1 & 0,2 & 0,1 & 0,0 \\
\hline & M & 0,0 & 0,1 & 0,3 & 0,4 & 0,5 & 0,5 \\
\hline & DP & 0,0 & 0,2 & 0,2 & 0,3 & 0,6 & 0,6 \\
\hline 5 Femur3 & X_DESLOCAMENTO_SUPERIOR & 0,0 & 0,7 & 0,6 & 0,6 & 0,7 & 0,7 \\
\hline 5 Femur12 & X_DESLOCAMENTO_SUPERIOR & 0,0 & 0,0 & 0,1 & 0,1 & 0,1 & 0,1 \\
\hline 5 Femur16 & X_DESLOCAMENTO_SUPERIOR & 0,0 & 0,3 & 0,3 & 0,2 & 0,2 & 0,2 \\
\hline 5 Femur22 & X_DESLOCAMENTO_SUPERIOR & 0,0 & 0,0 & 0,1 & 0,1 & 0,1 & 0,2 \\
\hline 5 Femur28 & X_DESLOCAMENTO_SUPERIOR & 0,0 & 0,1 & 0,3 & 0,7 & 0,6 & 0,8 \\
\hline \multirow[t]{3}{*}{5 Femur30 } & X_DESLOCAMENTO_SUPERIOR & 0,0 & 0,0 & 0,1 & 0,0 & 0,1 & 0,1 \\
\hline & M & 0,0 & 0,2 & 0,3 & 0,3 & 0,3 & 0,4 \\
\hline & $\mathrm{DP}$ & 0,0 & 0,3 & 0,2 & 0,3 & 0,3 & 0,3 \\
\hline
\end{tabular}


Tabela 5.24- Valores obtidos, em mm, de deslocamentos da porção inferior dos corpos de prova em relação à situação inicial, em cada intervalo dos ensaios realizados, obtidos por análise fotogramétrica, segundo a coordenada espacial X, nos ensaios de rotação- São Paulo - 2007.

\begin{tabular}{|c|c|c|c|c|c|c|c|}
\hline $\begin{array}{ll}\text { GRUPO } & \text { FEMUR }\end{array}$ & & 0,0 & 0,5 & 1,0 & 1,5 & 2,0 & 2,5 \\
\hline 1 Femur2 & X_DESLOCAMENTO_INFERIOR & 0,0 & 0,1 & 0,0 & 0,1 & 0,0 & 0,0 \\
\hline 1 Femur5 & X_DESLOCAMENTO_INFERIOR & 0,0 & 0,0 & 0,0 & 0,0 & 0,0 & 0,1 \\
\hline 1 Femur6 & X_DESLOCAMENTO_INFERIOR & 0,0 & 0,1 & 0,0 & 0,0 & 0,0 & 0,0 \\
\hline 1 Femur15 & X_DESLOCAMENTO_INFERIOR & 0,0 & 0,1 & 0,2 & 0,3 & 0,4 & 0,4 \\
\hline 1 Femur23 & X_DESLOCAMENTO_INFERIOR & 0,0 & 0,0 & 0,0 & 0,0 & 0,0 & 0,1 \\
\hline 1 Femur26 & X_DESLOCAMENTO_INFERIOR & 0,0 & 0,1 & 0,1 & 0,1 & 0,2 & 0,1 \\
\hline & M & 0,0 & 0,1 & 0,1 & 0,1 & 0,1 & 0,1 \\
\hline & $\mathrm{DP}$ & 0,0 & 0,1 & 0,1 & 0,1 & 0,2 & 0,1 \\
\hline 2 Femur1 & X_DESLOCAMENTO_INFERIOR & 0,0 & 0,0 & 0,0 & 0,0 & 0,1 & 0,1 \\
\hline 2 Femur8 & X_DESLOCAMENTO_INFERIOR & 0,0 & 0,0 & 0,0 & 0,0 & 0,0 & 0,0 \\
\hline 2 Femur13 & X_DESLOCAMENTO_INFERIOR & 0,0 & 0,0 & 0,0 & 0,1 & 0,1 & 0,1 \\
\hline 2 Femur14 & X_DESLOCAMENTO_INFERIOR & 0,0 & 0,2 & 0,3 & 0,3 & 0,3 & 0,4 \\
\hline 2 Femur19 & X_DESLOCAMENTO_INFERIOR & 0,0 & 0,1 & 0,1 & 0,2 & 0,1 & 0,2 \\
\hline 2 Femur25 & X_DESLOCAMENTO_INFERIOR & 0,0 & 0,0 & 0,0 & 0,0 & 0,0 & 0,1 \\
\hline & M & 0,0 & 0,1 & 0,1 & 0,1 & 0,1 & 0,2 \\
\hline & DP & 0,0 & 0,1 & 0,1 & 0,1 & 0,1 & 0,1 \\
\hline 3 Femur7 & X_DESLOCAMENTO_INFERIOR & 0,0 & 0,1 & 0,2 & 0,1 & 0,2 & 0,2 \\
\hline 3 Femur9 & X_DESLOCAMENTO_INFERIOR & 0,0 & 0,0 & 0,0 & 0,0 & 0,0 & 0,0 \\
\hline 3 Femur17 & X_DESLOCAMENTO_INFERIOR & 0,0 & 0,1 & 0,2 & 0,1 & 0,0 & 0,0 \\
\hline 3 Femur18 & X_DESLOCAMENTO_INFERIOR & 0,0 & 0,0 & 0,1 & 0,1 & 0,1 & 0,1 \\
\hline 3 Femur20 & X_DESLOCAMENTO_INFERIOR & 0,0 & 0,1 & 0,1 & 0,1 & 0,0 & 0,1 \\
\hline 3 Femur24 & X_DESLOCAMENTO_INFERIOR & 0,0 & 0,1 & 0,1 & 0,1 & 0,2 & 0,1 \\
\hline & M & 0,0 & 0,1 & 0,1 & 0,1 & 0,1 & 0,1 \\
\hline & DP & 0,0 & 0,1 & 0,1 & 0,0 & 0,1 & 0,1 \\
\hline 4 Femur4 & X_DESLOCAMENTO_INFERIOR & 0,0 & 0,0 & 0,0 & 0,0 & 0,0 & 0,0 \\
\hline 4 Femur10 & X_DESLOCAMENTO_INFERIOR & 0,0 & 0,1 & 0,0 & 0,0 & 0,1 & 0,1 \\
\hline 4 Femur11 & X_DESLOCAMENTO_INFERIOR & 0,0 & 0,0 & 0,0 & 0,0 & 0,0 & 0,1 \\
\hline 4 Femur21 & X_DESLOCAMENTO_INFERIOR & 0,0 & 0,1 & 0,1 & 0,1 & 0,1 & 0,2 \\
\hline 4 Femur27 & X_DESLOCAMENTO_INFERIOR & 0,0 & 0,2 & 0,2 & 0,2 & 0,4 & 0,4 \\
\hline 4 Femur29 & X_DESLOCAMENTO_INFERIOR & 0,0 & 0,0 & 0,0 & 0,0 & 0,1 & 0,1 \\
\hline & M & 0,0 & 0,1 & 0,1 & 0,1 & 0,1 & 0,2 \\
\hline & DP & 0,0 & 0,1 & 0,1 & 0,1 & 0,1 & 0,1 \\
\hline 5 Femur3 & X_DESLOCAMENTO_INFERIOR & 0,0 & 0,1 & 0,1 & 0,1 & 0,2 & 0,2 \\
\hline 5 Femur12 & X_DESLOCAMENTO_INFERIOR & 0,0 & 0,0 & 0,0 & 0,0 & 0,0 & 0,0 \\
\hline 5 Femur16 & X_DESLOCAMENTO_INFERIOR & 0,0 & 0,1 & 0,1 & 0,2 & 0,2 & 0,2 \\
\hline 5 Femur22 & X_DESLOCAMENTO_INFERIOR & 0,0 & 0,0 & 0,0 & 0,0 & 0,1 & 0,0 \\
\hline 5 Femur28 & X_DESLOCAMENTO_INFERIOR & 0,0 & 0,0 & 0,0 & 0,1 & 0,1 & 0,1 \\
\hline 5 Femur30 & X_DESLOCAMENTO_INFERIOR & 0,0 & 0,0 & 0,0 & 0,1 & 0,1 & 0,1 \\
\hline & M & 0,0 & 0,0 & 0,0 & 0,1 & 0,1 & 0,1 \\
\hline & DP & 0,0 & 0,1 & 0,1 & 0,1 & 0,1 & 0,1 \\
\hline
\end{tabular}


Tabela 5.25- Valores obtidos, em $\mathrm{mm}$, de deslocamentos da porção superior dos corpos de prova em relação à situação inicial, em cada intervalo dos ensaios realizados, obtidos por análise fotogramétrica, segundo a coordenada espacial $\mathrm{Y}$, nos ensaios de rotação- São Paulo - 2007.

\begin{tabular}{|c|c|c|c|c|c|c|c|}
\hline GRUPO FEMUR & & 0,0 & 0,5 & 1,0 & 1,5 & 2,0 & 2,5 \\
\hline 1 Femur2 & Y_DESLOCAMENTO_SUPERIOR & 0,0 & 1,6 & 2,7 & 4,3 & 4,6 & 4,9 \\
\hline 1 Femur5 & Y_DESLOCAMENTO_SUPERIOR & 0,0 & 0,3 & 0,7 & 1,0 & 1,2 & 1,5 \\
\hline 1 Femur6 & Y_DESLOCAMENTO_SUPERIOR & 0,0 & 3,5 & 4,6 & 5,0 & 5,2 & 5,4 \\
\hline 1 Femur15 & Y_DESLOCAMENTO_SUPERIOR & 0,0 & 1,7 & 2,5 & 3,1 & 3,4 & 3,7 \\
\hline 1 Femur23 & Y_DESLOCAMENTO_SUPERIOR & 0,0 & 0,1 & 0,3 & 0,5 & 0,7 & 1,0 \\
\hline \multirow[t]{3}{*}{1 Femur26 } & Y_DESLOCAMENTO_SUPERIOR & 0,0 & 0,1 & 0,5 & 2,1 & 2,5 & 2,8 \\
\hline & M & 0,0 & 1,2 & 1,9 & 2,7 & 2,9 & 3,2 \\
\hline & DP & 0,0 & 1,3 & 1,7 & 1,8 & 1,8 & 1,8 \\
\hline 2 Femur1 & Y_DESLOCAMENTO_SUPERIOR & 0,0 & 4,9 & 5,5 & 5,9 & 6,1 & 6,4 \\
\hline 2 Femur8 & Y_DESLOCAMENTO_SUPERIOR & 0,0 & 0,1 & 0,3 & 2,0 & 2,2 & 2,3 \\
\hline 2 Femur13 & Y_DESLOCAMENTO_SUPERIOR & 0,0 & 0,2 & 0,8 & 1,5 & 2,1 & 2,9 \\
\hline 2 Femur14 & Y_DESLOCAMENTO_SUPERIOR & 0,0 & 3,5 & 3,8 & 3,9 & 4,1 & 4,2 \\
\hline 2 Femur19 & Y_DESLOCAMENTO_SUPERIOR & 0,0 & 1,8 & 3,2 & 3,7 & 3,9 & 4,2 \\
\hline \multirow[t]{3}{*}{2 Femur25 } & Y_DESLOCAMENTO_SUPERIOR & 0,0 & 0,3 & 0,8 & 1,1 & 1,7 & 1,9 \\
\hline & M & 0,0 & 1,8 & 2,4 & 3,0 & 3,4 & 3,7 \\
\hline & DP & 0,0 & 2,0 & 2,1 & 1,8 & 1,7 & 1,7 \\
\hline 3 Femur7 & Y_DESLOCAMENTO_SUPERIOR & 0,0 & 2,2 & 3,3 & 3,8 & 4,0 & 4,3 \\
\hline 3 Femur9 & Y_DESLOCAMENTO_SUPERIOR & 0,0 & 3,9 & 5,3 & 5,6 & 5,9 & 6,2 \\
\hline 3 Femur17 & Y_DESLOCAMENTO_SUPERIOR & 0,0 & 3,9 & 5,1 & 5,5 & 5,8 & 6,0 \\
\hline 3 Femur18 & Y_DESLOCAMENTO_SUPERIOR & 0,0 & 2,4 & 3,1 & 3,4 & 3,5 & 3,7 \\
\hline 3 Femur20 & Y_DESLOCAMENTO_SUPERIOR & 0,0 & 0,0 & 0,4 & 2,0 & 2,2 & 2,5 \\
\hline \multirow[t]{3}{*}{3 Femur24 } & Y_DESLOCAMENTO_SUPERIOR & 0,0 & 0,2 & 1,1 & 2,0 & 2,6 & 3,4 \\
\hline & M & 0,0 & 2,1 & 3,1 & 3,7 & 4,0 & 4,4 \\
\hline & DP & 0,0 & 1,7 & 2,0 & 1,6 & 1,6 & 1,5 \\
\hline 4 Femur4 & Y_DESLOCAMENTO_SUPERIOR & 0,0 & 1,6 & 2,7 & 3,2 & 3,7 & 4,0 \\
\hline 4 Femur10 & Y_DESLOCAMENTO_SUPERIOR & 0,0 & 4,3 & 4,8 & 5,1 & 5,3 & 5,6 \\
\hline 4 Femur11 & Y_DESLOCAMENTO_SUPERIOR & 0,0 & 0,2 & 3,7 & 4,1 & 4,4 & 4,5 \\
\hline 4 Femur21 & Y_DESLOCAMENTO_SUPERIOR & 0,0 & 0,3 & 0,9 & 1,1 & 1,4 & 1,6 \\
\hline 4 Femur27 & Y_DESLOCAMENTO_SUPERIOR & 0,0 & 2,4 & 3,4 & 3,8 & 4,6 & 5,1 \\
\hline \multirow[t]{3}{*}{4 Femur29 } & Y_DESLOCAMENTO_SUPERIOR & 0,0 & 0,3 & 0,9 & 1,4 & 2,1 & 2,4 \\
\hline & M & 0,0 & 1,5 & 2,7 & 3,1 & 3,6 & 3,9 \\
\hline & DP & 0,0 & 1,6 & 1,6 & 1,6 & 1,5 & 1,6 \\
\hline 5 Femur3 & Y_DESLOCAMENTO_SUPERIOR & 0,0 & 6,1 & 6,4 & 6,7 & 6,8 & 7,1 \\
\hline 5 Femur12 & Y_DESLOCAMENTO_SUPERIOR & 0,0 & 2,8 & 3,5 & 3,9 & 4,1 & 4,5 \\
\hline 5 Femur16 & Y_DESLOCAMENTO_SUPERIOR & 0,0 & 0,9 & 1,8 & 2,0 & 2,2 & 2,3 \\
\hline 5 Femur22 & Y_DESLOCAMENTO_SUPERIOR & 0,0 & 0,2 & 1,1 & 1,9 & 2,3 & 2,7 \\
\hline 5 Femur28 & Y_DESLOCAMENTO_SUPERIOR & 0,0 & 0,0 & 1,2 & 2,0 & 2,2 & 2,3 \\
\hline \multirow[t]{3}{*}{5 Femur30 } & Y_DESLOCAMENTO_SUPERIOR & 0,0 & 0,5 & 2,4 & 3,1 & 3,4 & 3,7 \\
\hline & M & 0,0 & 1,8 & 2,7 & 3,3 & 3,5 & 3,8 \\
\hline & DP & 0,0 & 2,4 & 2,0 & 1,9 & 1,8 & 1,8 \\
\hline
\end{tabular}


Tabela 5.26- Valores obtidos, em mm, de deslocamentos da porção inferior dos corpos de prova em relação à situação inicial, em cada intervalo dos ensaios realizados, obtidos por análise fotogramétrica, segundo a coordenada espacial $\mathrm{Y}$, nos ensaios de rotação- São Paulo - 2007.

\begin{tabular}{|c|c|c|c|c|c|c|c|}
\hline GRUPO FEMUR & & 0,0 & 0,5 & 1,0 & 1,5 & 2,0 & 2,5 \\
\hline 1 Femur2 & Y_DESLOCAMENTO_INFERIOR & 0,0 & 0,0 & 0,0 & 0,0 & 0,0 & 0,0 \\
\hline 1 Femur5 & Y_DESLOCAMENTO_INFERIOR & 0,0 & 0,0 & 0,0 & 0,0 & 0,0 & 0,1 \\
\hline 1 Femur6 & Y_DESLOCAMENTO_INFERIOR & 0,0 & 0,0 & 0,1 & 0,1 & 0,1 & 0,1 \\
\hline 1 Femur15 & Y_DESLOCAMENTO_INFERIOR & 0,0 & 0,0 & 0,0 & 0,0 & 0,0 & 0,0 \\
\hline 1 Femur23 & Y_DESLOCAMENTO_INFERIOR & 0,0 & 0,0 & 0,1 & 0,1 & 0,1 & 0,1 \\
\hline \multirow[t]{3}{*}{1 Femur26 } & Y_DESLOCAMENTO_INFERIOR & 0,0 & 0,0 & 0,0 & 0,0 & 0,0 & 0,0 \\
\hline & M & 0,0 & 0,0 & 0,0 & 0,0 & 0,0 & 0,1 \\
\hline & DP & 0,0 & 0,0 & 0,1 & 0,1 & 0,1 & 0,1 \\
\hline 2 Femur1 & Y_DESLOCAMENTO_INFERIOR & 0,0 & 0,1 & 0,2 & 0,2 & 0,2 & 0,2 \\
\hline 2 Femur8 & Y_DESLOCAMENTO_INFERIOR & 0,0 & 0,0 & 0,0 & 0,1 & 0,0 & 0,0 \\
\hline 2 Femur13 & Y_DESLOCAMENTO_INFERIOR & 0,0 & 0,0 & 0,0 & 0,0 & 0,1 & 0,1 \\
\hline 2 Femur14 & Y_DESLOCAMENTO_INFERIOR & 0,0 & 0,1 & 0,1 & 0,0 & 0,1 & 0,0 \\
\hline 2 Femur19 & Y_DESLOCAMENTO_INFERIOR & 0,0 & 0,0 & 0,0 & 0,0 & 0,0 & 0,0 \\
\hline \multirow[t]{3}{*}{2 Femur25 } & Y_DESLOCAMENTO_INFERIOR & 0,0 & 0,1 & 0,1 & 0,2 & 0,2 & 0,2 \\
\hline & M & 0,0 & 0,1 & 0,1 & 0,1 & 0,1 & 0,1 \\
\hline & DP & 0,0 & 0,1 & 0,1 & 0,1 & 0,1 & 0,1 \\
\hline 3 Femur7 & Y_DESLOCAMENTO_INFERIOR & 0,0 & 0,1 & 0,2 & 0,3 & 0,3 & 0,3 \\
\hline 3 Femur9 & Y_DESLOCAMENTO_INFERIOR & 0,0 & 0,0 & 0,1 & 0,1 & 0,1 & 0,1 \\
\hline 3 Femur17 & Y_DESLOCAMENTO_INFERIOR & 0,0 & 0,0 & 0,0 & 0,0 & 0,0 & 0,0 \\
\hline 3 Femur18 & Y_DESLOCAMENTO_INFERIOR & 0,0 & 0,0 & 0,0 & 0,0 & 0,0 & 0,0 \\
\hline 3 Femur20 & Y_DESLOCAMENTO_INFERIOR & 0,0 & 0,0 & 0,0 & 0,0 & 0,1 & 0,0 \\
\hline \multirow[t]{3}{*}{3 Femur24 } & Y_DESLOCAMENTO_INFERIOR & 0,0 & 0,0 & 0,0 & 0,0 & 0,1 & 0,1 \\
\hline & M & 0,0 & 0,0 & 0,1 & 0,1 & 0,1 & 0,1 \\
\hline & DP & 0,0 & 0,0 & 0,1 & 0,1 & 0,1 & 0,1 \\
\hline 4 Femur4 & Y_DESLOCAMENTO_INFERIOR & 0,0 & 0,0 & 0,1 & 0,1 & 0,1 & 0,2 \\
\hline 4 Femur10 & Y_DESLOCAMENTO_INFERIOR & 0,0 & 0,1 & 0,1 & 0,1 & 0,2 & 0,2 \\
\hline 4 Femur11 & Y_DESLOCAMENTO_INFERIOR & 0,0 & 0,0 & 0,1 & 0,1 & 0,1 & 0,0 \\
\hline 4 Femur21 & Y_DESLOCAMENTO_INFERIOR & 0,0 & 0,0 & 0,1 & 0,1 & 0,1 & 0,1 \\
\hline 4 Femur27 & Y_DESLOCAMENTO_INFERIOR & 0,0 & 0,1 & 0,0 & 0,0 & 0,3 & 0,3 \\
\hline \multirow[t]{3}{*}{4 Femur29 } & Y_DESLOCAMENTO_INFERIOR & 0,0 & 0,0 & 0,0 & 0,0 & 0,0 & 0,0 \\
\hline & M & 0,0 & 0,0 & 0,1 & 0,1 & 0,1 & 0,1 \\
\hline & DP & 0,0 & 0,1 & 0,1 & 0,1 & 0,1 & 0,1 \\
\hline 5 Femur3 & Y_DESLOCAMENTO_INFERIOR & 0,0 & 0,0 & 0,0 & 0,0 & 0,0 & 0,0 \\
\hline 5 Femur12 & Y_DESLOCAMENTO_INFERIOR & 0,0 & 0,0 & 0,0 & 0,0 & 0,1 & 0,1 \\
\hline 5 Femur16 & Y_DESLOCAMENTO_INFERIOR & 0,0 & 0,0 & 0,1 & 0,0 & 0,0 & 0,1 \\
\hline 5 Femur22 & Y_DESLOCAMENTO_INFERIOR & 0,0 & 0,0 & 0,1 & 0,1 & 0,1 & 0,1 \\
\hline 5 Femur28 & Y_DESLOCAMENTO_INFERIOR & 0,0 & 0,0 & 0,0 & 0,0 & 0,0 & 0,1 \\
\hline \multirow[t]{3}{*}{5 Femur30 } & Y_DESLOCAMENTO_INFERIOR & 0,0 & 0,0 & 0,0 & 0,0 & 0,0 & 0,0 \\
\hline & M & 0,0 & 0,0 & 0,0 & 0,0 & 0,0 & 0,1 \\
\hline & DP & 0,0 & 0,0 & 0,1 & 0,0 & 0,1 & 0,1 \\
\hline
\end{tabular}


Tabela 5.27- Valores obtidos, em $\mathrm{mm}$, de deslocamentos da porção superior dos corpos de prova em relação à situação inicial, em cada intervalo dos ensaios realizados, obtidos por análise fotogramétrica, segundo a coordenada espacial Z, nos ensaios de rotação- São Paulo - 2007.

\begin{tabular}{|c|c|c|c|c|c|c|c|}
\hline GRUPO FEMUR & & 0,0 & 0,5 & 1,0 & 1,5 & 2,0 & 2,5 \\
\hline 1 Femur2 & Z_DESLOCAMENTO_SUPERIOR & 0,0 & 0,2 & 0,2 & 0,3 & 0,4 & 0,5 \\
\hline 1 Femur5 & Z_DESLOCAMENTO_SUPERIOR & 0,0 & 0,1 & 0,0 & 0,0 & 0,1 & 0,1 \\
\hline 1 Femur6 & Z_DESLOCAMENTO_SUPERIOR & 0,0 & 0,2 & 0,2 & 0,3 & 0,3 & 0,3 \\
\hline 1 Femur15 & Z_DESLOCAMENTO_SUPERIOR & 0,0 & 0,1 & 0,1 & 0,2 & 0,2 & 0,2 \\
\hline 1 Femur23 & Z_DESLOCAMENTO_SUPERIOR & 0,0 & 0,0 & 0,0 & 0,1 & 0,0 & 0,1 \\
\hline \multirow[t]{3}{*}{1 Femur26 } & Z_DESLOCAMENTO_SUPERIOR & 0,0 & 0,0 & 0,1 & 0,2 & 0,2 & 0,2 \\
\hline & M & 0,0 & 0,1 & 0,1 & 0,2 & 0,2 & 0,2 \\
\hline & DP & 0,0 & 0,1 & 0,1 & 0,1 & 0,1 & 0,2 \\
\hline 2 Femur1 & Z_DESLOCAMENTO_SUPERIOR & 0,0 & 0,3 & 0,4 & 0,4 & 0,3 & 0,3 \\
\hline 2 Femur8 & Z_DESLOCAMENTO_SUPERIOR & 0,0 & 0,0 & 0,0 & 0,3 & 0,3 & 0,3 \\
\hline 2 Femur13 & Z_DESLOCAMENTO_SUPERIOR & 0,0 & 0,0 & 0,0 & 0,1 & 0,1 & 0,2 \\
\hline 2 Femur14 & Z_DESLOCAMENTO_SUPERIOR & 0,0 & 0,1 & 0,1 & 0,1 & 0,1 & 0,2 \\
\hline 2 Femur19 & Z_DESLOCAMENTO_SUPERIOR & 0,0 & 0,1 & 0,3 & 0,3 & 0,3 & 0,4 \\
\hline \multirow[t]{3}{*}{2 Femur25 } & Z_DESLOCAMENTO_SUPERIOR & 0,0 & 0,0 & 0,1 & 0,1 & 0,1 & 0,1 \\
\hline & M & 0,0 & 0,1 & 0,2 & 0,2 & 0,2 & 0,3 \\
\hline & DP & 0,0 & 0,1 & 0,2 & 0,1 & 0,1 & 0,1 \\
\hline 3 Femur7 & Z_DESLOCAMENTO_SUPERIOR & 0,0 & 0,3 & 0,4 & 0,4 & 0,4 & 0,4 \\
\hline 3 Femur9 & Z_DESLOCAMENTO_SUPERIOR & 0,0 & 0,0 & 0,0 & 0,0 & 0,0 & 0,0 \\
\hline 3 Femur17 & Z_DESLOCAMENTO_SUPERIOR & 0,0 & 0,2 & 0,3 & 0,3 & 0,4 & 0,3 \\
\hline 3 Femur18 & Z_DESLOCAMENTO_SUPERIOR & 0,0 & 0,2 & 0,3 & 0,3 & 0,4 & 0,4 \\
\hline 3 Femur20 & Z_DESLOCAMENTO_SUPERIOR & 0,0 & 0,0 & 0,1 & 0,1 & 0,2 & 0,2 \\
\hline \multirow[t]{3}{*}{3 Femur24 } & Z_DESLOCAMENTO_SUPERIOR & 0,0 & 0,0 & 0,0 & 0,2 & 0,2 & 0,3 \\
\hline & M & 0,0 & 0,1 & 0,2 & 0,2 & 0,3 & 0,3 \\
\hline & DP & 0,0 & 0,1 & 0,2 & 0,1 & 0,2 & 0,2 \\
\hline 4 Femur4 & Z_DESLOCAMENTO_SUPERIOR & 0,0 & 0,1 & 0,1 & 0,2 & 0,3 & 0,3 \\
\hline 4 Femur10 & Z_DESLOCAMENTO_SUPERIOR & 0,0 & 0,3 & 0,4 & 0,4 & 0,4 & 0,4 \\
\hline 4 Femur11 & Z_DESLOCAMENTO_SUPERIOR & 0,0 & 0,0 & 0,4 & 0,4 & 0,4 & 0,3 \\
\hline 4 Femur21 & Z_DESLOCAMENTO_SUPERIOR & 0,0 & 0,0 & 0,1 & 0,2 & 0,2 & 0,2 \\
\hline 4 Femur27 & Z_DESLOCAMENTO_SUPERIOR & 0,0 & 0,1 & 0,3 & 0,4 & 0,3 & 0,4 \\
\hline \multirow[t]{3}{*}{4 Femur29 } & Z_DESLOCAMENTO_SUPERIOR & 0,0 & 0,0 & 0,1 & 0,2 & 0,2 & 0,3 \\
\hline & M & 0,0 & 0,1 & 0,2 & 0,3 & 0,3 & 0,3 \\
\hline & DP & 0,0 & 0,1 & 0,2 & 0,1 & 0,1 & 0,1 \\
\hline 5 Femur3 & Z_DESLOCAMENTO_SUPERIOR & 0,0 & 0,4 & 0,5 & 0,5 & 0,5 & 0,5 \\
\hline 5 Femur12 & Z_DESLOCAMENTO_SUPERIOR & 0,0 & 0,1 & 0,2 & 0,3 & 0,3 & 0,3 \\
\hline 5 Femur16 & Z_DESLOCAMENTO_SUPERIOR & 0,0 & 0,0 & 0,2 & 0,2 & 0,1 & 0,2 \\
\hline 5 Femur22 & Z_DESLOCAMENTO_SUPERIOR & 0,0 & 0,0 & 0,0 & 0,1 & 0,1 & 0,2 \\
\hline 5 Femur28 & Z_DESLOCAMENTO_SUPERIOR & 0,0 & 0,0 & 0,1 & 0,3 & 0,3 & 0,4 \\
\hline \multirow[t]{3}{*}{5 Femur30 } & Z_DESLOCAMENTO_SUPERIOR & 0,0 & 0,0 & 0,2 & 0,3 & 0,3 & 0,4 \\
\hline & $M$ & 0,0 & 0,1 & 0,2 & 0,3 & 0,3 & 0,3 \\
\hline & DP & 0,0 & 0,2 & 0,2 & 0,1 & 0,2 & 0,1 \\
\hline
\end{tabular}


Tabela 5.28- Valores obtidos, em mm, de deslocamentos da porção inferior dos corpos de prova em relação à situação inicial, em cada intervalo dos ensaios realizados, obtidos por análise fotogramétrica, segundo a coordenada espacial Z, nos ensaios de rotação- São Paulo - 2007.

\begin{tabular}{|c|c|c|c|c|c|c|c|}
\hline GRUPO FEMUR & & 0,0 & 0,5 & 1,0 & 1,5 & 2,0 & 2,5 \\
\hline 1 Femur2 & Z_DESLOCAMENTO_INFERIOR & 0,0 & 0,0 & 0,0 & 0,1 & 0,0 & 0,1 \\
\hline 1 Femur5 & Z_DESLOCAMENTO_INFERIOR & 0,0 & 0,0 & 0,0 & 0,0 & 0,1 & 0,0 \\
\hline 1 Femur6 & Z_DESLOCAMENTO_INFERIOR & 0,0 & 0,1 & 0,1 & 0,1 & 0,0 & 0,0 \\
\hline 1 Femur15 & Z_DESLOCAMENTO_INFERIOR & 0,0 & 0,0 & 0,1 & 0,1 & 0,1 & 0,1 \\
\hline 1 Femur23 & Z_DESLOCAMENTO_INFERIOR & 0,0 & 0,0 & 0,0 & 0,0 & 0,0 & 0,0 \\
\hline 1 Femur26 & Z_DESLOCAMENTO_INFERIOR & 0,0 & 0,0 & 0,0 & 0,0 & 0,0 & 0,0 \\
\hline & M & 0,0 & 0,0 & 0,0 & 0,1 & 0,0 & 0,0 \\
\hline & DP & 0,0 & 0,0 & 0,1 & 0,1 & 0,1 & 0,1 \\
\hline 2 Femur1 & Z_DESLOCAMENTO_INFERIOR & 0,0 & 0,0 & 0,1 & 0,0 & 0,0 & 0,0 \\
\hline 2 Femur8 & Z_DESLOCAMENTO_INFERIOR & 0,0 & 0,0 & 0,0 & 0,0 & 0,0 & 0,0 \\
\hline 2 Femur13 & Z_DESLOCAMENTO_INFERIOR & 0,0 & 0,0 & 0,0 & 0,0 & 0,0 & 0,0 \\
\hline 2 Femur14 & Z_DESLOCAMENTO_INFERIOR & 0,0 & 0,1 & 0,1 & 0,1 & 0,1 & 0,1 \\
\hline 2 Femur19 & Z_DESLOCAMENTO_INFERIOR & 0,0 & 0,1 & 0,0 & 0,1 & 0,0 & 0,1 \\
\hline 2 Femur25 & Z_DESLOCAMENTO_INFERIOR & 0,0 & 0,1 & 0,0 & 0,0 & 0,0 & 0,0 \\
\hline & M & 0,0 & 0,1 & 0,0 & 0,0 & 0,0 & 0,0 \\
\hline & DP & 0,0 & 0,1 & 0,1 & 0,1 & 0,0 & 0,1 \\
\hline 3 Femur7 & Z_DESLOCAMENTO_INFERIOR & 0,0 & 0,0 & 0,0 & 0,0 & 0,0 & 0,0 \\
\hline 3 Femur9 & Z_DESLOCAMENTO_INFERIOR & 0,0 & 0,0 & 0,0 & 0,0 & 0,0 & 0,0 \\
\hline 3 Femur17 & Z_DESLOCAMENTO_INFERIOR & 0,0 & 0,0 & 0,0 & 0,0 & 0,0 & 0,1 \\
\hline 3 Femur18 & Z_DESLOCAMENTO_INFERIOR & 0,0 & 0,1 & 0,1 & 0,0 & 0,0 & 0,0 \\
\hline 3 Femur20 & Z_DESLOCAMENTO_INFERIOR & 0,0 & 0,0 & 0,0 & 0,0 & 0,1 & 0,0 \\
\hline 3 Femur24 & Z_DESLOCAMENTO_INFERIOR & 0,0 & 0,0 & 0,0 & 0,0 & 0,0 & 0,0 \\
\hline & M & 0,0 & 0,0 & 0,0 & 0,0 & 0,0 & 0,0 \\
\hline & DP & 0,0 & 0,0 & 0,0 & 0,0 & 0,0 & 0,0 \\
\hline 4 Femur4 & Z_DESLOCAMENTO_INFERIOR & 0,0 & 0,1 & 0,1 & 0,1 & 0,1 & 0,1 \\
\hline 4 Femur10 & Z_DESLOCAMENTO_INFERIOR & 0,0 & 0,1 & 0,0 & 0,0 & 0,1 & 0,0 \\
\hline 4 Femur11 & Z_DESLOCAMENTO_INFERIOR & 0,0 & 0,1 & 0,0 & 0,0 & 0,0 & 0,1 \\
\hline 4 Femur21 & Z_DESLOCAMENTO_INFERIOR & 0,0 & 0,0 & 0,0 & 0,0 & 0,0 & 0,1 \\
\hline 4 Femur27 & Z_DESLOCAMENTO_INFERIOR & 0,0 & 0,0 & 0,0 & 0,0 & 0,1 & 0,0 \\
\hline 4 Femur29 & Z_DESLOCAMENTO_INFERIOR & 0,0 & 0,0 & 0,0 & 0,0 & 0,1 & 0,1 \\
\hline & M & 0,0 & 0,1 & 0,0 & 0,0 & 0,1 & 0,1 \\
\hline & DP & 0,0 & 0,1 & 0,0 & 0,0 & 0,1 & 0,1 \\
\hline 5 Femur3 & Z_DESLOCAMENTO_INFERIOR & 0,0 & 0,1 & 0,0 & 0,1 & 0,1 & 0,1 \\
\hline 5 Femur12 & Z_DESLOCAMENTO_INFERIOR & 0,0 & 0,0 & 0,0 & 0,0 & 0,0 & 0,0 \\
\hline 5 Femur16 & Z_DESLOCAMENTO_INFERIOR & 0,0 & 0,0 & 0,0 & 0,1 & 0,0 & 0,1 \\
\hline 5 Femur22 & Z_DESLOCAMENTO_INFERIOR & 0,0 & 0,0 & 0,0 & 0,0 & 0,0 & 0,0 \\
\hline 5 Femur28 & Z_DESLOCAMENTO_INFERIOR & 0,0 & 0,0 & 0,0 & 0,0 & 0,0 & 0,1 \\
\hline 5 Femur30 & Z_DESLOCAMENTO_INFERIOR & 0,0 & 0,0 & 0,0 & 0,1 & 0,0 & 0,0 \\
\hline & M & 0,0 & 0,0 & 0,0 & 0,1 & 0,0 & 0,1 \\
\hline & DP & 0,0 & 0,0 & 0,0 & 0,1 & 0,0 & 0,1 \\
\hline
\end{tabular}




\subsection{GRÁFICOS DE COMPARAÇÃO DAS MÉDIAS OBTIDAS NO DESLOCAMENTO}

Pela análise dos gráficos de comparação das médias, melhor compreende-se o comportamento dos corpos de prova durante os ensaios propostos. Foram demonstrados os gráficos de deslocamento tridimensional da porção superior dos corpos de prova em relação à porção inferior, para cada ensaio, dispostos nas figuras 5.1, 5.2 e 5.3.

\subsubsection{Ensaio de Compressão}

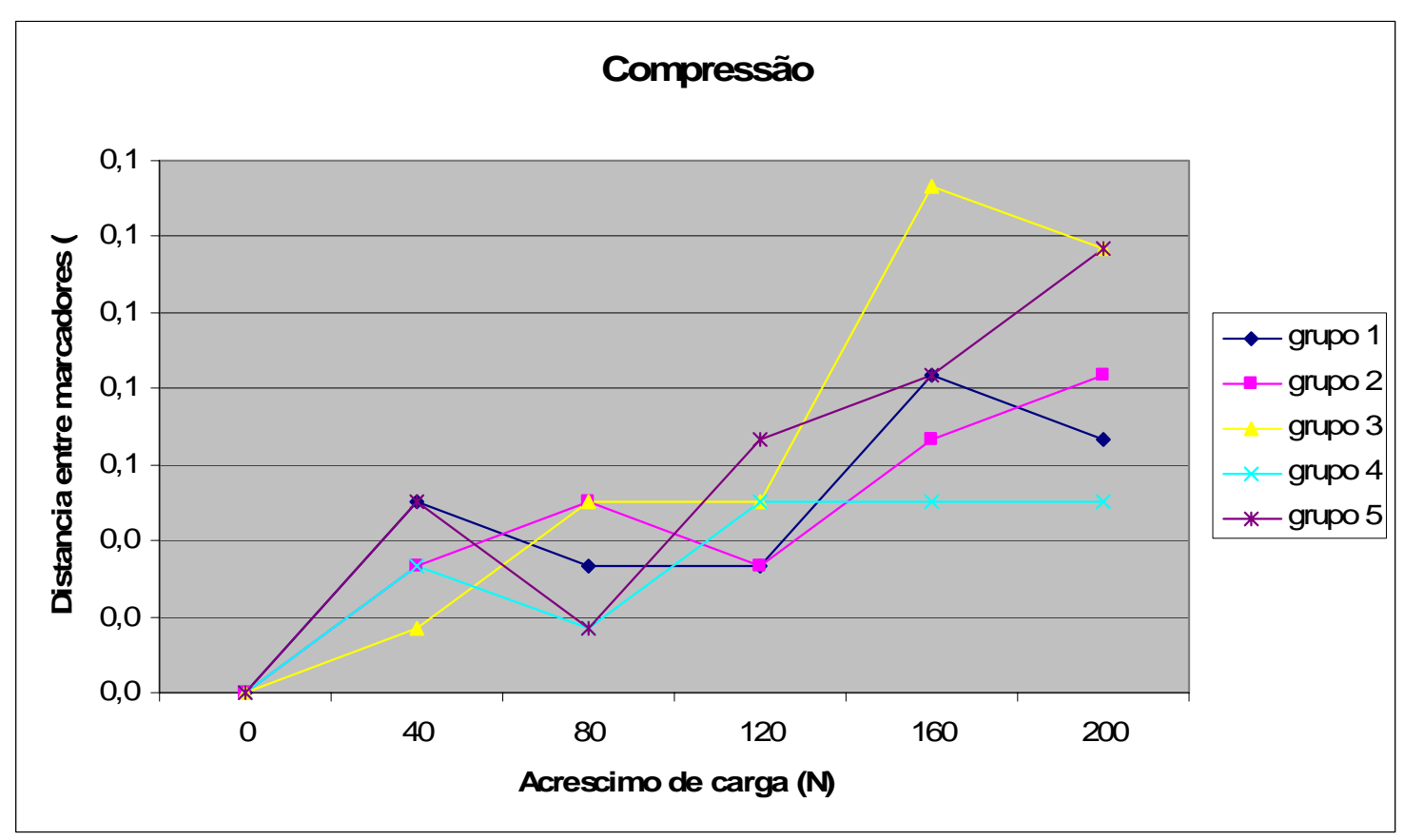

Figura 5.1 - Gráfico de comparação das médias dos grupos estudados, obtidas no deslocamento em milímetros da porção superior dos corpos de prova, em relação à porção inferior, segundo cada tempo de parada, durante o ensaio de compressão - São Paulo - 2007. 


\subsubsection{Ensaio de Encurvamento}

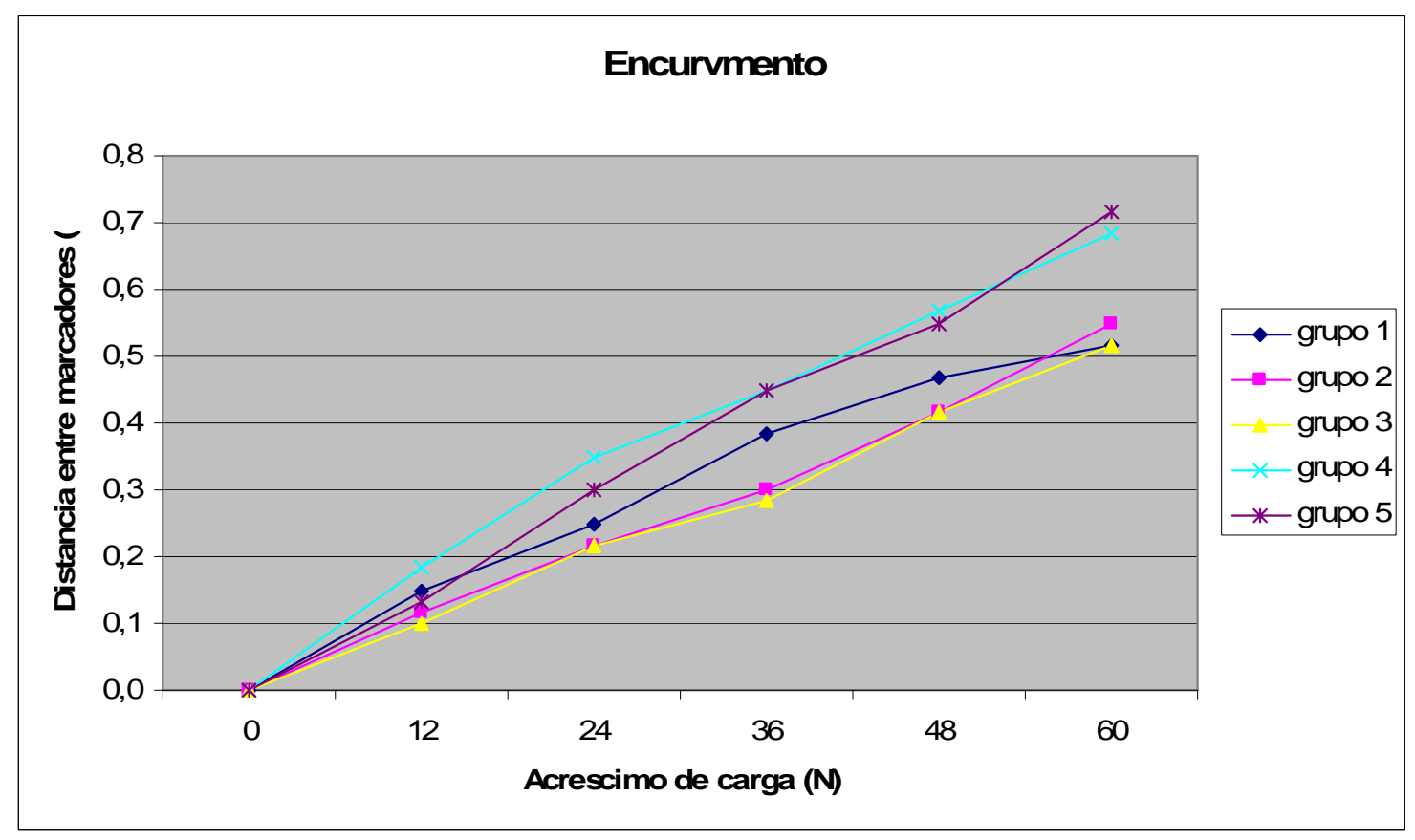

Figura 5.2 - Gráfico de comparação das médias dos grupos estudados, obtidas no deslocamento em milímetros da porção superior dos corpos de prova, em relação à porção inferior, segundo cada tempo de parada, durante o ensaio de encurvamento- São Paulo - 2007. 


\subsubsection{Ensaio de Rotação}

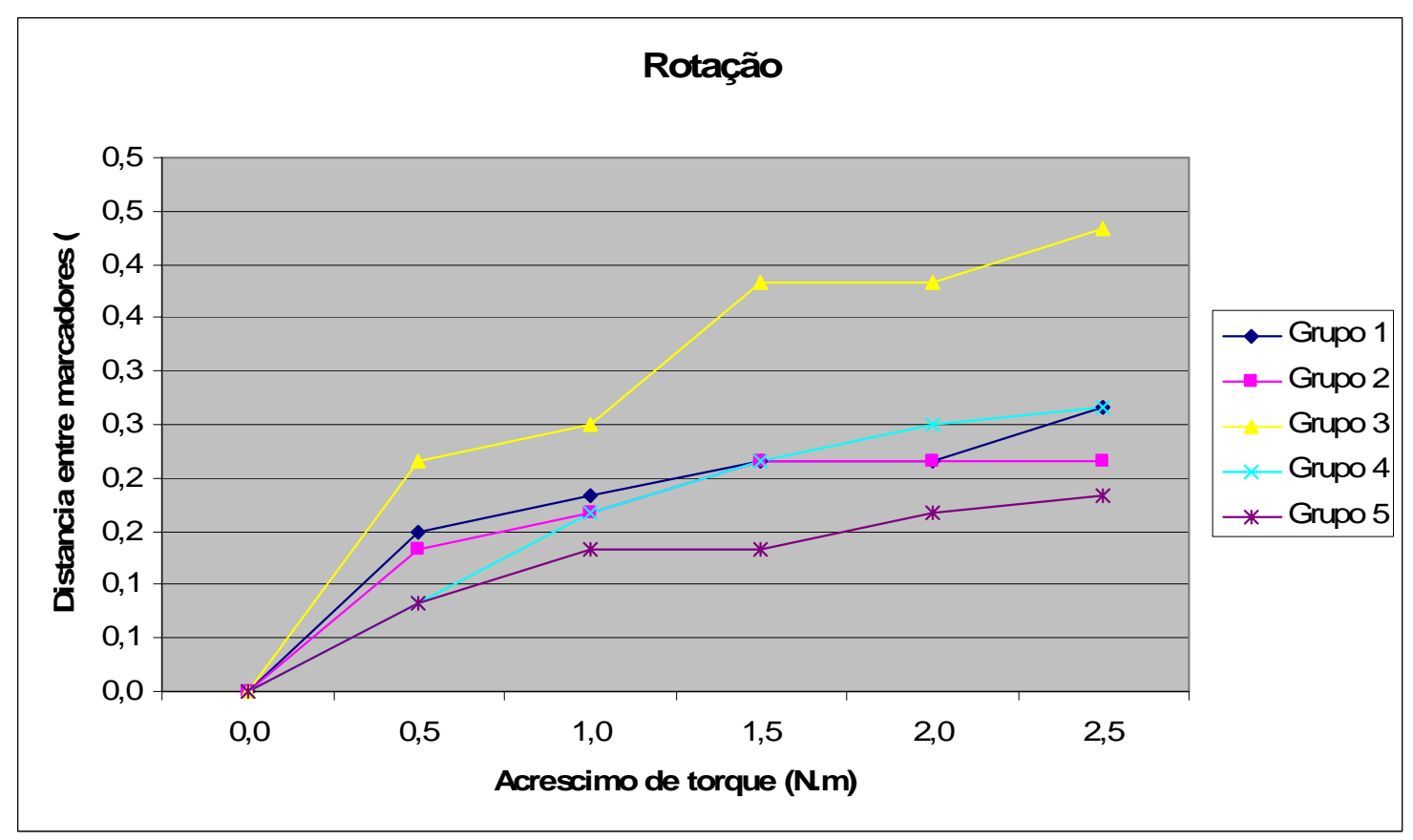

Figura 5.3 - Gráfico de comparação das médias dos grupos estudados, obtidas no deslocamento em milímetros da porção superior dos corpos de prova, em relação à porção inferior, segundo cada tempo de parada, durante o ensaio de rotação- São Paulo - 2007. 


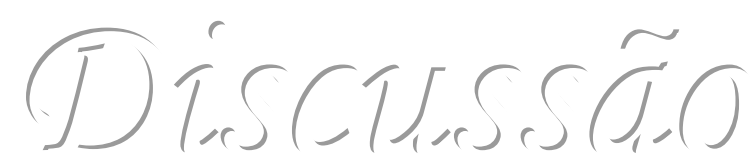




\section{DISCUSSÃo}

A arquitetura dos ossos longos, como o fêmur, confere significativa resistência

à aplicação de forças, com distribuição ao longo de seu eixo longitudinal (REILLY et al., 1974; CARTER; SPENGLER, 1977; DICKSON et al., 2001; SUMNER-SMITH, 2002; HARASEN, 2003). Embora descrito por Schatzker e Houlton (2002), Beardsley et al.(2005), Berkson e Virkus (2006) e Harris et al.(2006), a cominução das fraturas nem sempre está diretamente relacionada com a energia absorvida, mas sim, tem relação à direção desta força (FERRIGNO; PEDRO, 2006). Portanto, fraturas decorrentes de traumas de baixa energia podem também apresentar característica de cominução.

A osteossíntese biológica, com preservação do hematoma fraturário tem suplantado a técnica de redução anatômica, por apresentar resultados com redução do tempo de cirurgia e recuperação precoce do paciente, conforme Davenport et al.(1988), Johnston et al.(1991), Perren (1991), Aron et al.(1995), Johnson et al.(1996), Kesemenenli et al.(2002), Jubel et al.(2003), Perren et al.(2003), Pospula et al.(2003) e Woo et al.(2004).

Hastes intramedulares, além de preservar o modelo biológico de osteossíntese, apresentam vantagens por atuar no eixo central do osso (SUMNER-SMITH, 2002; STIFFER, 2004; DIAZ-BERTRANA et al., 2005), com diminuição do tempo cirúrgico e de complicações (WHITE et al., 2006).

Desde a primeira utilização de fixação intramedular como sistema de osteossíntese, no século XVI, muito se tem em termos de avanços das hastes e, mais propriamente, dos conceitos ligados a esta prática. Kaessmann e Weber foram, segundo Gollwitzer et al. (2004), os pioneiros no 
desenvolvimento de haste bloqueada que reduzia movimento no foco da fratura e, ao mesmo tempo, mantinha estabilidade rotacional do sistema. Muito se tem em literatura sobre as características das fraturas cominutivas (ARON et al., 1995; GAUTIER e SOMMER, 2003; BEARDSLEY et al., 2005; BERKSON; VIRKUS, 2006; HARRIS et al., 2006) e os efeitos biológicos ou mecânicos das hastes e suas comparações com outras técnicas de osteossíntese, no processo de formação do calo ósseo, tanto em pacientes humanos (WISS et al., 1990; DUDLEY et al., 1997; DAVENPORT et al., 1998; El SHAFIE et al., 2001; HOTZ, 2003; AGUILA et al., 2005), quanto em animais (MC CLURE et al., 1998; DUELAND et al., 1999; Mc LAUGHLIN, 1999; PALMER, 1999; LARIN et al., 2001; LANGLEY-HOBS e FRIEND, 2002; MOSES et al., 2002; HARASEN, 2003; HORSTMAN et al., 2004; SARAVANIAN et al., 2002a).

No entanto, a carência de dados publicados por estudos biomecânicos em relação ao comportamento das hastes em ossos longos de animais, conforme apontado por Markel et al.(1994), Bernardé et al.(2002) e Reems et al.(2006), foi o motivo maior da realização deste estudo, não tendo sido encontrado, no levantamento bibliográfico pesquisado, nenhum outro trabalho realizado contemplando a análise da movimentação interfragmentária tridimensional, sendo aplicadas todas as forças atuantes em um mesmo ensaio. Mais do que este fato, não foi encontrado em literatura pesquisada, análise fotogramétrica como metodologia para estudo biomecânico em Medicina Veterinária.

O método DLT (ABDEL-AZIZ; KARARA, 1971) utilizado para análise fotogramétrica realizada neste estudo possibilitou a obtenção dos dados descritos com erro inferior à $0,1 \mathrm{~mm}$, conforme descrito como ideal por Bernardé et al.(2002). 
Devido a sua maior facilidade de aplicação e preservação de elementos fundamentais da biologia do foco fraturário, as hastes bloqueadas têm se tornado o sistema de eleição para a osteossíntese de fêmur, úmero e tíbia dos pacientes descritos. No entanto, alguns fatores são apontados como risco eminente para a falha do sistema. Em pacientes humanos, conforme publicado por Lin et al.(2001) e Bankston et al.(1992), a sobrecarga de força nos parafusos, principalmente no proximal da região inferior da haste gera quebra dos mesmos e instabilidade. Tal estresse é, segundo os autores, marcadamente influenciado pelo diâmetro da haste ou extensão do contato entre a haste e a cortical óssea. Neste estudo pode-se observar valores discrepantes nos dados obtidos em análise de um único corpo de prova, provavelmente relacionados à instabilidade provocada pela diminuição da área de contato entre cortical e haste, uma vez que a mesma estava corretamente posicionada, no centro do canal medular, com os parafusos bloqueando adequadamente os orifícios.

Para a introdução das hastes em animais, face à não disponibilização ampla e irrestrita em veterinária de mecanismos de magnificação de imagens como fluoroscópios, foram desenvolvidos sistemas acoplados a guias externos que indicam o ponto exato de inserção dos parafusos, conforme dados de Dueland et al.(1996), Endo et al.(1998), Gupta (2001), Diaz-Bertarana et al(2005) e Schmaedecke et al.(2005). Grande parte das falhas do sistema em pacientes veterinários está ligada à inexatidão destes guias, principalmente no tocante ao orifício mais distal da haste. No presente estudo, não houve perda de nenhum bloqueio, sempre sendo obedecida a mesma seqüência operacional; primeiramente era realizado bloqueio do orifício mais distal, sendo realizados 
os bloqueios seguintes pela seqüência dos orifícios, respeitando a disposição de cada grupo de análise.

Para a análise realizada, foram utilizados fêmures caninos ostectomizados, onde a implantação da haste fora feita mediante dissecção óssea prévia. A opção por ostectomia em detrimento à osteotomia e distração se deu por respeitar o tamanho fisiológico do osso em análise.

Embora não seja realizada a alocação do implante por acesso cirúrgico convencional (ROE, 1998), não houve comprometimento da análise, pois os pontos de referência utilizados para mensurar a profundidade de implantação da haste seguiram a padronização cirúrgica, através do trocânter maior. Nos estudos biomecânicos in vitro descritos por Hulse et al.(1997), Lopez et al.(1999), Mc Duffee et al.(2000), Widjaja et al.(2001), Bernardé et al.(2002), Galuppo et al.(2002) e Reems et al.(2006) foram igualmente desenvolvidos por dissecção inicial seguida de montagem dos sistemas, sem que qualquer dos pesquisadores apontasse está prática como deletéria para a análise dos resultados finais.

A análise radiográfica prévia dos ossos utilizados permitiu avaliação da integridade dos mesmos, bem como, avaliação de quaisquer sinais de osteopenia, que invalidariam o material. A utilização de modelo em filme transparente disposto por sobre o filme radiográfico, conforme Dueland et al.(1996), se mostrou adequada em para todos os ossos utilizados, por respeitar a discrepância gerada entre o diâmetro original do osso daquele projetado radiograficamente.

A inserção da haste por via retrógrada, realizada em todos os corpos de prova deste estudo, é a mais comumente utilizada em fraturas de fêmur em cães, 
conforme Dueland et al.(1996), Larin et al.(2001), Duhautois (2003), Cheung et al.(2004) e Schmaedecke et al. (2005). Para esta inserção em todos os ossos foi realizada fresagem, por instrumento manual, para que os tecidos moles fossem removidos, havendo maior superfície de contato entre osso e implante, aumentando assim a rigidez dos corpos de prova, conforme indicado por Fairbank et al.(1995). No entanto, por serem estruturas cilíndricas de diâmetro uniforme ao longo de toda sua estrutura, a fresagem provavelmente não venha a alterar a rigidez do implante de forma tão significativa quanto em pacientes humanos, cujo diâmetro do canal medular não apresenta a mesma característica, conforme exposto por Fairbank et al.(1995), Abbas et al.(2000), Frolke et al.(2001).

O intervalo de ostectomia de $25 \mathrm{~mm}$, seguindo modelo proposto por Bernardé et al.(2002) para mimetizar fratura cominutiva, foi mensurado após cada bloqueio, com auxílio de paquímetro, para que não houvesse discrepância entre os corpos de prova, gerando braços de força diferentes e, conseqüente a isto, perda de referência quanto às respostas observadas. Lopez et al.(1999) e Reems et al.(2006) utilizaram intervalo de ostectomia de $10 \mathrm{~mm}$.

Os fêmures dissecados foram criopreservados em freezer convencional, com temperatura de $-24^{\circ} \mathrm{C}$, até o momento de implantação das hastes, conforme Hulse et al.(1997), Lopez et al.(1999), Mc Duffee et al.(2000), Widjaja et al.(2001), Bernardé et al.(2002), Galuppo et al.(2002), Gollwitzer et al.(2004) e Reems et al.(2006), quando foram descongelados em água corrente. Após inserção das hastes, os corpos de prova foram mantidos apenas resfriados em recipiente térmico, pois o congelamento provocaria diferentes padrões de 
retração do osso em relação ao metal, provocando possível alteração na região dos bloqueios.

Para o bloqueio dos orifícios não foi respeitada a transposição de apenas um passo do parafuso pela cortical oposta, conforme proposto por Miller (1998), pois tal feito somente teria efeito deletério nos tecidos moles adjacentes ao osso fraturado. Por se tratar de ensaio biomecânico, o único cuidado referente aos parafusos foi para que não houvesse qualquer contato entre si ou com qualquer outra estrutura durante os ensaios, para não haver força discrepante atuando neste ponto, distorcendo os resultados finais.

A inserção dos parafusos seguiu sempre a disposição látero-medial, conforme descrito por Dueland et al.(1996) e Duhautois (2003). Após a realização dos testes, todos os parafusos e hastes foram removidos, e em nenhum deles ocorreu quebra ou perda de características, demonstrando o caráter não destrutivo do ensaio.

O modelo de haste adotado neste estudo foi o estático, com orifícios circulares, conforme descrito por Dueland et al. (1996) e Frigg e Ulrich (2003), para as configurações das hastes adotadas em Medicina Veterinária. Diferentemente desta disposição, Durall et al.(2004) descreve dinamização do sistema para consolidação óssea, embora Saravanian et al.(2002b) e Gollwitzer et al.(2004) qualifiquem como inferior o calo ósseo originado em processos dinâmicos.

Diferentes formas de acoplamento dos corpos de prova à máquina de ensaios foram usados para as epífises superior e inferior. Para a epífise inferior, foi utilizado o envolvimento de toda a epífise por resina acrílica, para que a força dos parafusos de fixação fosse igualmente distribuída por toda superfície epifisária, conforme realizado por Markel et al. (1994) e Hulse et al.(1997) . 
Embora Radclife et al.(2001) tenha colocado esta forma de fixação como pouco adequada a testes biomecânicos, a análise de movimentação da porção inferior dos corpos de prova, nos eixos x, y e z, não demonstrou movimentação decorrente de deslizamentos, embora permitisse a micromovimentação da estrutura como um todo.

A formação dos grupos se deu por diferentes formas de bloqueio na região proximal da haste, mantendo iguais os bloqueios da região distal. Tal fato se deve aos apontamentos de Reems et al. (2006), que indicam a necessidade de dois bloqueios na região distal, uma vez que, em estudo cíclico destrutivo, demonstraram a fragilidade do sistema, com quebra de parafuso, em caso de bloqueio distal único. Além disso, conforme descrito por Markel et al.(1994), as deformações ósseas são originadas de forças atuantes principalmente na região proximal dos ossos longos.

A epífise superior foi mantida livre, para o adequado posicionamento da célula de carga, sobre o ponto de apoio para realização do ensaio. Para o ensaio de compressão, mimetizando a característica excêntrica da força em animais vivos, foi tomado como ponto de apoio o centro da cabeça femoral, conforme Woodard et al.(1998) e Bernardé et al.(2002). Para o ensaio de encurvamento, foi adotada a posição crânio-caudal, fisiologicamente mais significativa que a médio-lateral em cães, segundo Carter et al.(1981) Matushek et al.(1989) e Dueland et al.(1996), posicionando o corpo de prova em eixo horizontal e aplicando a força novamente no centro da cabeça do fêmur. Esta posição foi preferida em relação ao ensaio de encurvamento de três ou quatro apoios, conforme utilizado por Bramer et al.(1998), Lopez et al.(1999) e McDuffee et al.(2000), uma vez que o ponto de aplicação da força não poderia interferir no 
intervalo da ostectomia, nos implantes ou parafusos. Além disto, conforme citado por Bernardé et al.(2002) nenhuma das três configurações citadas demonstrou ter maior proximidade que as demais com a situação fisiológica.

A epífise proximal somente foi mantida presa no momento do ensaio de torção, onde garra com dez parafusos foi acoplada à máquina e ajustada ao corpo de prova, permitindo fixação adequada independentemente da variação anatômica dos ossos. Pela análise dos dados obtidos, em nenhum dos ensaios foram observados dados discrepantes decorrentes de falha dos métodos de fixação. Para todos os corpos de prova foi adotada a mesma seqüência de três ensaios não destrutivos: compressão excêntrica, encurvamento crânio-caudal e torção. Tal metodologia foi adotada pela dinâmica apresentada pelo dispositivo mecânico, cuja arquitetura permitia total movimentação dos ossos em todos os planos, possibilitando a realização do estudo com seis graus de liberdade (três lineares e três rotacionais). Cada ensaio realizado foi precedido pela aplicação da força total do mesmo, sem captura de dados, a fim de eliminar qualquer forma de frouxidão dos corpos de prova.

A análise fotogramétrica realizada, descrita por Chadwick (1992), e inédita em estudos biomecânicos em Medicina Veterinária, foi realizada com duas câmeras fotográficas digitais que foram configuradas para captação de imagens com 3,3 mpixels, para que não houvesse perda de imagens por digitalização com baixa qualidade.. Para que duas imagens fotográficas pudessem ser obtidas ao mesmo tempo, as mesmas foram calibradas para disparar 10 segundos após a parada da máquina de ensaios, a qual era avisada por sinal sonoro. Por esta calibração, também foi possível obter imagens sem movimentação do travessão de suporte que prendia as câmeras. 
O calibrador foi utilizado para marcação dos oito pontos laterais, que serviram como definição da profundidade durante os ensaios. Através de software desenvolvido no laboratório de análises mecânicas, foi possível dimensionar as distâncias entre os oito pontos do calibrador. A análise da movimentação interfragmentária foi tomada pela relação entre os seis pontos dos marcadores presos na linha de ostectomia e os oito pontos do calibrador.

Como o disparo das câmeras foi realizado manualmente, qualquer movimentação inadequada dos aparelhos poderia gerar imagens inadequadas, impedindo análise fotogramétrica. Mesmo tendo fixadas as câmeras rigidamente, tomou-se por precaução a manutenção do calibrador em todas as imagens, pois caso houvesse qualquer movimentação, nova calibração poderia ser realizada para cada imagem.

O software desenvolvido permitiu utilização de imagens digitalizadas com a perda de um dos pontos do calibrador, que por vezes ocorrreu, por sobreposição da imagem do corpo de prova. Pelo fato das câmeras ficarem em projeções defasadas a 45 graus entre si, algumas vezes os ossos encobriram o ponto do calibrador.

A arquitetura do travessão permitiu a angulação das câmeras livremente, adequando a melhor posição para captação da imagem, sempre mantendo distância fixa em relação ao corpo de prova.

Com relação aos resultados obtidos, levando-se em consideração a movimentação interfargmentária da porção superior em relação à inferior dos corpos de prova, as médias obtidas para todos os grupos foram inferiores à 1 mm, citada por Bernardé et al.(2002) como a máxima permitida para formação de calo ósseo, demonstrando assim a viabilidade deste modelo de 
osteossíntese em fraturas cominnutivas, em oposição ao citado por Gupta (2001), dizendo não haver micromovimentação interfragmentária em fraturas estabilizadas com hastes de IN. Atenção deve ser tomada à característica deste estudo, com ossos dissecados, cuja instabilidade gerada pelo sistema é maior que em pacientes vivos, onde os grupos musculares regionais conferem maior estabilidade, conforme descrito por Falcis et al. (2006).

Neste estudo foi adotada a análise interfragmentária tridimencional do sistema, para as três forças atuantes: compressão, encurvamento e rotação. Muitos autores realizaram estudos de movimentação interfragmentária em análises in vitro ou in vivo, com aplicação de forças unidirecionais. A complexidade deste estudo foi conferir precisão aos resultados, demonstrando a movimentação tridimensional dos corpos de prova para todos os ensaios propostos. Tal precisão foi obtida adotando-se modelo similar ao de Bernardé et al.(2002), utilizando pontos circulares fixados na linha de ostectomia, comparando a relação de movimentação espacial destes pontos entre si. O fato de, após os pontos serem fixados, não mais serem removidos, conferiu maior precisão aos resultados, em contraposição ao citado por Bernardé et al.(2002), que citam em seu artigo a desvantagem encontrada no sistema por eles adotado de a cada ensaio reposicionar os transdutores.

A máquina universal $\operatorname{KRATOS}^{\circledR}$ utilizada neste estudo permitiu a realização dos ensaios tanto de rigidez, conforme descrito por Romano et al.(2005) como de análise fotogramétrica, pois possibilitou sua programação para ensaios descontínuos, com paradas de tempo desejadas, sem diminuição significativa da força aplicada durante os intervalos. 
A captação dos dados dos eixos $X, Y$ e $Z$ de cada ensaio permitiu demonstrar não somente sua movimentação tridimensional, validando esta pesquisa, como analisar tanto a movimentação axial, mas também transversal do foco da fratura. Tais dados se opõem aos de Markel et al.(1994), que cita desenvolver ensaio de encurvamento puro. Os resultados demonstraram a mínima movimentação transversal quando utilizado este sistema, fato este também demonstrado por Bernardé et al.(2002), e que valida o uso da haste bloqueada em fraturas cominutivas de fêmur em cães.

Pela análise estatística dos dados apontados pelos cinco diferentes grupos estudados, não houve diferença significativa entre os mesmos, para os ensaios de compressão, encurvamento ou rotação. Tal fato demonstra a segurança do sistema, caso corretamente empregado, para osteossíntese de fraturas cominutivas em cães, levando em consideração apenas forças fisiológicas.

Este estudo levou em consideração apenas forças fisiológicas, em ensaio não destrutivo. Sabe-se no entanto que o comportamento animal gera, por vezes, forças maiores, que culminam com a falha do implante. Reems et al.(2006) descrevem que os primeiros modelos de haste bloqueada de $8 \mathrm{~mm}$, bloqueadas com parafusos de $4,5 \mathrm{~mm}$ apresentavam falha por quebra da haste, no orifício de bloqueio. Os modelos da quarta geração, bloqueados com parafusos de $3,5 \mathrm{~mm}$, apresentam falha por quebra do parafuso, que possui momento de inércia de área menor. Para minimizar este acontecimento, os autores indicam utilização de dois bloqueios na região distal, principal ponto de falha, segundo os mesmos. Embora não seja este o foco principal desta pesquisa, pode-se, pela análise dos gráficos de comparação das médias de deslocamento, sugerir a falha de alguns sistemas mais precocemente. Para o 
ensaio de rotação, há nítida diferença entre a curva apresentada pelo grupo 3, cujo sistema foi bloqueado com hastes de $185 \mathrm{~mm}$, com 3 bloqueios, sendo 2 distais e 1 proximal, realizado no orifício distal à linha da ostectomia, deva apresentar falha em tempo inferior.

Embora não tenha havido qualquer anormalidade durante o progresso da pesquisa, alguns pontos podem ser descritos como críticos e mereçam atenção especial em futuras pesquisas com esta metodologia: os fêmures de cães apresentam, ao longo de sua diáfise, aproximadamente o mesmo diâmetro, sendo a fresagem muitas vezes utilizada somente para remoção de material medular, mais do que para homogeneização morfométrica. No entanto, como as hastes apresentam diâmetros pré-definidos, pacientes cujos fêmures apresentem diâmetros de $9 \mathrm{~mm}$, por exemplo, tenham que ser submetidos à osteossíntese com hastes de 8mm. A diminuição da área de contato da haste com a camada cortical neste caso pode ser responsável por aumento da movimentação interfragmentária. Tal fato explica os dados apresentados pelo corpo de prova número 3, durante seus ensaios de compressão e encurvamento, embora a discrepância apresentada não tenha alterado a análise estatística do grupo.

Embora não haja resultado discrepante para o ensaio de rotação, Bernardé et al.(2002) desprezaram esta prova em sua pesquisa por afirmarem que, após os ensaios de compressão e encurvamento, exista fragilidade rotacional do corpo de prova. Ainda assim, e associado à instabilidade dos ensaios in vitro descrita por Falcis et al.(2006), em nenhum grupo estudado a média de movimentação interfragmentária superou 1,0 mm. 
Gompclitusongers 


\section{CONCLUSÕES}

Esta pesquisa comparou cinco diferentes formas de bloqueio de Interocking nail em fraturas diafisárias de fêmur de cães, através da análise fotogramétrica da micromovimentação interfragmentária do foco de fratura. Pelos resultados obtidos, todas as formas analisadas são factíveis, uma vez que não houve diferença estatística significativa entre os grupos, seja por análise de resistência ou por análise de micromovimentação.

Além disso, todas as médias obtidas, para os grupos analisados, os ensaios de rotação, encurvamento e compressão apresentaram valores inferiores ao máximo permitido para formação de calo ósseo.

No entanto, por se tratar de ensaio não destrutivo, a análise de resistência dos grupos estudados foi subjetiva, apenas por avaliação do gráfico de movimentação. Deste modo, estudos posteriores, através de ensaios cíclicos e/ou destrutivos podem ser realizados para análise da resistência dos grupos pesquisados. 
Teferéctictidurs 


\section{REFERENCIAS}

ABBAS, D.; FAISAL, M.; BUTT, M.S. Unreamed femoral nailing. Injury. v. 31. p.711-717, 2000.

ABDEL-AZIZ, Y.I. E KARARA, H.M. Direct linear transformation from comparator coordinates into object-space coordinates in close-range photogrammetry. In symposium on close-range photogrammetry. Urbana Champaign, Ilinois, p. 1-18, 1971.

AGUILA, A.Z.; MANOS, J.M.; ORLANSKY A.S.; TODHUNTER, R.T.; TROTTER, E.J.; VAN DER MEULEN, M.C. In vitro biomechanical comparison of limit contact dynamic compression plate and locking compression plate. Veterinary Compendium of Orthopedics and Traumatology. v. 18, n. 4. p. 220-226, 2005.

ARON, D.N.; PALMER, R.H.; JOHNSON, A.L. Biologic strategies and a balanced concept for repair of highly comminuted long bone fractures. Veterinary and Comparative Orthopedics and Traumatology. v. 7, p. 35-38. 1995.

BANKSTON, A.B.; KEATING, E.M.; SAHA, S. The Biomechanical evaluation of intramedullary nails in distal femoral shaft fractures. Clinical Orthopaedics Related Research, v. 276, p. 277-282, 1992.

BEARDSLEY, C.L.; ANDERSON, D.D.; MARSH, J.L.; BROWN, T.D. Interfragmentary surface area as an index of comminution severity in cortical bone impact. Journal of Orthopedic Research. v. 23, n. 3, p. 686-690, 2005.

BERKSON, E.M.; VIRKUS, W.W. High-energy tibial plateau fractures. Journal of American Academy of Orthopaedic Surgery. v. 14, n. 1, p. 20-31, 2006.

BERNARDÉ, A.; DIOP, A.; MAUREL, N.; VIGUIER, E. An in vitro biomechanical comparison between bone plate and interlocking nail. 3-D interfragmentary motion and bone strain analysis in ostectomized canine femurs. Veterinary Compendium of Orthopedics and Traumatology. v. 15, p. 57-66. 2002.

CARTER, D.R.; SPENGLER, D.T. Mechanical properties and composition of cortical bone. Clinical Orthopaedics. v. 127, p. 265, 1977.

CARTER, D.R.; VASU, R.; SPENGLER, D.M.; Stress fields in the updated and plated canine femur calculated from in vivo strain measurements. Journal of Biomechanics v. 14, p. 63-70, 1981.

CHADWICK, R.G. Close range photogrammetry - a clinical dental research tool. Journal of Dentistry. v. 20.p. 235-239. 1992.

CHEAL, E.I.; MANSMANN, K.A.; DiGIOIA, A.M. The role of interfragmentary strain in fracture healing: Ovine modelo of a healing osteotomy. Journal of Orthopaedical Research. v. 9. p. 131-142, 1991. 
CHEUNG, G.; ZALZAL, P.; BHANDARI, M.; SPELT, J.K.; PAPINI, M. Finite element analysis of a femoral retrograde intramedullary nail subject to gait loading. Medical Engineering and Physics. v. 26. N. 2. p. 93-108, 2004.

DAVENPORT, S.R.; LINDSEY, R.W.; LEGGON, R.; MICLAU, T.; PANJABI, M. Dynamic compression plate fixation: a biomechanical comparison of unicortical vs bicortical distal screw fixation. Journal of Orthopaedic Trauma. v. 2, n. 2, p. 146-150, 1988.

DIAZ-BERTRANA, M.C.; DURALL, I.; PUCHOL, J.L.; SANCHEZ, A.; FRANCH, J. Interlocking nail treatment of long-bone fractures in cats: 33 cases(19952004). Veterinary and Comparative of Orthopedic and Traumatology. v. 18, n. 3, p. 119-126, 2005.

DICKSON, K.F.; MONTGOMERY, S.; FIELD, J. High energy plafond fractures treated by an spanning fixator initially and followed by a second stage open reduction internal fixation of the articular surface - preliminary report. Injury. v. 32 suppl. 4. p. 92-98, 2001.

DUDLEY, M.; JOHNSON, A.L.; OLMSTEAD, M.; SMITH, C.W.; SCHAEFFER, D.J.; ABBUEHL, U. Open reduction and bone plate stabilization, compared with closed reduction and external fixation, for treatment of comminuted tibial fractures: 47 cases (1980-1995) in dogs. Journal of American Veterinary Medical Association. v. 211. p. 1008-1012, 1997.

DUELAND, R.T.; BERGLUND, L.; VANDERBY Jr, R.; CHAO, E.Y.S. Structural Properties fo Interlocking nails, Canine Femora, and Femur-Interlocking nail Constructs. Veterinary Surgery. v. 25. p. 386-396. 1996.

DUELAND, R.T.; JOHNSON, K.A.; ROE, K.A.; ENGEN, M.H.; LESSER, A.S. Interlocking nail treatment of diaphyseal long-bone fractures in dogs. Journal of American veterinary medical association. v. 214, n.1, p. 59-66. 1999.

DUHAUTOIS, B. Use of veterinary Interlocking Nails for diaphyseal fractures in dogs and cats: 121 cases. Veterinary Surgery. v. 32, p. 8-210. 2003

DURALL, I.; FALCÓN, C.; DÍAZ-BERTANA, M.C.; FRANCH, J. Effects of Static Fixation and Dynamization after Interlocking Femoral Nailing Locked with na External Fixator: An experimental Study in Dogs. Veterinary Surgery. v. 33. p. 323-332, 2004.

EISHAFIE, M.H.; MORSEY, H.A.; EID, Y.E. Ipsilateral fracture of the femoral neck and shaft, treatment by reconstruction interlocking nail. Archieves of orthopedic and trauma surgery. v. 121, p. 71-74, 2001.

ENDO, K.; NAKAMURA, K.; MAEDA, H.; MATUSHITA, T. Interlocking intramedullary nail method for the treatment of femoral and tibial fractures in cats and small dogs. The Journal of Veterinary Medical Science. v. 60, n. 1, p. 119-122. 1998. 
FAIRBANK, A.C.; THOMAS, D.; CUNNINGHAM, B.; CURTIS, M.; JINNAH, R.H. Stability of reamed and undreamed intramedullary nails: a biomechanical study. Injury. v. 26.N. 7. p. 483-485, 1995.

FERRIGNO, C.R.A., PEDRO, C.R. Fraturas. In: MIKAIL, S., PEDRO, C.R. Fisioterapia Veterinária. São Paulo. Ed. Manole, 2006, p. 138-152.

FRIGG, R.; ULRICH, D. Innovative implants - a prerequisite for biological osteosynthesis. Therapeutische Umschau. v. 60, n. 12. p. 723-728, 2003. abstract.

FROLKE, J.P.; PETERS, R.; BOSHUIZEN, K.; PATKA, P.; BAKKER, F.C.; HAARMAN, H.J. The assessment of cortical heat during intramedullary reaming of long bones. Injury. v. 32.n. 9, p. 693-688. 2001.

GALUPPO, L.D.; STOVER, S.M.; ALDRIDGE, A.; HEWES, C.; TAYLOR, K.T. An in vitro biomechanical investigation of an mp35n intramedullary interlocking nail system for repair of third metacarpal fractures in adult horses.Veterinary Surgery. v. 31. p. 211-225, 2002.

GAUTIER, E.; SOMMER, C. Biological internal fixation- guidelines for rehabilitation. Therapeutische Umschau. v. 60, n. 12, p. 729-735, 2003.

GOLLWITZER H, KARAMPOUR K, HAUSCHILD M, DIEHL P, BUSCH R, MITTELMEIER W. Biomechanical investigation of the primary stability of intramedullary compression nails in the proximal tibia: experimental study using interlocking screws in cryopreserved human tibias. Journal of Orthopaedic Science. v. 9, n. 1, p. 22-28, 2004.

GUPTA, A. Dynamic compression nail: a preliminary report. BMC Musculoskeletal disorders. v. 2, n. 6. 2001.

HARASEN, G. Common long bone fractures in small animal practice - part 1. Canadian Veterinary journal. v. 44, p.333-334, 2003.

HARRIS A.M.; PATTERSON, B.M.; SONTICH, J.K.; VALLIER, H.A. Results and outcomes after operative treatment of high-energy tibial plafond fractures. Foot and Ankle International. v. 27, n. 4, p. 256-265, 2006.

HORSTMAN, C.L.; BEALE, B.S.; CONZEMIUS, M.G. Biological osteosynthesis versus traditional anatomic reconstruction of 20 long-bone fractures using an interlocking nail: 1994-2001. Veterinary Surgery. v. 33, p. 232-237. 2004.

HOTZ, T. Biological osteosynthesis in children and adolescents. Therapeutische Umschau. v. 60, n. 12, p. 776-782, 2003.

HULSE, D.; HYMAN, W.; NORI, M.; SLATER, M. Reduction in Plate Strain by Addition of na Intramedullary Pin. Veterinary Surgery. v. 26, p. 451-459, 1997.

JOHNSON, A.L.; SEITZ, S.E.; SMITH, C.W. Closed reduction and type II external fixation of comminuted fractures of the radus and tíbia in dogs: 23 
cases (1990-1994). Journal of American Veterinary Medical Association. v. 209, p. 1445-1448, 1996.

JOHNSTON, S.A.; LANCASTER, R.L.; HUBBARB, R.P. A biomechanical comparison of 7-hole $3.5 \mathrm{~mm}$ broad and 5-hole 4,5 $\mathrm{mm}$ narrow dynamic compression plates. Veterinary Surgery. v.20, p. 235-239, 1991.

JUBEL, A.; ANDERMAHR, J.; BERGMAN, H.; INSENBER, J.; REHM, K.E. Elastic stable intramedullary nailing of midclavicular fractures in athletes. British Journal of Sports Medicine. v. 37, n. 3, p. 480-483, 2003.

KESEMENENLI, C.; SUBAI, M.; NECMIOGLU, S.; KAPUKAYA, A. Treatment of multifragmentary fractures of the femur by indirect reduction (biological) and plate fixation. Injury. v. 33, n. 8, p. 691-699, 2002.

KHAN, F.A.; IKRAM, M.A.; BADR, A.A.; AL-KHAWASHKI,H. Femoral neck fracture: a complication of femoral nailing. Injury. v. 26, n. 5, p. 319-321. 1995.

LANGLEY-HOBBS, S.J.; FRIEND, E. Interlocking nail repair of a fractured femur in a turkey. Veterinary record. v. 150, p. 247-248, 2002.

LARIN, A.; EICH, C.S.; PARKER, R.B.; STUBBS, W.P. Repair of diaphyseal femoral fractures in cats using interlocking intramedullary nails: 12 cases (19962000). Journal of American veterinary medical association. v. 219, n.8, p. 1098 - 1104. 2001.

LIN J, LIN S.J.; CHEN P.Q., YANG S.H. Stress analysis of the distal locking screws for femoral interlocking nailing. Journal of Orthopaedic Research. v. 19, n. 1. p. 57-63, 2001.

LOPEZ, M.; WILSON, D.G.; VANDERBY Jr, R.; MARKEL, M.D. An in vitro biomechanical comparision of an interlocking nail system and dynamic compression plate fixation of ostectomized equine third metacarpal bones. Veterinary Surgery. v. 28, p. 333-340. 1999.

MARKEL , M.D.; SIELMAN, E.; RAPOFF, A.J.; KOHLES, S.S. Mechanical properties of long bones in dogs. American Journal of Veterinary Research. v. 55. n. 8, p. 1178-1183. 1994.

MATUSHEK, K.J.; SUMNER-SMITH, G.; SCHATZKER, J. A Strain-gauge study of the effect of external fixation on the canine tíbia. Archieves of

Orthopaedics and Trauma Surgery. v. 108, p. 159-165, 1989.

McCLURE, S.R.; WATKINS, J.P.; ASHMAN, R.B. In vivo evaluation of intramedullary interlocking nail fixation of transverse femoral osteotomies in foals. Veterinary Surgery. v. 27, p. 29-36.1998.

McDUFFEE, L.A.; STOVER, S.M.; BACH, J.M.; TAYLOR, K.T. Na In Vitro Biomechanical Investigation of na Equine Interlocking Nail. Veterinary Surgery. v.29, p. 38-47, 2000. 
MCLAUGHLIN, R. Internal fixation, Intramedullary pins, cerclagem wires and interlocking nails. Veterinary clinics of north America - small animal practice. v. 29, p. 1097-1116. 1999.

MILLER, A.; Principles of Fracture Surgery. In: COUGHLAN, A., MILLER, A. Manual of Small Animal Fracture Repair and Management. BSAVA, 1998. p. $65-94$

MINITAB RELEASE, 13 - Software estatístico. 2000.

MOSES, P.A.; LEWIS, D.D.; LANZ, O.I.; STUBBS, W.P.; CROSS, A.R.; SMITH, K.R. Intramedullary interlocking nail stabilisation of 21 humeral fractures in 19 dogs and one cat. Australian veterinary journal. v. 80, n. 6, p. 326-343. 2002.

PALMER, R.H. Biological osteosynthesis. Veterinary clinics of north America - small animal practice. v. 29, p. 1171-1185. 1999.

PERREN, S.M. The concept of biological plating using the limited contact: dynamic compression plate (LC-DCP) - scientific background, design and application. Injury. v. 22, p.1-41. 1991.

PERREN, S.M.; PERREN, T.; SCHNEIDER, E. Are the terms "biology" and "osteosynthesis" contradictory? Therapeutische Umschau. v. 60, n. 12, p. 723-728, 2003.

POSPULA, W.; ABU AL NOOR, T.; EZZAT, F.; ABUL MALAK, F. Percutaneous fixation of comminuted fractures of the fémur and tibia. Preliminary study. Medical Principles and Practice. v. 12, n. 4, p. 214-217, 2003.

RADCLIFFE RM, LOPEZ MJ, TURNER TA, WATKINS JP, RADCLIFFE CH, MARKEL MD. An in vitro biomechanical comparison of interlocking nail constructs and double plating for fixation of diaphyseal femur fractures in immature horses. Veterinary Surgery. v. 30, n. 2. p. 179-190, 2001.

REEMS, M.R.; PLUHAR, G.E.; WHELLER, D.L. Ex vivo comparison of one versus two distal screws in $8 \mathrm{~mm}$ model 11 interlocking nails used to stabilize canine distal femoral fractures. Veterinary Surgery. v. 35, n. 2, p. 161-167, 2006.

REILLY, D.T.; BURSTEIN, A.H.; FRANKEL, V.H.; The elastic modulus of bone. Journal of Biomechanics. v. 7, p. 271, 1974.

ROE, J.; Principles of Fracture Surgery. In: COUGHLAN, A., MILLER, A. Manual of Small Animal Fracture Repair and Management. BSAVA, 1998. p. $65-94$

ROMANO, L.; PEREIRA, C.A.; SCHMAEDECKE, A.; SAUT, J.P.E.;

FERRIGNO, C.R.A. Biomechanical analysis of the normal knee and with cranial cruciate ligament rupture to the cranial translation degree and articular stiffness in dogs. Acta Cirurgica Brasileira. v. 21, n. 1. p. 47-51, 2006. 
SARAVANAN, B.; MAITI, S.K.; HOQUE, M.; AITHAL, H.P.; SINGH, G.R. Management of comminuted femoral fracture by different internal fixation techniques in dogs. Indian journal of Animal sciences. v. 72, n. 12, p. 11041107. 2002.

SARAVANAN, B.; MAITI, S.K.; KALICHARAN, M.; HOQUE, M.; SINGH, G.R. Histopathological evaluation of different internal fixation techniques for the management of comminuted fracture in dog. Indian journal of Animal sciences. v. 72, n. 8, p. 665-667, 2002.

SCHATZKER, J.; HOULTON, J.E.F. Concepts of fracture stabilization. In: SUMNER-SMITH,G. Bone in Clinical Orthopedics. Thieme Medical Publishers, 2nd ed. 2002. p 337-347.

SCHMAEDECKE, A.; FERRAZ, V.C.M.; FERRIGNO,C.R.A. Aplicabilidade e exeqüibilidade da técnica de interlocking nail como tratamento de fraturas diafisárias de fêmur em cães. Revista de educação continuada do CRMVSP. v. 8, n. 1, p. 19-25. 2005

STIFFLER, K.S. Internal fracture fixation. Clinical techniques in small animal practice v. 19, n. 3, p. 105-113, 2004

SUMNER-SMITH,G. Bone in Clinical Orthopedics. Thieme Medical Publishers, 2nd ed. 2002. 492 pp.

WHITE, T.O.; CLUTTON, R.E.; SALTER, D.; SWANN, D.; CHRISTIE, J.; ROBINSON, C.M. The early response to major trauma and intramedullary mailing. Journal of Bone and Joint Surgery. v. 88, n.6, p. 823-827, 2006.

WIDJAJA, W.; HARTUNG, C. Biomechanical comparison of different fixations of femur-interlocking-nails. Clinical Biomechanics. v. 16. p. 702-705, 2001.

WISS D.A., BRIEN W.W., STETSON W.B. Interlocked nailing for treatment of segmental fractures of the femur.Journal of Bone and Joint Surgery. v. 72, $n$. 5. p. 724-728, 1990.

WOO, S. L. Y.; LOTHRINGER, K. S.; AKESON, W. H. Less rigid internal fixation plates: historical perspectives and new concepts. Journal of Orthopedic research. v. 1, P. 431-435, 1984.

WOODARD, P.L.; SELF, J.; CALHOUN, J. The effect of implant axial and torsional stiffness on the fracture healing. Journal of Orthopaedics and Trauma. v. 1, p. 331-340, 1988. 